\title{
Drug targeting to the kidney : N-acetyl-L-y-glutamyl derivatives as kidney-selective prodrugs
}

Citation for published version (APA):

Drieman, J. C. (1989). Drug targeting to the kidney : N-acetyl-L-y-glutamyl derivatives as kidney-selective prodrugs. [Doctoral Thesis, Maastricht University]. Datawyse. https://doi.org/10.26481/dis.19891117jd

Document status and date:

Published: 01/01/1989

DOI:

10.26481/dis.19891117jd

Document Version:

Publisher's PDF, also known as Version of record

\section{Please check the document version of this publication:}

- A submitted manuscript is the version of the article upon submission and before peer-review. There can be important differences between the submitted version and the official published version of record.

People interested in the research are advised to contact the author for the final version of the publication, or visit the DOI to the publisher's website.

- The final author version and the galley proof are versions of the publication after peer review.

- The final published version features the final layout of the paper including the volume, issue and page numbers.

Link to publication

\footnotetext{
General rights rights.

- You may freely distribute the URL identifying the publication in the public portal. please follow below link for the End User Agreement:

www.umlib.nl/taverne-license

Take down policy

If you believe that this document breaches copyright please contact us at:

repository@maastrichtuniversity.nl

providing details and we will investigate your claim.
}

Copyright and moral rights for the publications made accessible in the public portal are retained by the authors and/or other copyright owners and it is a condition of accessing publications that users recognise and abide by the legal requirements associated with these

- Users may download and print one copy of any publication from the public portal for the purpose of private study or research.

- You may not further distribute the material or use it for any profit-making activity or commercial gain

If the publication is distributed under the terms of Article $25 \mathrm{fa}$ of the Dutch Copyright Act, indicated by the "Taverne" license above, 


\section{DRUG TARGETING TO THE KIDNEY}

$\mathrm{N}$-acetyl-L- $\gamma$-glutamyl derivatives as kidney-selective prodrugs 
The work decribed in this thesis was supported generouslly by Ciba-Geigy (Basel, Switserland).

The costs of publication of this thesis were in part supported by Inpharzam Nederland. 


\title{
DRUG TARGETING TO THE KIDNEY
}

$\mathrm{N}$-acetyl-L- $\gamma$-glutamyl derivatives as kidney-selective prodrugs

\author{
proefschrift \\ ter verkrijging van de graad van doctor \\ aan de Rijksuniversiteit Limburg te Maastricht, \\ op gezag van de Rector Magnificus, Prof. dr. F.I.M. Bonke, \\ volgens het besluit van het College van Dekanen, \\ in het openbaar te verdedigen \\ op vrijdag, 17 november 1989 om 16.00 uur \\ door \\ Johannes Cornelis Drieman \\ geboren te Meppel 1961
}


Promotor:

Co-promotor:

Beoordelingscommisie:
Prof. dr. H.A.J. Struyker Boudier

Dr. H.H.W. Thijssen

Prof. dr. P. Henderson

Prof. dr. P. Brombacher

Prof, dr. C.A.M. van Ginneken

Prof. dr. S. de Lange

Prof. dr. R. Zwaal

\section{CIP-GEGEVENS KONINKLIJKE BIBLIOTHEEK, DEN HAAG}

Drieman, Johannes Cornelis

Drug targeting to the kidney: $\mathrm{N}$-acetyl-L- $\gamma-$ glutamyl derivatiwes as kidney-selective prodrugs / Johannes

Cornelis Drieman, - Maastricht: Datawyse. - Ill.

Proefschrift Maastricht. - Met lit.opg.

ISBN 90-5291-005-7

SISO 612.8 UDC 615:616.61(043.3)

Trefw.: genesesmiddelen / nierziekten.

Uitgave: Datawyse - Matastricht

Druk: Krips Repro Meppel

Lay-out: Ineke Groot

Met dank aan iedereen die heeft meegewerkt aan de totstandkoming van dit proefschrift. 



\section{List of abbreviations}

\begin{tabular}{|c|c|}
\hline$A G A W$ & N-acetyl-y-glutamyl-4'-amino warfarin \\
\hline AGSM & N-acetyll-y-glutamyl sulfamethoxazole \\
\hline 4'AW & 4 -amino warfarin \\
\hline AT -125 & $\begin{array}{l}\text { acivicin; } L-(\alpha S, 5 S) \text {-a-amino-3-chloro-4,5-dihydro-5-isoxazoleacetic } \\
\text { acid }\end{array}$ \\
\hline CCP 18137 & 5-n-butyl,2-hydrazinopyridin \\
\hline CGP 22979 & $\mathrm{~N}\left[\mathbb{N}^{\prime}\right.$-acetyl-y-glutamyl]-5-n-butyl,2-hydrazinopyridin \\
\hline $\mathrm{D}$ & active drug; CGP 18137 \\
\hline GAW & $\gamma$-glutamyl-4"amino warfarin \\
\hline GGT & $\gamma$-glutamyl transpeptidase \\
\hline GSH & glutathione \\
\hline GSM & $\gamma$-glutamyl sulfamethoxazole \\
\hline PAH & para-aminohippuric acid \\
\hline PD & prodrug; CGP 22979 \\
\hline SM & sulfamethoxazole \\
\hline
\end{tabular}




\section{CONTENTS}

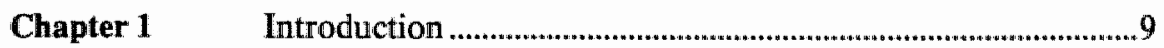

PART 1

Studies on CGP 22979...................................................................3

Chapter 2 Pharmacokinetic studies on the mechanism of the renal selectivity of the vasodilator prodrug CGP $22979 \ldots \ldots . . . .35$

Chapter 3 A study on the mechanism of activation of the renal vasodilator prodrug CGP 22979.

Chapter 4 The hemodynamic consequences of manipulating the

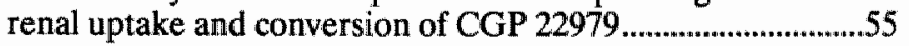

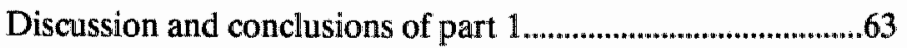

PART 2 The role of carrier-mediated transport in the renal selectivity of prodrugs.

Chapter 5 Carrier-mediated transport and intracellular conversion as determinants in the renal selectivity of $\mathrm{N}$-acetyl- $\gamma$ glutamyl sulfamethoxazole

Chapter 6 Limits to the transport of $\mathrm{N}$-acetyl- $\gamma$-glutamyl prodrugs ..........79

Chapter 7 The use of kidney slices in the assessment of kidney selectivity of $\mathbf{N}$-acetyl- $\gamma$-glutamyl prodrugs ...............................91

Discussion and conclusions of part 2........................................97

Chapter 8 General discussion and outlook.............................................101

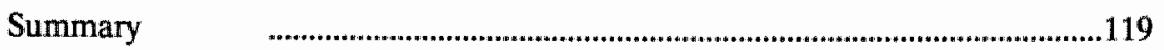

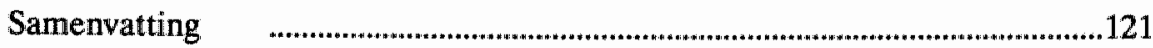

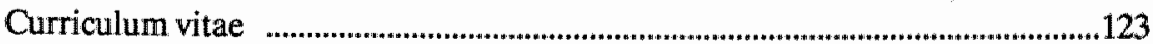





\section{CHAPTER 1}

\section{INTRODUCTION}

\subsection{GENERAL INTRODUCTION}

At the beginning of this century Paul Ehrlich presented his "magic bullet" concept. His revolutionary ideas on receptors and antibodies led him to envisage the design of drugs interacting with target cells only and having virtually no side effects. The magic bullet is the ideal form of drug targeting. The realization of Ehrlich's ideals was far from easy; it was not until the 1950 s that significant progress was made with research on receptors and antibodies.

Drug targeting can be defined as the design or application of drugs which exert their pharmacological action only at the desired site, thus creating a tissue-specific effect with as little side effects (toxicity) as possible. Ideally, the drug interacts with a tissue-specific receptor. In that case, the therapeutic index is usually high: at low concentrations of the drug the effect is therapeutic, and only at much higher concentrations toxic side effects occur. No targeting is needed for these drugs. Many drugs which are currently being used exert their actions through receptors, but the specificity is often not absolute because more than one type of receptor is activated simultaneously. A second reason for the lack of tissue-specificity of some drugs is the fact that many target receptors are not tissue specific.

When less specific drugs are employed, such as antineoplastic agents, or when only a part of the receptor population is to be activated, targeting is needed to achieve site-specificity.

In chosing the right approach to site-selective drug delivery, the properties of the target site must be the starting point. For instance, it is important to know whether the target is located in the intra- or extravascular space, whether the target tissue receives a high or low bloodflow, and which barriers the drug must surmount before it reaches the target site. 
The experimental approaches to drug targeting can be devided into three main groups. The first one is the bio-mechanical approach, which includes intra-arterial infusions, intra-thecal injections, topical administration, aerosols, et cetera. Intraarterial infusions will be dealt with in chapter 1.2 as an example of this approach. The second group is called carrier-mediated drug delivery. This includes among other macromolecular carriers, liposomes, and monoclonal antibodies. The properties of some of these carrier systems, with emphasis on the possibilities and limitations with regard to targeting, will be discussed briefly in chapter 1.3. The third and last approach is the chemical or prodrug approach. This approach will be discussed in detail in chapter 1.4 and will be the further subject of this thesis.

\subsection{INTRA-ARTERIAL INFUSIONS}

An infusion of an active drug into the artery supplying the target organ with blood seems one of the most straightforward routes to achieve site-selectivity. It is applied clinically in, for instance, cancer chemotherapy (Niederhuber et al., 1984; Cohen et al., 1986). A thorough discussion on the subject of intra-arterial drug administration falls beyond the scope of this thesis; the thesis of Daemen (1987) may be consulted for a detailed discussion on this subject.

Only under specific conditions the effect of local (i.a.) drug administration is more beneficial (i.e. significantly higher tissue concentrations of active drug) compared to a systemic (i.v.) infusion of the drug (Smits and Thijssen, 1986; Daemen et al., 1988a,b). These main conditions are: (i), the extraction ratio of the drug by the target organ must be high; (ii), if the drug is not cleared by the target tissue, this tissue must receive a relatively low blood-flow and the systemic clearance of the drug must be high.

To be successful, intra-arterial administration should be based upon the use of specific drug-delivery devices, such as osmotic minipumps to achieve a chronic (up to several days) infusion, or microparticulate drug-carrier systems which obstruct the capillaries and release the drug slowly (Reviews: Burger et al., 1985; Benoit, 1985).

Enhanced therapeutic effects of intra-arterial infusions of immunosuppressive agents in the kidney have been found (Ruers et al., 1986, 1987, 1989; Gruber et al., 1988). The studies of Ruers $e t$ al. show that local prednisolon concentrations in rat kidney allografts were twice as high when the drug was given intra-arterially compared to when it was given intraveneously, and that the survival time of the transplant was increased significantly. However, the renal blood flow is high and the renal extraction ratio of the drug is relatively low, so the above mentioned theory predicts that only little advantage can be obtained by intra-arterial infusion. The cause of the discrepancy between theory and practice is not yet understood. 
In general, local treatment via intra-arterial infusions is an invasive method with little applicability and when alternatives are available to achieve site-selectivity these should be preferred.

\section{DRUG TARGETING VLA CARRIERS}

\subsubsection{Macromolecular drug carriers}

A macromolecular drug carrier system for targeted drug delivery usually consists of a backbone, drug, spacer (sometimes), recognition site (or "homing" device) and (possibly) an additional group or device for controlling the physico-chemical properties (Sezaki and Hashida, 1984, 1985). The backbone of macromolecular carriers can be constituted by polypetides, albumin, lectin, polylysin, dextran, inulin, and others. The drug can be attached covalently or via electrochemical or hydrophobic interactions, either directly or via a spacer. A covalently bound drug may be active when it is still bound to the backbone (Verlander et al., 1976), but this is not usual. For general information on the subject of macromolecular carriers the following reviews can be consulted: Kramer (1982); Poznansky and Juliano (1984); Sezaki and Hashida $(1984,1985)$.

In the scope of this chapter, the most interesting part of the macromolecule is the homing device or recognition moiety. Sometimes the carrier backbone itself has an increased affinity for certain tissues. Although not highly specific, polycationic electrolytes, such as polylysines, have high affinity for negatively charged cell surfaces and appear to react more potently with some tumor cells than with other cells (Arnold et al., 1978, 1979; Kramer, 1982). Lectines are another example of carrier molecules with some selectivity. They are proteins which possess high specificity and high binding affinity for specific saccharide residues on glycolipids and glycoproteins (Bittiger and Schnebli, 1976), and can stimulate endocytosis by transformed cells at much lower concentrations than those nescessary for en docytosis by normal cells. For this reason, lectines are very interesting as carriers for chemotherapeutic agents (Shier, 1979).

Selectivity can also be obtained by using lactosylated albumins. Hepatocytes possess receptors for these glycoproteins and are able to transport these compounds (van der Sluijs et al., 1986, 1988). When a drug is attached to the lactosylated albumin, the complex can still be internalized, but when the amount of drug per mol carrier is increased, the intra-hepatic distribution of the carrier complex is changed, due to the altered surface of the carrier complex (van der Sluijs et all, 1986).

A high degree of selectivity can be achieved in vitro by coupling an antibody to 
the carrier (Rowliand et al, 1975; Garnet et al., 1983). The antibody is usually directed against tumor specific cell surface antigens. The antibody-carrier complex has the combined properties of the separate systems. The properties of monoclonal antibodies will be discussed in more detail in section 1.3.2. The main advantage of a macromolecular drug carrier system coupled to an antibody above an antibodydrug conjugate is that the first can contain a much higher drug load per mol carrier.

The group of carriers is very diverse and the carriers can be modified in several ways, which means that a large variety of physico-chemical properties can be obtained. In theory, it should therefore be possible to achieve a reasonable sitespecificity of the carrier, for instance to tumor tissue.

However, many problems remain. The carriers, especially protein-derived carriers, may induce adverse immunological reactions. Another problem is the toxicity of the carrier itself. Polylysins, for instance, are very toxic when they exceed a certain size. But even relatively non-toxic carriers may present a problem because of their accumulation in the body. They generally have a low systemic clearance and remain in the body when the drug has been released, thus causing accumulation upon repeated administration of the conjugate.

Macromolecules can be readily extracted from the circulation by the reticuloendothelial system. This is of course no problem if targeting to infected macrophages is intended (Fiume et al., 1983, 1986), but it is a severe complication if targeting to another tissue (e.g. a tumor) is desired.

Due to their size and other physicochemical properties, a number of the macromolecular carriers have difficulties in leaving the vascular space, thus limiting the number of possible target sites. These considerations indicate one major application for macromolecular drug carriers: treatment of leukemia. Trouet and coworkers have investigated the possibility of targeting antitumor drugs to L1210 leukemia bearing mice by using protein carriers (Trouet et al., 1982). This approach is promising and possibly also clinically applicable.

Finally, even if the macromolecular drug conjugate has excellent binding properties to the target tissue and is able to reach this site, the drug will have to be released from the conjugate and to be taken up by the cells. This is a major problem when the drug is bound covalently to the carrier. An example hereof is described by Raso et al. (1988). They found that a methotrexate-antibody complex, directed against the transferrin receptor, did bind to this receptor, but that this complex was not internalized.

\subsubsection{Monoclonal antibodies}

The possibilities and limitations of antibodies as drug or enzyme carriers in targeted drug delivery have been discussed by Poznansky and Juliano (1984) in a review on controlled delivery of drugs. Other reviews which can be consulted on this subject are: Edwards et al. (1982), Weinstein et al. (1986, 1987). Apart from the treatment of tumors, labeled antibodies can be used for tumor localization (Mach 
et al., 1985; Schlom, 1989).

Antibodies, directed against a tumor-specific antigen and coupled to a drug often give encouraging results in vitro (tissue cell cultures). In vivo, however, the results are not very spectacular up to now. Several problems severely limit the effective use of antibodies in anti-cancer therapy. Firstly, the complex will have to escape the reticuloendothelial system (RES). The RES is specially equipped to remove foreign proteins and other macromolecules from the circulation. Secondly, the antibody must be able to reach the tumor. The fact that intact antibodies have difficulties in leaving the circulation, limits their use in the treatment of solid tumors. Fragments of antibodies are more capable of leaving the circulation. Thirdly, the antibody must be specific, i.e. it should not react with antigens on the surface of normal cells. But an antibody with high specificity for a single tumor-specific antigen usually fails to kill all tumor cells because of the heterogeneity of the antigen expression of malignant cells. And finally, even if the antibody-drug conjugate binds selectively to the tumor cells in vivo, the drug will have to be released and taken up by the cells, or, if the antibody complex is internalized after binding to the tissue, the drug will have to be released from the lysosomes to the cytoplasm of the cells.

It seems possible to solve some of these problems. For instance, the internalization of the drug-antibody complex can be improved by co-administration of monensin, a carboxylic ionophore. A methotrexate-anti-transferrin complex binds effectively to CEM cells, but is not transported into the cells, unless monensin is added (Raso et al, 1988).

By using antibody fragments instead of whole antibody, the transport in solid tumors can be improved. Matzku et al. (1988) showed that a more even distribution of iodine-labeled antibody was found in solid tumors in mice when a fragment was used instead of the whole antibody, especially in small spontaneous metastases.

In evaluating the results of targeted delivery of drugs via antibodies, the synergistic action of antibody and drug should be taken into account (Poznansky and Juliano, 1984). When an antineoplastic drug and a monoclonal antibody are administered simultaneously (i.e. no drug targeting occurs because the drug is not bound to the antibody), the effect on tumor growth is often found to be larger than following administration of either drug or antibody alone, due to a synergistic action.

In short, antibodies as drug carriers are not the "magic bullets" hoped for. They may be used to inhibit the metastazation of established tumors, but before they can be used effectively against solid tumors, many problems will have to be solved.

\subsubsection{Liposomes}

Liposomes are vesicles that consist of phospholipids. These vesicles can be unilamellar (small or large) or multilamellar. The physical properties of liposomes depend upon their chemical composition; different saturated and unsaturated fatty acids, sterols and other amphiphilic compounds can be incorporated into the 
membranes. Liposomes can contain a large number of different drugs; hydrophilic drugs will be found in the internal aqueous compartment, while lipophilic or amphiphilic drugs can intercallate into the lipid bilayer membrane of the liposome. Potential advantages of liposomes are: (relatively) non-toxic, biodegradable and easy to prodice relative to other drug-carrier systems. For a thorough discussion on the properties and applications of liposomes, including the targeting of liposomes, see Gregoriadis (1988). Other reviews include: Gregoriadis et al. (1982 a,b), Weinstein et al. (1982), Poznansky and Juliano (1984) and Schneider (1985).

Important for the targeting of liposomes is their interaction with cells. This issue has been reviewed by Pagano and Weinstein (1978), Juliano and Layton (1980) and Juliano et al. (1987). The four basic mechanisms for interaction are: (i) absorbtion to the cell surface, (ii) endocytosis, (iii) fusion and (iv) lipid exchange. These processes, however, are general and cannot be used for targeting.

Target site recognition can be achieved by coupling an antibody to the liposome or by changing the surface of the liposome membrane, e.g. with mannose as a recognition marker (Umezawa and Eto, 1988), glycosides (Ghosh $e t$ al., 1982) or carbohydrates (Skoza and Mayhew, 1983). The above mentioned general mechanisms of liposome-cell interaction, however, can cause a considerable loss of selectivity.

Two main problems in the targeting of liposomes are: (i) a specific binding of the antibody-liposome complex to a cell does not guarantee intracellular delivery of the contents of the liposome; (ii) many barriers exist in vivo which can frustrate the targeting, even if the targeting can be accomplished in vitro (Poznansky and Juliano, 1984). These barriers are largely the same as those described for monoclonal antibodies in section 1.3.2.

The main barrier encountered in vivo with targeting to tissues other than the reticuloendothelial system (RES) is the high extraction of liposomes by the RES. Blockade of the RES with dextran sulphate or carbon (Souhami et al., 1981) or with empty liposomes (Kao and Juliano, 1981) does not influence the distribution of radiochemically labeled liposomes dramatically. Due to these problems liposomes will probabely only be useful in the targeting to intravascular targets, such as macrophages (RES) infected by Leishmania (Alving et al., 1978; Hunter et al., 1988), or other pathogens like Brucella, Listeria, Salmonella, Myobacteria or Legionella pneumophila (Schneider, 1985); T-cells (Gray et al., 1988); or to erythrocytes (Peeters et al., 1988a,b).

The targeting of liposomes to tumor cells in non-macrophagic, extravascular tissue is still being attempted with varying success (Papahadjopoulos and Gabizon, 1987; Khokhar et al., 1988). It seems possible to control the rate of clearance of liposomes with antibody conjugated on the surface by changing the membrane composition. If relatively small (approx. $100 \mathrm{~nm}$ in diameter) vesicles are used, the liposomes might be able to escape from the vasculature in tissues with fenestrated or "leaky" epithelium (Papahadjopoulos and Gabizon, 1987). 


\subsubsection{Magnetically directed drug targeting}

Magnetic microspheres typically consist of the following components: watersoluble drug; $10-\mathrm{nm}$ magnetite ( $\mathrm{Fe} 3 \mathrm{O}_{4}$ ) particles; matrix (usually albumin). These components are emulsified in a biodegradable oil and sonificated (to produce submicron particles); next the matrix is stabilized by (chemical or controlled heat) cross-linking; then the oil is removed by extraction and finally the product is lyophilized (Ranney and Huffaker, 1987).

Magnetic microspheres are usually injected into the proper artery and sometimes intravenously. Because of their size $(<1, \mathrm{~m})$ they would ordinarily pass through the capillaries of the target tissue, but by applying an extracorporal gradient magnetic field they are captured in small arterioles and capillaries of the magnetic targeting volume. When the magnetic field is maintained sufficiently long (several hours), the particles can extravasate so that when the magnet is removed no redistribution takes place and the drug-carrier complex is retained at the target site (review: Gupta and Hung, 1989). The extravasation is an important advantage over other carrier systems, which usually cannot leave the vasculature.

It has been suggested that tissue uptake could even be enhanced by using chitosan as a matrix (Gallo and Hassan, 1988). Chitosan is a cationic polysaccharide which has a high affinity for glycosaminoglycans like heparin (Gallo and Hassan, 1988). This, however, has not yet been tested in vivo.

Because of the localization of the complex, uptake by the the RES is avoided, the latter being one of the main problems with almost all other carrier systems (see above). Magnetic carriers administered i.v. without applying a magnetic field are also taken up by the RES, as shown by Papisov et al. (1987).

On the basis of a mathematical model, Papisov and Torchilin (1987) showed that the best results can be obtained with drugs with a short half-life (about several minutes or less), while long acting drugs benefit only slightly by targeting via magnetic carriers. It is also important that the drug is active at low concentrations in order to avoid overloading of the carrier material in the tissue. This concept has been tested using a magnetically driven immobilized streptokinase carrier complex (Torchilin et al., 1988). Thrombosis was induced in both canine carotid arteries and a magnet was secured around one of the arteries. When the magnetical streptokinase complex was injected intravenously, the trombus which was in the magnetic field completely disappeared, while no effect on the control clot was observed.

In spite of the excellent targeting possibilities, magnetically driven drug targeting can only be employed in severe cases of illness when other therapies have failed. The reasons for this are the high costs and the toxicity of the preparations. Another drawback is the need to know the exact location of the pathological process (e.g. tumor) in the body, which renders this method unsuitable for the treatment of metastases. 


\subsubsection{Cells as drug carriers}

Several cellular carriers have been used to investigate the possibility of sitespecific drug delivery (Poznansky and Juliano, 1984). These include: erythrocytes, fibroblasts, leukocytes, encapsulated cells (e.g. pancreatic isles of Langerhans cells; Lim and Sun, 1980), reconstituted virus envelopes (Earl et al, 1988), and artificial cells.

When erythrocytes are submitted to hypotonic hemolysis, large holes or pores appear in the membranes. Through these pores, drugs or macromolecules such as enzymes can pass. Upon restoration of the original osmotic conditions, the holes close and the drug or enzyme molecules are trapped in the erythrocytes (Ihler, 1982). Damaged cells are taken up by the reticuloendothelial cells and can be used to target enzymes to these cells (useful in enzyme deficiencies).

The latter approach is also called "passive targeting". Active targeting to other tissues than the RES seems very hard to achieve due to the nature of the carrier.

\subsubsection{Conclusión}

The use of carriers in the targeting of drugs shows the following general pattern. It is possible to target drugs or enzymes to the RES by most of the systems described. However, targeting to extravascular sites such as tumors or non-macrophagic cell types presents major problems. The only systems which are potentially able to deliver drugs selectively at those sites seem to be magnetic drug carriers and antibody-fragment-drug conjugates. Magnetic carriers are only suitable in the treatment of well-localized tumors; antibody-fragment-drug conjugates seem most suitable for the treatment of tumor metastases but not of large, solid tumors. Neither system is suitable for targeting to other tissues, such as kidney, brain or heart.

\subsection{PRODRUGS}

\subsubsection{Definition and applications}

Prodrugs are compounds which must undergo chemical transformation prior to exhibiting their pharmacological action (Stella, 1977). This term was first used by Albert (1958); the concept has also been called "drug latentiation" (Harper et al, 
1962).

Prodrugs are used to overcome certain barriers or problems which limit the use of pharmacologically active agents (see Fig. 1.1). They may arise in either the pharmaceutic or pharmacokinetic phase of drug development; prodrugs cannot improve the pharmacodynamics of a drug. This subject has been reviewed extensively (e.g. Ariens, 1969; Stella, 1977; Bundgaard and Hansen, 1981; Notari, 1981; Stella et al., 1985; Giudicelli, 1988).

The problems in the pharmaceutical phase include: bad taste, gastro-intestinal irritation, low stability, low solubility, and pain upon injection. The pharmacokinetic goals for prodrugs include: increased oral absorption, decreased presystemic metabolism, increased topical penetration, increased duration of action, control of the rate of drug release, increased site specificity, decreased side effects. Since many examples have been mentioned in review articles, only a few recent examples of prodrugs as a solution for pharmaceutic or pharmacokinetic problems will be mentioned here. In Table 1.1 examples are given of prodrugs in therapeutic use.

The chronic use of aspirin is still an important cause of gastro-intestinal irritation. Numerous esters of acetylsalicylic acid have been prepared and evaluated (Bundgaard et al., 1988; Nielsen and Bundgaard, 1989), but this has not yet resulted in a safer prodrug which can be marketed.

A large number of prodrugs aim at the improvement of bioavailability (i.e. increased gastrointestinal absorption and/or decreased presystemic metabolism). Some recent examples of drugs of which prodrugs for improved bioavailability have been described are: naltrexone (Hussain et al., 1987), propranolol (Irwin and Bellaid, 1988), dyphylline (a theophylline analogue, Huang and Ayres, 1988) and sulbactam and analogues (Ikeda et $a l ., 1988$ ).

Naltrexone, for instance, undergoes extensive first-pass metabolism upon oral administration. The benzoate and acetylsalicylate esters of this drug protect it from conjugation in the liver and hence the bioavailability is greatly enhanced (Hussain et al., 1987)...

One of the main requirements to be met by prodrugs for improved bioavailability is that they must be converted to the active drug as soon as possible after the barrier has been crossed. Bundgaard and co-workers have done a lot of research on the possibilities of derivatising drugs with certain chemical groups to prodrugs which can be hydrolized in plasma (among other: Bundgaard, 1985 ; Bundgaard and Buur, 1987; Bundgaard and Nielsen, 1987; Larsen and Bundgaard, 1987; Nielsen and Bundgaard; 1987).

The absorption of prodrugs through the skin has been reviewed by Hadgraft (1985). More recent research includes studies on the effect of variation of the chemical structure on the ability of prodrugs to deliver theophylline and 5fluorouracil (Sloan et al., 1988) or 6-mercaptopurine (Waranis and Sloan, 1988) through the skin.

Sustained drug action via prodrugs has been reviewed by Sinkula (1985). An interesting way to increase the duration of action or control the rate of release of a drug is the combination of a prodrug and liposomes (Tokunaga et $a l$, 1988a, $b_{3}, c_{*}^{*}$ Hashida et al., 1988). 


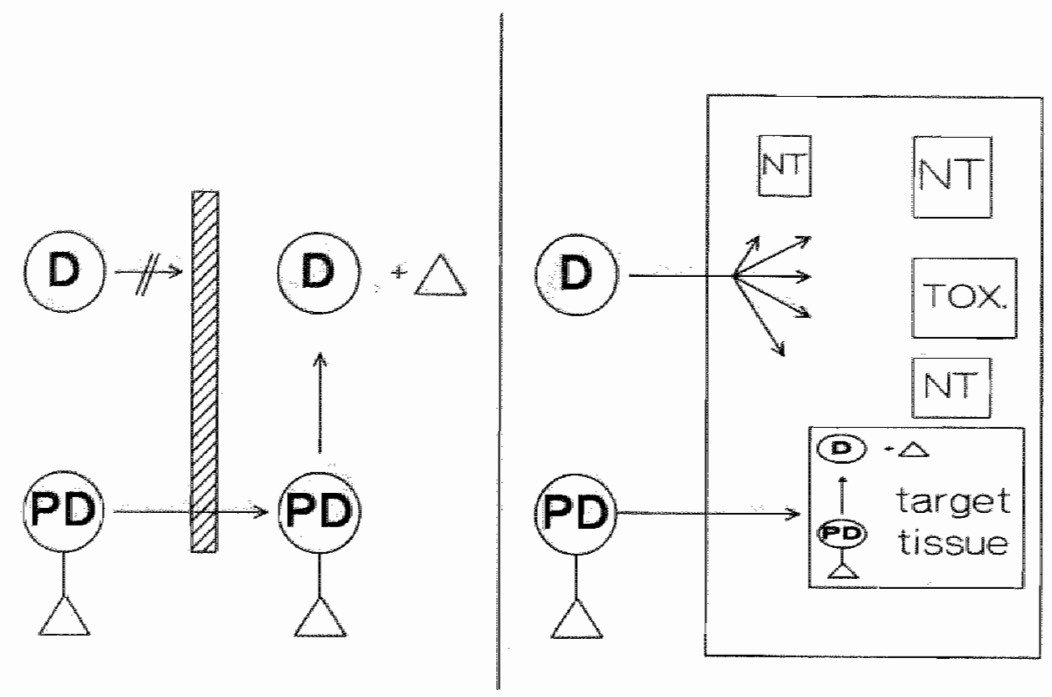

VIg. 1.1 Left panel: The prodrug (PD) is able to owercome a barrier which the active drug cannot overcome; right figure: When the active drug is administered, it is distributed throughout the whole body, including non-target (NT) tissue and tissues were it can exert a toxic action, while following prodrug administration the active drug is released only at the target site.

Table 1.1 Some examples of prodrugs in therapeutical use.

\section{prodrug}

acetylsalicylic acid

bacampiciline

chloramphenicolsuccinate

clindamycinpalmitate

cyclophosphamide

dipivefrine

enalapril

erythromycinethylsuccinate

ibopamine

ibuterol

L-dopa

methenamide

$\mathrm{N}$-acetylsulfafurazole

prednisolonesodiumsuccinate

salazosulfapyridine

sulindac

\section{active drug}

salicylic acid

ampiciline

chloramphenicol

clindamycin

fosforamide mustard

epinephrine

enalaprilate

erythromycin

epinine

terbutaline

dopamine

formaldehyde

sulfafurazole

prednisolone

5-aminosalicylic acid

sulindac sulfide

\section{reason of use}

toxicity

taste

taste

taste

toxicity

local effect

bioavailability

taste/solubility

bioavailability

local effect

CNS-effects

local effect

taste

solubility

local effect

stability 
Prodrugs can also be used for site-specific drug delivery. This will be the subject of the next chapters.

\subsubsection{Targeting via prodrugs: history}

Site-specific drug delivery and action via prodrugs already existed before these terms were used. Methenamide is a classic example of a site-specific prodrug. At acidic $\mathrm{pH}$ it is converted to formaldehyde, hence it is used as an urinary tract antiseptic.

In the past several attempts have been made to achieve site-specificity via prodrugs. The basis usually was the increased activity of an enzyme in a certain (mostly tumor) tissue. In the 1950s, for instance, it was attempted to use the high level of acid or alkaline phosphatases in some tumors by designing phosphate esters of cytostatics. The best known examples are: stilboestrol diphosphate and mustard phosphate.

Preliminary in vitro studies showed that a prostatic tumor, possessing a high level of phosphatase, was able to activate the prodrug stilboestrol diphosphate; however, it was found in vivo that no selectivity was obtained because activation of the drug also occurred at a high rate in other tissues. The same applies to the phosphate mustard: the compound was too toxic because of a rapid systemic activation. Several other esters of cytostatics have been tried, usually with little success (these and other examples were reviewed by Harper, 1962; Ariens, 1969; Workman and Double, 1978; see also Sinkula, 1987).

Double and Workman (1977) have correlated the tumor activity of some enzymes with the beneficial effect of aniline mustard and some of its derivatives. It was concluded that a high tumor level of $\beta$-glucuronidase is essential in the curative action of aniline mustard.

An elegant approach would be a selective induction of an enzyme in tumor tissue, followed by treatment with a prodrug which is a good substrate for that particular enzyme. Danielli (1961) tried this by inducing the enzyme carbaminase with urethanes. Unfortunately, the carbaminase activity in other tissues (liver) was also induced.

Many types of tumors display an elevated level of plasminogen activator and hence an increased level of plasmine. Prodrugs of antitumor agents which are good substrates of plasmine are potentially tumor-selective. Carl and co-workers (1980) have designed peptidy] prodrugs (D-Val-Leu-Lys-X) of AT-125 and pphenylenediamine mustard as substrates of plasmine. It was shown in vitro that these prodrugs were 5-7 times as selective for transformed cells as for the parent drugs. However, no increase in therapeutic index was observed in vivo (Chakravarty et al., 1983); again, this was probably due to a significant activation of the prodrugs by non-target tissue.

It has been suggested that, in spite of the high activity of $\gamma$-glutamyl transpeptidase (GGT) in the kidney, $\gamma$-glutamyl prodrugs could be designed as tumor-selec- 
tive prodrugs. Some liver tumors display a high activity of GGT; kidney cells are resistent to many classes of anticancer agents. Nagasawa and co-workers (Nagasawa et al., 1980; Magnan et al., 1982) have tested a series of $\gamma$-glutamyl derivatives as substrates for GGT. However, neither in vitro nor in vivo selectivity tests of these compounds have been described. In vitro, a $\gamma$-glutamyl derivative of $p$ phenylenediamine mustard was shown to be 30 times more toxic than the parent compound in a hepatocyte cell line with a high GGT level, in contrast to the toxicity in a mormal hepatocyte cell line (Manson et al., 1981). It is not very likely that this concept will work in vivo. The kidney may not be susceptible to some antineoplastic agents, but the renal GGT activity is very high. As the kidney receives $20 \%$ of the cardiac output, large amounts of free drug will be generated by the kidney and a substantial part hereof will be systemically available, thus causing the usual systemic toxicity.

These examples illustrate that a thorough knowledge of all biochemical, physiological and pharmacokinetic factors involved is necessary for the rational design of site-specific prodrugs.

\subsubsection{Targeting via prodrugs: theoretical backgrounds}

The requirements which should be met by both prodrug and active drug have been discussed extensively by Stella and Himmelstein $(1980,1982)$ and Smits and Thijssen (1986). These authors used a hybrid physiologic-mathematical model to simulate the influence of several factors on the site-selectivity of prodrugs. The most important results will be discussed here.

First of all, the prodrug must be able to reach the target site. The accessibility must be very good, essentially perfusion-rate limited (this point is important especially in poorly perfused tissues). Secondly, the prodrug should be converted to the active drug in the target tissue. The converting enzyme should really be located exclusively in the target organ. The most important factor is not relative enzymatic activity (i.e. activity per gram tissue), but rather absolute activity (i.e. total enzymatic activity in the tissue) and availability of prodrug (blood flow). A combination of these two factors is probably responsible for the failure of phosphate esters of antineoplastic agents to produce a tumor-selective effect.

The third factor is that the target tissue must be able to retain (or metabolize) the released active drug. If the drug is very lipophilic it will usually redistribute quickly throughout the body, thus causing a loss of selectivity, even if the activation of the prodrug takes place only in the target tissue.

This last point was emphasized by Stella and Himmelstein, because its importance was not realized till then (Stella and Himmelstein, 1980). If a highly efficient drug-delivery system is available, much consideration should be given to the choice of the right drug to be delivered.

A number of more successful attempts at targeting via prodrugs will be discussed in the next few paragraphs. 


\subsubsection{Gastric proton pump inhibition}

Recently a new and very elegant approach to the treatment of peptic ulcers has become available. Inhibition of the proton pump in the parietal cell of the gastric mucosa is very effective in inhibiting gastric acid secretion (Wallmark, 1986). This is achieved by using substituted benzimidazoles, which are acid-labile prodrugs. One of these drugs, omeprazole (Clissold and Campoli-Richards, 1988), has recently been introduced on the market, but many more have been tested (Brändström et al. 1985; Bohnenkamp et al. 1987).

The mechanism of action of these prodrugs can be summarized as follows (Wallmark, 1986; see Fig. 1.2). The prodrugs are stable above $\mathrm{pH} 4$, but at more acidic $\mathrm{pH}$ they are activated. A rearrangement in the structure of the molecule takes place, as a result of which the sulfur atom in the molecule becomes highly reactive. This activated molecule can react with compounds containing an SH group, such as the $\mathrm{H}^{+}, \mathrm{K}^{+}$-ATPase (proton pump). The inhibition is irreversible.

In vitro, the activated drug is also able to react with other SH-containing enzymes. However, this does not occur in vivo. The selectivity is reached by a local activation of the prodrug and a very effective retention of the active drug at the site of formation. The prodrug is distributed throughout the whole body, but only in the acid-secretory canaliculi of the parietal cell the $\mathrm{pH}$ is low enough $(<4)$ to activate the prodrug. The protonated drug cannot cross the membrane and is trapped in the lumen of the secretory canaliculi, where it can react rapidly with the mercaptogroup of the $\mathrm{H}^{+}, \mathrm{K}^{+}$-ATPase, which is located at the luminal side of the membrane. In this way the action of the drug is restricted very effectively to the site of formation and few side-effects can occur (Clissold and Campoli-Richards, 1988).

This is a clear example of the importance of the requirements for the site-selective action of a prodrug as formulated by Stella and Himmelstein (1980; see section 1.4.3), especially the site-specific conversion and the site-retention of the active drug.

\subsubsection{Targeting to the brain}

An example of a greatly enhanced delivery to the brain via prodrugs is constituted by the redox-delivery systems developed by Bodor and co-workers. The dihydropyridine carrier system approach was applied (among other) to pro-2-PAM (N-methyldihydropyridinium-2-carbaldoxime chloride, Bodor et al., 1975; 1976), dihydroberberine (Bodor and Brewster, 1983) and dopamine (Bodor and Simpkins, 1983). In this concept a combination of two (or more) steps ensures the delivery to the brain of drugs which would not ordinarily pass the blood-brain barrier.

These redox targeting systems have the following characteristics (Fig. 1.3). A lipophylic prodrug, containing a dihydropyridine moiety (either in the structure of the active drug or else as promoiety), is made. The dihydropyridine group is easily oxidized (in vivo half life time of $2-10 \mathrm{~min}$, Bodor, 1982) to a quaternary pyridinium 


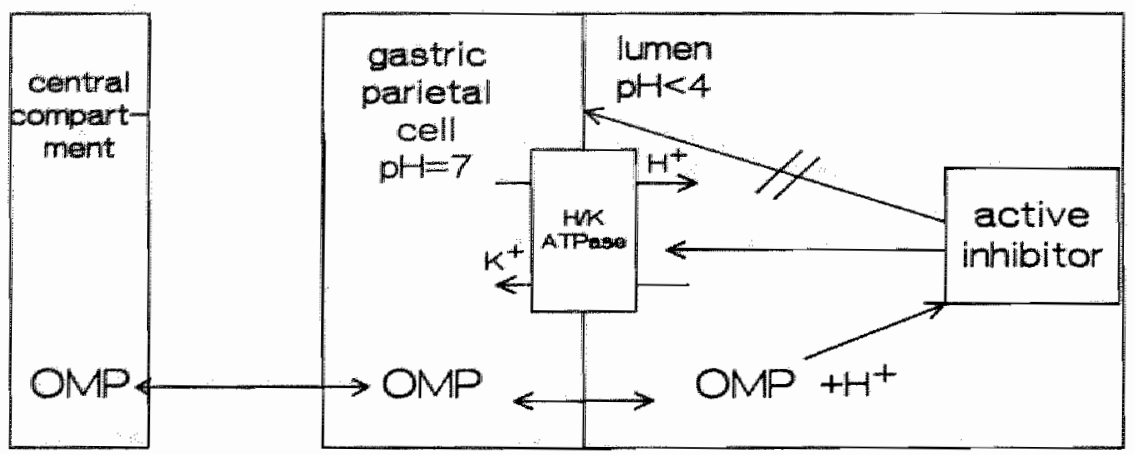

Flg. 1.2. The mechanism of selectivity of omeprazol (OMP). For explanation, see chapter 1.4.4.

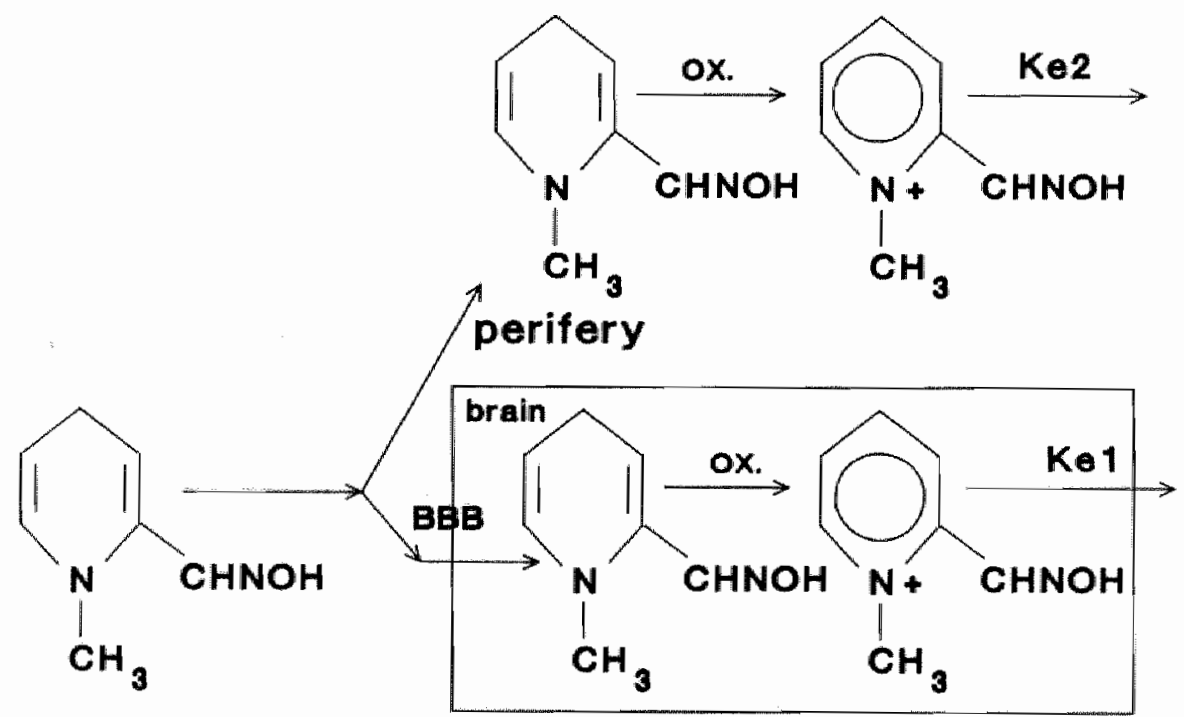

Wig. 13. Enhanced delivery of 2-PAM to the brain by pro-2-PAM. 2-PAM is not able to cross the BBB, contrary to pro-2-PAM. The released quaternary compound (2-PAM) can be excreted periferally, but its elimination from the brain is slow, i.e. $\mathrm{Ke} 1<<\mathrm{Ke} 2(\mathrm{Ke}=$ elimination rate constant). See chapter 1.4.5. 
ion. The latter compound is trapped in the brain because charged compounds cannot pass the blood-brain barrier except via carrier-mediated transport. Either thiis quaternary compound is the active drug (e.g. berberine and pro-2 PAM) or the pyridinium promoiety can be removed to generate the active drug (e.g. dopamine).

This approach does not ensure selectivity but an enhanced delivery to the brain. A certain degree of selectivity is possible, depending upon the systemic rate of excretion of the quaternary pyridinium form of the drug: the faster this compound is excreted, the higher the selectivity is.

Recent applications of this concept are described by Palomino et al., (1989) and Gogu et al., 1989. The drugs 2',3'-didehydro-2'3'-dideoxythymidine and 3'-azido$2^{\prime}, 3^{\prime}$-dideoxythymidine (AZT), potentially useful in the treatment of AIDS, were coupled to a dihydropyridine carrier system in order to enhance the delivery to the brain.

\subsubsection{Kidney selective prodrugs}

The kidney is a very interesting organ as a target for site-selective drug delivery. The kidney is involved in many processes of homeostasis, such as acid-base balance, volume regulation and blood pressure regulation. In addition, the kidney possesses high levels of some enzymes and in combination with the high tissue blood flow this offers opportunities for renal selective drug delivery.

Compared to other tissues, the kidney contains a high level of $\gamma$-glutamyl transpeptidase (GGT). Therefore, it was attempted to use this enzyme for kidneyselective delivery of drugs via $\gamma$-glutamyl prodrugs.

Gamma-glutamyl dopamide (Minard et al., 1980) and $\gamma$-glutamyl dopa (Wilk et al. 1978) were developed as renal vasodilators on basis of a kidney selective delivery of dopamine. It was shown that the renal dopamine level following $\gamma$-glutamyl dopa (gludopa) was significantly higher than following an equimolar administration of L-dopa, whereas the concentrations in other tissues (especially the heart) were not enhanced (Wilk et al., 1978). Lee and co-workers have investigated the pharmacologic effects of gludopa in man (Worth ef al., 1986; Jeffrey et al., 1988a,b; McDonald et al., 1988). It was shown that this compound is an effective renal vasodilator in man and produces significant natriuresis. However, a drawback is that this compound is not orally applicable.

Orlowski and co-workers (1980) have presented a study in which they showed that the $\gamma$-glutamyl prodrug of sulfamethoxazole (SM) produced only slightly higher SM concentrations in the kidney compared to SM administration, whereas the $\mathrm{N}$-acetyl- $\gamma$-glutamyl derivative caused significantly higher SM concentrations in the kidney and lower concentrations in other tissues (e.g. liver). This means that the renal selectivity of the $\mathrm{N}$-acetyl- $\gamma$-glutamyl compound was much higher than that of the $\gamma$-glutamyl prodrug. This was explained by assuming that the prodrug was converted by two kidney-selective enzymes: acylase and GGT.

Another renal selective prodrug is SIM 2055 ( $\mathrm{N}$-methyldopamine-4-O-phos- 
phate), an orally active renal vasodilator (Casagrande et al., 1988, Casagrande, 1989). This prodrug was developed on the basis of the high phosphatase activity in the kidney. This enzyme is located primarily at the brush-border membrane of the tubular cells (Guder and Ross; 1984). At doses of 1-10 mg only minimal changes were found in the general hemodynamics and cardiac function, whereas the renal resistance was decreased significantly. The success of this phosphate prodrug is possibly due to a combination of a high blood flow to the target organ, a high enzymatic activity in the target organ (cfr the failure of phosphate esters for tumor selective drug delivery, section 1.4.2) and a high affinity of the kidney for the released compound. The mechanism of the renal selectivity is however not yet understood in detail.

Recently, a new renal selective vasodilator prodrug, TA-870, was described (Yoshikawa et al., 1988; Yamaguchi et al., 1989). TA-870 is the N-(N-acetyl-Lmethionyl)-O,O-bisethoxycarbonyl derivative of dopamine. This prodrug serves as an orally active dopamine precursor and has dopamine-like effects. The renal selectivity, however, does not seem to be very large, the mesenteric blood flow was also increased and the compound has some $a$-receptor activity (Yamaguchi $e t$ al., 1989), although less than ibopamine, which is a prodrug with both renal vasodillatory and positive inotropic effects (Casagrande et al., 1985). More research will have to be carried out to investigate the renal selectivity of TA-870 and the mechanisms behind this selectivity.

\subsubsection{THIS THESIS}

The initial goal of the investigations described in this thesis was to elucidate the mechanism of the renal selectivity of CGP 22979 , the N-acetyl- $\gamma$-glutamyl prodrug of CGP 18137 (2-hydrazino-5-n-butyl-pyridine, see Fig. 1.4). This compound was developed to act as an orally active renal vasodilator (Hofbauer et al., 1985). Hemodynamic studies showed that upon acute administration this prodrug caused a renal selective vasodilation and a decrease in vascular resistance (Smits et al., 1985; Nievelstein et al., 1985), although after chronic administration a decrease in mesenteric resistance (smaller than the decrease in renal resistance) occurred as well (Nievelstein et al., 1987).

The active compound CGP 18137 is a hydralazine-like directly acting vasodilator (Hofbauer et al., 1985). This fact raises the question how it is possible that the prodrug CGP 22979 has a renal selective action. When the active drug, generated in the kidney, exerts its action at the vascular wall, it is systemically available. This means that site-retention of the active drug, which is necessary for site-specificity (see section 1.4.3), does not occur. Another problem in explaining the selectivity of this $\mathrm{N}$-acetyl- $\gamma$-L-glutamyl prodrug is that GGT is not able to hydrolyse $\mathrm{N}$-substituted $\gamma$-glutamyl derivatives (Cook et al., 1987). Theory (Stella and Himmelstein, 


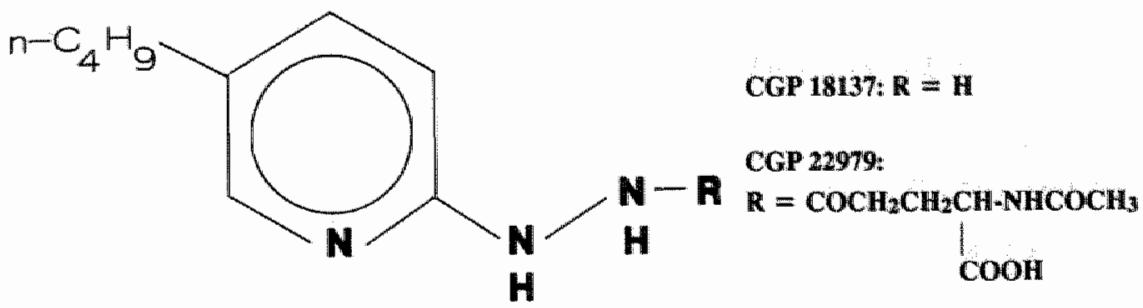

Fig. 1.4. Structural formulas of CGP 18137 and CGP 22979.

$1980,1982)$ predicts that this prodrug can not be renal selective. However, the fact remains that CGP 22979 is a renal-selective vasodilator over a considerable dose. range.

In animal toxicity studies it appeared that CGP 22979 was too toxic to start clinical trials. A number of similar $\mathrm{N}$-acetyl- - -glutamyl prodrugs of vasodilators were synthetized and tested, but these appeared to be not renal selective. This raises the question by which mechanism the renal selectivity of CGP $22979, \mathrm{~N}$-acetyl $-\gamma-$ glutamylsulfamethoxazole and $\gamma$-glutamyl dopa is reached. When the exact mechanism of selectivity of these prodrugs is known, new prodrugs can be developed in a more rational way and with a better chance of achieving renal selectivity.

For these reasons, studies were undertaken to investigate the mechanism of the renal selectivity of CGP 22979. Part one of this thesis (chapter 2-4) gives a description of these studies and presents a model for the renal handling of CGP 22979. In order to validate and extend this model the $\mathrm{N}$-acetyl- $\gamma$-glutamyl prodrug of sulfamethoxazole was used; the results of this study are presented in chapter 5. Subsequently, the prodrug of 4-aminowarfarin was designed as a possible application of the model (chapter 6). Finally, the use of kidney slices in the assessment of tubular transport was investigated, the results of which are evaluated in chapter 7.

\subsection{REFERENCES}

Albert, $A_{r,}$ Chemical aspects of selctive toxicity. Nature 182: 421-423, 1958.

Alving, C.R., Steck, E.A., Hanson, W.L. Loizeaux, P.S., Chapman Jr, W.L. and Waits, V.B., Improved therapy of experimental leishmaniasis by use of a liposome-encapsulated antimonial drug. Life 
30. 22: 1021-1026, 1978 .

Alving $C . R_{\text {, }}$ Therapeutic potential of liposomes as carriers in leishmaniasis, malaria and vaccines. la: Targeting of drugs (eds.: Gregoriadis, G., Senior, J. and Trouet, A.), Plenum press, N.-Y., 1982, pp $337-353$.

Arieni, EJ., Modulation of pharmacokinetics by modification of the various factors involved. II Farmaco 24: 1 102, 1969.

Arnold, LJ, Dagan, A., Simon, S.D. and Kaplan, N.O., Polymer linked derivatives of nicotinamide analogs Elimination of toxic side effects with an increase in antineoplastic activity. Proc. Amer. Assoc. Cancer Res. 19: 114, 1987.

Arnold, L., Dagan, A. Gutheil, J. and Kaplan, N.O. Antineoplastic activity of poly (L-lysine) with some ascites tumor cells. Proc. Nat. Acad. Sci. USA 76: 4246-4250, 1979.

Benoit, J.P., Microcapsules and microspheres for chemoembolization. In: Drug targeting (eds: Buri, P. and Cumma, A.), Elzevier, Amsterdam, 1985, pp 95-117.

Bittiger, H. and Schnebli, H.P. (eds.), Concanawalin A as a tool. John Wiley \& sons, N.-Y., 1976.

Bodor, N. Nowel approaches in prodrug design. In: Optimization of drug delivery (eds.: Bundgaard,

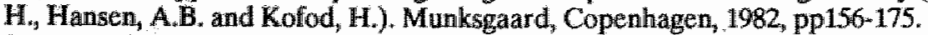

Bodor, N, and Brewster, M.E. Problems of delivery of drugs to the brain. Pharmacol. Therap. 19: $337-386,1983$.

Bodor, N. and Simpkins, J.W. Redox delivery system for brain specific sustained release of dopamine. Science 221: 65-67, 1983.

Bodor, $\mathbb{N}_{s,}$ Shek, $E$ and Higuchi, $T_{\text {, }}$, Delivery of a quaternary pyridinium salt across the blood brain barrier by its dihydro derivative. Science 190: $155-156,1975$.

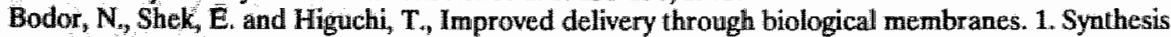
and properties of 1-methyl-5,6-dihydropyridine-2-carbaldoxime, a prodrug of $\mathrm{N}$-methylpyridinium-2-carbaldoxime chloride. J. Med. Chem. 19: 102-107, 1976.

Bohnenkamp, W., Eltze, M., Heintze, K., Kromer, W. Riedel, R, and Schudt, $C_{\text {. }}$ Specificity of the substituted benzimidazole B 823-08: a prodrug for gastric proton pump inhibition. Pharmacology 34: 629-278, 1987.

Brändström, A., Lindberg, P. and Junggren, U., Structure-activity relationships of substituted benzimidazoles. Scand. J. Gastroenterol. 20 (suppl 108): 15-22, 1985.

Bundgaard, $H$., Design of prodrugs: Bioreversible derivatives for various functional groups and chemical entities. In: Design of prodrugs, (ed.: Bundgaard, H.), Elsevier, Amsterdam, $1985_{\text {p }}$ pp $1-92$,

Bundgaard, $H$. and Buur, A., Prodrugs as drug delivery systems. 65 . Hydrolysis of $\alpha$-hydroxy-and $a$-acyloxy-N-benzoylglicine derivatives and implicatoins for the design of prodrugs of $\mathrm{NH}$-acidic compounds. Int. J. Pharmac. 37: 185-194, 1987.

Bundgaard, H. and Hansen, A.B., Pro-drugs as drug delivery systems. Pharmacy Int. pp 136-140, 1981.

Bundgaard, $\mathrm{H}_{4}$ and Nielsen, N.M., Prodrugs as drug delivery systems. 74. Facile hydrolysis of $\mathrm{N}$-(acyloxymethyl)anide derivalives and implications for the design of prodrugs of $\mathrm{NH}$-acidic compunds and of carboxylic acids. Acta Pharm. Suec. 24: 233-246, 1987.

Bundgaard, H., Nielsen, N.M. and Buur, A., Aspirin prodrugs: synthesis and hydrolysis of 2acetoxybenzoate esters of various $\mathrm{N}$-(hydroxyalkyl) amides. Int. J. Pharm. 44: 151-158, 1988.

Burger, J.J., Tomlinson, $\mathbb{E}$. and McVie, J.G., Microparticles intended for microvascular blockage. Drug incorporation and rellease. In: Drug targeting (eds: Buri, P. and Gumma, A.), Elsevier, Amsterdam, 1985, pp 81-94.

Carl, P.L., Chakravarty, P.K., Katzenellenbogen, J.A. and Weber, M.J, Protease-activated "prodrugs" for cancer chemotherapy. Proc. Nat. Acad. Sci. USA 77: 2224-2228, 1980.

Casagrande, $\mathrm{C}_{4}$, Cardiovascular and renal action of dopaminergic prodrugs. $\mathrm{J}$ Cardiovascular Pharmacol. 1989, in press.

Casagrande, C., Ghirardi, P. and Marchetti, $G$, Ibopamine. New drugs annual: Cardiovascular drugs (ed.: Scriabine, A.), vol. 3. Raven press, New York, 1985, pp 173-196.

Casagrande, C., Merlo, L., Santangelo, F., Doggi, F., Gerli, F., Pocchiari, F., Pataccini, R. and Semeraro, $\mathrm{C}$., SIM 2055, N-methyldopamine-4-O-phosphate, an orally active renal vasodilator. Communication presented at the Xth international symposium on medicinal chemistry, Budapest, 
Hungary, 15-19 aug. 1988.

Charkrawarty, P.K., Carl, P.L., Weber, M.J. and Catzenellenbogen, J.A., Plasmin actiwated prodrugs for cancer chemotherapy. 1. Synthesis and biological activity of peptidylacivicin and peptidyl pherylenediamine mustard. J. Med Chem. 26: 633-638, 1983.

Clissold, S.P. and Campoli-Richards, D.M., Omepravole, an updated review. Drugs: $1-41,1988$.

Cohen, A.M., Schaeffer $\mathbf{N}$. and Higgins, J., Treatment of metastatic colorectal cancer with hepatic artery combination chemotherapy. Cancer 57: 1115-1117, 1986.

Cook, N.D., Upperton, K.P., Challis, B.C. and Peters, T. $J_{\text {, }}$, The donor specificity and kinetics of the hydrolysis reaction of gamma-glutamyl transferase. Biochim. Biophys. Acta 914: 240-245, 1987.

Daemen, M.J.A.P., Local drug administration. Thesis, Maastricht, 1987.

Daemen, M.J.A.P., Vervoort-Peters, H.T.M. and Thijssen, H.H.W., Pharmacokinetic evaluation of local drug delivery: the intratesticular and intrarenal administration of acenocoumarol in the rat. J. Pharm. Pharmacol. 40: 283-285, 1988a.

Daemen, MJ.A.P., Smits, J.F.M., Thijssen, H.H.W. and Struyker Boudier, H.A.J. Pharmacokinetic considerations in target-organ directed drug delivery. Trends Pharmacol. Sci. 9: 138-142, 1988b.

Danieli, J.F., General cell theory and drug design. In: Biological approaches to cancer chemotherapy (Ed.: Harris, R.J.C.), Acad. Press, London, 1961, pp 1-9.

Double, J.A. and Workman, P., A new high-glucuronidase mouse tumor curable by aniline mustard therapy. Cancer Treat. Rep. 61: 909-911, 1977.

Edwards, D.C., Thorpe, P.E. and Davies, AJ.S., Antibody-toxin conjugates as potential therapeutic agents. In: Targeting of drugs (eds. Gregoriadis ${ }_{9} \mathrm{G}_{2}$, Senior, J, and Trouet, A.). Plenum press, $N-Y$, 1982, pp 83-96.

Earl, R.T., Hunneyball, I.M., Billett, E.E. and Mayer, R.J., Evaluation of reconstituted sendai virus envelopes as intra-articular drug vectors: effects on normal and experimentally arthritic rabbit knee joints. J. Pharm. Pharmacol. 40: 166-170, 1988.

Fiume, L., Busi, C. and Mattioli, A., Targeting of antiviral drugs by coupling with protein carriers. FEBS Letters 153: 6-12, 1983 .

Fiume, L., Bassi, B., Busi, C., Mattioli, A. and Spinosa, G., Drug targeting in antiviral therapy. Biochem. Pharmacol. 35: 967-972, 1986.

Gallo, J.M. and Hassan ${ }_{n}$ E.E., Receptor-mediated magnetic carriers: basis for targeting. Pharmac. Res. 5: 300-304, 1988 .

Garnet, M.C., Embleton, M.J., Jacobs, E. and Baldwin, R.W., Preparation and properties of a drug-carrier-antibody conjugate showing selective antibody-directed cytotoxicity in vitro. Int. $J$. Cancer 31: 661-670, 1983.

Ghosh, P., Das, P.K. and Bachhawat, B.K., Targeting of liposomes towards different cell types of rat liver through the involvement of liposomal surface glycosides. Arch. Biochem. Biophys. 213: $266-270,1982$.

Giudicelli, J.F., Les promédicaments. La Presse Médicale 17: 1000-1009, 1988.

Gogu, S.R. Aggarwal, S.K., Rangan, S.R.S. and Agrawal, K.C., A prodrug of zidovudine with enhanced efficacy against human deficiency virus. Biochem. Biophys. Res, Comm. 160: 656-661, 1989.

Gray, A.G., Morgan, $J_{*}$, Linch, D.C. and Huehns, E.R., Uptake of antibody directed cytotoxic liposomes by $\mathrm{CD} 3$ on human $\mathrm{T}$ cells. Clin. Exp. Immunol 72: 168-173, 1988. Gregoriadis, $G$. (ed.). Liposomes as drug carriers. Recent trends and progress. John Wiley \& sons, Chichester, 1988.

Gregoriadis, G., Kirby, C., Large, $\mathbb{P}_{\text {, }}$ Meehan, A. and Senior, J., Targetimg of liposomes: study of influencing factors. In: Targeting of drugs (eds.: Gregoriadis, $G$., Senior, J. and Trouet, A.), Plenum press N.-Y., 1982, pp 155-184.

Gregoriadis, $G_{\text {, }}$ Kirby, $C$. and Senior, $J$., Targeting of liposomes: studies on optimization. In: Optimization of drug delivery (eds.: Bundgatard, H., Hansen, A.B. and Kofod, H.), Munksgaard, Copenhagen, 1982, pp 365-383.

Gruber, S.A., Cipolle, R.J., Canafax, D.M., Erdmann, G.R., Burke, B.A., Rabatin, J.T., Hynes, P.E., Ritz, J.A., Gould, F.H., Ascher, N.L., Simmons, R.L. and Hrushesky, W.J.M., An implantable pump for intrarenal infusion of immunosuppressants in a canine autotransplant model. Pharmac. Res. 5: 781-785, 1988. 
Guder, W. G. and Ross, B,D E, Enzyme distribution along the nephron. Kidney Int. 26: 101-111, 1984.

Gupta, P.K. and Hung, C.T., Magnetically controlled targeted micro-carrier systems. Life Sci. 44: $175-186,1989$.

Hadgraft, $\mathbf{J}$., Prodrugs and skin absorption. In: Design of prodrugs (ed.: Bundgaard, H.), Elsevier, Amsterdam, 1985, pp 271-289:

Harper, N.I. Drug latentiation. In: Fortschritte der arzneimittelforschung (ed.: Jucker, E,), Burkhduser werlag Basel, 1962, pp 221 294.

Hashida, $M$, Sato, $K$, Takakura, $Y$. and Sezaki, $H$., Characterization of a lipophillic prodrug of 5whorouracil with a cholesterol promoiety and its application to liposomes. Chem. Pharm. Bull. 36: $3186-3189,1988$.

Holbauer, KG, Sonnenburg, C., Stalder, R., Criscioni, L, Kraetz, J., Fuhrer, W. and Habicht, $\mathbb{E}_{\text {, }}$ CGP 22979 A, a renal vasodilt or with natriuretic properties. J. Pharmacol. Exp. Ther. 232: 838-844, 1985.

Huang, H-P. and Ayres, J.W., Dyphylline prodrugs: plasmahydrolysis and dyphylline release in rabbits. J. Pharm. Sci. 77: 104-109, 1988.

Hunter, C.A., Dolan, T.F., Coombs, G.H. and Baillie, A.J., Vesicular systems (niosomes and liposomes) for delivery of sodium stibogluconate in experimental murine visceral leishmaniasis. $J$. Pharm. Pharmacol. 40: 161-165, 1988.

Hussain, M.A., Koval, C.A., Myers, MJ., Shami, E.G. and Shefter, E., Improvement of the oral bioavailability of naltrexone in dogs: a prodrug approach. J. Pharm. Sci. 76: 356-358, 1987.

Ihler, G.M. ${ }_{4}$ Erythrocytes as carriers for recombinant cloned DNA. In: Targeting of drugs (eds.: Gregoriadis, G., Senior, J. and Trouet, A.), Plenum press, N.-Y., 1982, pp 145-153.

Ilkeda, S., Sakamoto, F., Hirayama, R., Takebe, Y., Sotomura, M. and Tsukamoto, G., Studies on prodrugs. VII. Preparation and characterization of (5-methyl-2-oxo-1,3-dioxol-4-yl)methyl esters of sulbactam and its analogs. Chem. Pharm. Bull 36: 218-226, 1988.

Irwin, W.J. and Belaid, K.A., Drug-delivery by ion-exchange. Hydrolysis and rearrangement of ester pro-drugs of propranolol. Int. J. Pharm. 46: 57-67, 1988.

Jeffrey, R.F., MacDonald, T.M., Marwick, K. and Lee, M.R., The effect of carbidopa and indomethacin on the renal response to $\gamma$-L-glutamyl-L-dopa in normal man. $\mathrm{Br}$. J. Clin. Pharmacol. 25: 195-201, 1988a.

Jeffrey, R.F., MacDonald, T.M. and Lee, M.R., A comparison of the renal actions of $\gamma$-L-glutamylL-dopa and $\gamma$-L-glutamyl-L-tyrosine in normal man. Clin. Sci. 74: 37-40, $1988 \mathrm{~b}$.

Juliano, R.L. and Layton, D. Liposomes as drug delivery systems. In: Drug delivery systems (ed. Juliano, R.L.), Oxford university press 1980, pp 137-145.

Juliano, R.L., Liposomes and the reticuloendothelial system; interactions of liposomes with macrophages and behaviour of liposomes in vivo. In: Targeting of drugs (eds: Gregoriadis, G., Senior, J. and Trouet, A.), Plenum press, N.-Y., 1982, pp 285-300.

$\mathrm{Kao}_{*} \mathrm{YJ}$. and Juliano, R.L., Interactions of liposomes with the reticuloendothelial system. Effects of reticuloendothelial blockade on the clearance of large unilamellar vesicles. Biochim. Biophys. Acta 677 : 453-461, 1981.

Khokhar, A.R., Wright, K, Siddik, Z.H and Perez-Soler, R., Organ distribution and tumor uptake of liposome entrapped cis-bis-neodecanoato-trans- $\mathbb{R}, \mathbf{R}-1,2$ diaminocyclohexane platinum(II) administered intravenously and into the proper hepatic artery. Cancer Chemother. Pharmacol. 22: 223-227, 1988 .

Kramer, P.A, Synthetic polyelectrolytes as modifiers of drug disposition and effectiveness: an overview. In: Optimization of drug delivery (eds.: Bundgaard, H., Hansen, A.B. and Kofod, H.), Munksgaard, Copenhagen, 1982, pp 239-252.

Larsen, J.D. and Bundgaard, H., Prodrugs for the sulfonamide group. I. Evaluation of $\mathrm{N}$-acyl derivatives, $\mathbf{N}$-sulfonylamidines, $\mathbf{N}$-sulfonylsulfimines and sulfonylureas as possible prodrug derivatives. Int. J. Pharm. 37: 87-95, 1987.

Lim, F. and Sun, A.M., Microencapsulated islets as bioartificial endocrine pancreas. Science 210: $908 \times 910,1980$.

MacDonald, T.M., Jeffrey, R.F., Freestone, S. and Lee, M.R., (+)-sulpiride antagonisis the renal effects of $\gamma$-L-glutamyl-L-dopa in man. Br. J. Clin. Pharmacol. 25: 203-212, 1988. 
Mach, J.P., Grob, J.-Ph., Buchegger, F., Schreyer, M., von Fliedner, V: Carrel, S., Bischof-Delaloye, A. and Delaloye, B., Tumor localization of radiolabelled monoclonal antibodies and their fragments as a model for drug targeting studies. In: drug targeting (eds: Buri, P. and Gumma, An), Elsevier, Amsterdam, 1985, pp 2533.

Magnan, S.D.J, Shirota, F.N. and Nagasawa, H.T., Drug latentiation by $\gamma$-glutamyl transpeptidase. J. Med. Chem. 25: 1018-1021, 1982 .

Manson, M.M., Legg, R.F., Watson, J.W., Green, J A and Neal, G.E., An examination of the relative resistances to aflatoxin $B$ and susceptibilities to $\gamma$-glutamyl-p-phenylenediamine mustard of $\%$-glut amyll negative and positive cell lines. Carcinogenesis 2: 661-670, 1981.

Matzku, S., Tilgen, W., Kalthoff, H., Schmiegel, W.H. and Bröcker, E.-B., Dynamics of antibody transport and internalization. Int. J. Cancer Suppl. 2: 11-14, 1988.

Minard, F.N., Grant, D.S., Cain, J.C., Jones, P.H. and Kyncl, J., Metabollism of $\gamma$-glutamyl dopamide and its carboxilic acid esters. Biochem. Pharmacol. 29:69-75, 1980.

Nagasawa, H.T. Elberling, J.A. and Shirota, F.N., Latentiated forms of the transport-inhibitory y-aminoacid adamantine. J. Pharmac. Sci. 69: 1022-1025, 1980.

Niederhuber, J.E., Ensminger, W., Gyves, J., Thrall, J., Walker, $S$. and Cozzi, E, Regional chemotherapy of colorectal cancer metastatic to the liver. Cancer $53: 1336-1343,1984$.

Nielsen, N.M. and Bundgaard, H., Prodrugs as drug delivery systems. 68. Chemical and plasmacatalyzed hydrolysis of various esters of benzoic acid: a reference system for designing prodrug. esters of carboxylic acid agents. Int. J. Pharm. 39: 75-85, 1987.

Nielsen, N.M. and Bundgaard, H., Evaluation of glycolamide esters and various other esters of aspirin as true aspirin prodrugs. J. Med. Chem. 32: 727-734, 1989.

Nievelstein, H.M.N.W., van Essem, H., Horsnveld, R., Struyker Boudier, H.A.J. and Smits, J.F.M., Effects of the renal vasodilator prodrug CGP 22979A and its parent compound CGP 18137A on renal and central hemodynamics in concious spontaneously hypertensive rats. I. Pharmacol. Exp. Ther. 235: 778-782, 1985 .

Nievelstein, H.N.M.W., Smits, J.F.M. and Struyker Boudier, H.A.J., Long-term haemodynamic consequences of renal vasodilation in conscious spontaneously hypertensive rats. J. Hypertension 5 (suppl. 5): \$439-\$441, 1987.

Notari, R.E., Prodrug design. Pharmac. Ther. 14: 25-53, 1981.

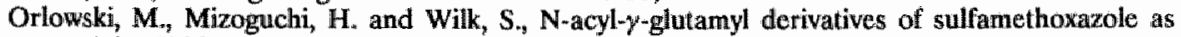
models of kidney-selective prodrugs. J. Pharmacol. Exp. Ther. 212: 167-172, 1980.

Pagano, R.E. and Weinstein, J.N. Interactions of liposomes with mammelian cells. Annu. Rev. Biophys. Bioeng. 7: 435-468, 1978.

Palomino, E., Kessel, D, and Horwitz, J.P. A dihydropyridine carrier system for sustained delivery of $2^{*}$, 3"-dideoxynucleosides to the brain. J. Med. Chem. 32: 622-625, 1989.

Papahadjopoulos, D. and Gabizon, A., Targeting of liposomes to tumor cells in vivo. In: Biological approaches to the controlled delivery of drugs (ed.: Juliano, R.L.) Ann N.-Y. Acad. Sci. 507:64-74, 1987.

Papisow, M.I., Savelyew, V.Y., Sergienko, V.B. and Torchilin, V.P. Magnetic drug targeting. I. In viwo kinetics of radiolabelled magnetic drug carriers. Int. J. Pharmac. 40: 201-206, 1987.

Papisow, M.I. and Torchilin, V.P. Magnetic drug targeting. II. Trargeted drug transport by magnetic microparticles: factors influencing therapeutic effect. Int. J. Pharmac. 40; 207-214, 1987.

Peeters, P.A.M., Oussoren, C., Eling, W.M.C. and Crommelin, D.J.A., Immunospecific targeting of liposomes, $F\left(a^{\prime}\right)_{2}$ and IgG to red blood cells in vivo. Biochim. Biophys, Acta 943: 137.147, 1988a.

Peeters, P.A.M., Claessens, C.A.M., Eling, W.M.C. and Crommelin, D.J.A., Immunospecific target ing of liposomes to erythrocytes. Biochem. Pharmacol. 37: 2215-2222, 1988b.

Poznansky, MJ. and Juliano, R.J., Biological approaches to the controlled delivery of drugs: a critical review. Pharmac. Rev. 36: 277-336, 1984.

Ranney, D.R. and Huffaker, H.H., Magnetic microspheres for the targeted controlled release of drugs and diagnostic agents. In: Büological approaches to the controlled deliwery of drugs (ed.: Juliano, R.L.), Ann. N.-Y. Acad. Sci. 507:104-119, 1987.

Raso, ${ }_{\text {, Fehrmann, }}$ C., Solan, V.C. and Rosowsky, A., Monensin is obligatory for the cytotoxic action of a disulfide linked methotrexate-anti-transferrin receptor conjugate. Biochem. Biophys. Res. 
Comm. 150: 104-110, $198 \%$

Rowland. C.F., O'Neill, G.J. and Davies, D., Suppression of tumor growth in mice by a drug-antibody conjugate of the antitumor drug methotrexate. Macromol. Chem. 179: 1719-1733, 1975.

Ruers, T.J.M., Buurman, W.A, Smits, J.F.M., Van der Linden, C.J., Van Dongen, JJ., Struyker Boudier, H. A.J. and Kootstra, G., Local treatment of renal allografts, a promising way to reduce the dosage of immunosuppressive drugs. Transplantation 41: 156-159, 1986.

Ruers, T.J.M., Buurman, W.A., Van Boxtel, CJ., Van der Linden, C.J. and Kootstra, G. Immunohistological observations in rat kidney allografts after local steroid administration. J. Exp. Med. 166: $1205-1210,1987$.

Ruers, TJ.M., Daemen, M J.A.P., Thijssen, H.H.W., Vander Linden, C.J. and Buurman, W.A., Graft rejection in rats proves sensitive to local immunosuppressive therapy. Transplantation, in press, 1989.

Schlon, I., Innovations in monoclonal antibody tumor targeting. Diagnostic and therapeutic implications. JAMA 261: 744-746, 1989.

Schneider, M., Liposomes as drug carriers: 10 years of research. In: Drug targeting (eds.: Buri, P. and Gumma, A.), Elsevier, Amsterdam, 1985, pp 119-134.

Sezaki, H. and Hashida, M., Macromolecule-drug conjugates in targeted cancer chemotherapy. CRC Crit. Rev, Therap. Drug carrier Systems 1: 1-38, 1984.

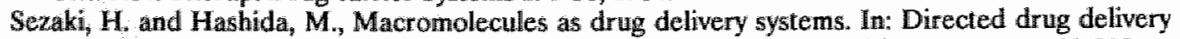
(eds.: Borchardt, R.T., Repta, A.J. and Stella, V.J.), Humana press, Clifton, 1985, pp 189-208.

Shier, W.T, Lectins as drug carriers. In: Drug carriers in biology and medicine (ed.: Gregoriadis, G.), Acedemic pres $s$, London, 1979, p 43.

Sinkula, A.A., Sustained drug action accomplished by the prodrug approach. In: Design of prodrugs (ed: Bundgaard, H.), Elsevier, Amsterdam, 1985, pp 157-176.

Sinkula, A.A., Some perspectives an targeted delivery with prodrugs. In: Biological approaches to the controlled delivery of drugs (ed.: Juliano, R.L.), Ann. N.-Y. Acad. Sci. 507: 281-288, 1987.

Sloan, K.B., Sherertz, E.F. and McTiernan, R.G., The effect of structure of Mannich base prodrugs on their abillity to deliver theophylline and 5 -fluorouracil through hairless mouse skin. Int. J. Pharm. 44: $87-96,1988$.

Smits, J.F.M. and Struyker Boudier, H.A.J., Preferential renal vasodilator effects of CGP 22979A in conscious spontaneously hypertensive rats. J. Pharmacol. Exp. Ther. 232: 845-849, 1985.

Smits, J.F.M. and Thijssen, H.H.W., Spatial control of drug action: theoretical considerations on the pharmacokinetics of target-aimed drug delivery. In: Rate controlled drug administration and action (ed.: Struyker Boudier, H.A.J.), CRC Press Inc., Florida, 1986, pp 83-113.

Souhami, R.L., Patel, H.M. and Ryman, B.A., The effect of reticuloendothelial blockade on the blood clearance and tissue distribution of liposomes. Biochim. Biophys. Acta 674: 354-371, 1981.

Stella, V.J., Drug substances in particular prodrugs. Problems and methods of approach. In: Formulation and preparation of dosage forms (ed.: Polderman, J.), Elsevier, Amsterdam, 1977, pp 91-111.

Stella, V.J. and Himmelstein, K.J., Prodrugs and site-specific drug delivery. J. Med. Chem. 23: $1275-1282,1980$.

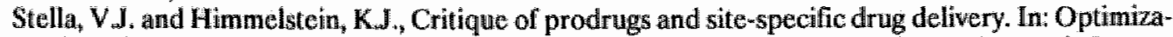
tion of drug delivery (eds.: Bundgaard, H., Hansen, A.B. and Kofod, H.), Munksgaard, Copenhagen, 9182 , pp 134-155.

Stella, V.J. and Himmelstein, K.J., Prodrugs: a chemical approach to targeted drug delivery. In: Directed drug delivery (eds.: Borchardt, R.T., Repta, A.J, and Stella, V.J.), Humana press, Clifton, 1985, pp $247-267$.

Stella, V.J., Charman, W.N.A. and Naringrekar, V.H., Prodrugs, do they have advantages in clinical practice?? Drugs 29: 455-473, 1985.

Szoka Jr., F.C. and Mayhew, E., Alteration of liposome disposition in vivo by bilayer situated carbohydrates. Biochem. Biophys. Res. Comm. 110: 140-146, 1983.

Tokunaga, Y., Iwasa, T., Fujisaki, J., Sawai, S. and Kagayama, A, Liposomal sustained release delivery systems for intraveneous injection. II. Design of liposome carriers and blood disposition of lipophitlic mitomycin C prodrug bearing lipsomes. Chem. Pharm. Bull. 36: 3557-3564, $1988 \mathrm{a}$.

Tokunaga, $Y$., Iwasa, $T$, Fujisaki, $J_{4}$, Sawai, S. and Kagayama, $A_{n}$, Liposomal sustained release delivery 
systems for intraveneous injection. III. Antitumor activity of lipophilic miltomycin $\mathrm{C}$ prodtugg bearing liposomes. Chem. Pharm. Bull. 36: 3565-3573, 1988 b.

Tokunaga, Y., Iwasa, T., Fujisaki, J., Sawai, S. and Kagayama, A., Liposonal sustained release delivery systems for intraveneous injection. IV. Antitumor activity of newly synthesized lipophillic 1-B-D. arabinofuranosylcytosine prodrug bearing liposomes. Chem. Pharm. Bull. 36; 3574-3583, 1988c.

Torchilin, V.P. Papisov, M.I, Orekhova, N.M., Belyaev, A.A., Petrov, A.D. and Ragimov, S.E. Magnetically driven trombolytic preparation containing inmobilized streptokinase-targeted transport and action. Haemostasis 18: 113-116, 1988.

Trouet, A., Baurain, R., Deprez-de Campeneere, D., Masquelier, M. and Pierson, $\mathbb{P}_{\text {. }}$ Targeting of antitumor and antiprotozoal drugs by covalent linkage to protein carriers. In: Targeting of drugs (eds.: Gregoriadlis, $G_{m,}$ Senior, $J$, and Trouet, A.), Plemum press, New York, 1982, pp 19-30.

Umezawa, $F$. and Eto, $Y$., Liposome targeting to mouse brain: mannose as a recognition marker. Biochem. Biophys. Res. Comm. 153: 1038-1044, 1988.

Van der Sluijs, P., Bootsma, H.P., Postema, B., Moolenaar, F. and Meijer, D.K.F., Drug targeting to the liver with lactosylated albumins: does the glycoprotein target the drug or is the drug targeting the glycoprotein. Hepatology 6: 723-728, 1986.

Van der Sluijs, P., Braakman, J., Meijer, D.K.F. and Groothuis, G.M.M., Heterogeneous acinar localization of the asialoglycoprotein internalization system in rat hepatocytes. Hepatology 8 : 1521-1529, 1988.

Verlander, M.S., Venter, J.C., Goodman, M., Kaplan, N.O. and Saks, B., Biological activity of catecholamines covalently linked to synthetic polymes: proof of immobilized drug theory. Proc. Natl. Acad. Sci. USA 73; 1009-1013, 1976.

Waildstein, B., Mechanism of action of omeprazole. Scand. J. Gastroenterol. 21 (suppl 118): 11-16, 1986.

Waranis, R.P. and Sloan, K.B., Effects of vehicles and prodrug properties and their interactions on the delivery of 6-mercaptopurine through skin: $S^{6}$-acyloxymethyl-6-mercaptopurine prodrugs. J. Pharm. Sci. 77: 210-215, 1988.

Weinstein, J.N., Leserman, L.D., Henkart, P.A. and Blumenthal, R. Antibody mediated targeting of liposomes. In: Targeting of drugs (eds.: Gregoriadis, G., Senior, J. and Trouet, A.), Plenum press, N.-Y, 1982, pp 185-202.

Weinstein, J.N., Black, C.D.V., Barbet, J., Eger, R.R., Parker, R.J., Holton, O.D., Mulshine, J.L., Keenan, A.M., Larson, A.M., Carrasquillo, J,A., Sieber, S.M. and Covell, D.G., Selected issues in the pharmacology of monoclonal antibodies. In: Site-specific drug delivery (eds.: Tomlinson, $\mathrm{E}$. and Davis, S.S.). John Wiley \& sons, Chichester, 1986, pp 81-91.

Weinstein, J.N., Eger, R.R., Covell, D.G., Black, C.D.V., Mulshine, J., Carrasquillo, J.A., Larson, S.M. and Keenan, A.M., The pharmacology of monocional antibodies. In: Biological approaches to the controlled delivery of drugs (ed.: Juliano, R.L.). Ann. N.-Y. Acad. Sci. 507: 199-210, 1987.

Wilk, S., Mizoguchi, H. and Orlowski, M., $\gamma$-Glutamyl dopa: a kidney-specific dopamine precursor. J. Pharmacol. Exp. Ther 206: 227-232, 1978.

Workman, P. and Double, J.A., Drug latentiation in cancer chemotherapy. Biomedicine 28: 255-262, 1978.

Worth, D.P., Harvey, J.N., Brown, J, Worral, A. and Lee, M.R., Domperidone treatment inthibits the tall in plasma renin activity induced by intravenous $y_{-L}-$ glutamyl-L-dopa. Br. J. Clin. Phat macol. 21: $497-502,1986$.

Yamaguchi, I., Nishiyama, S., Akimoto, Y., Yoshikawa, M. and Nakajima, H., A novel orally active dopamine prodrug TA-870. I. Renal and cardiovascular effects and plasma levels of free dopamine in dogs and rats. J. Cardiovascular Pharmacol. 13: 879-886, 1989.

Yoshikawa, M., Endo, H., Otsuka, M., Yamaguchi, I. and Harigaya, S, Comparative study on the disposition of a new orally active dopamine prodrug, $\mathrm{N}$-(N-acetyl-L-methionyl)-O,Obis(ethoxycarbonyl)dopamine (TA-870) and dopamine hydrochloride in rats and dogs. Drug Metab. Disp. 16: $754758,1988$. 

PART I

\section{STUDIES ON CGP 22979}





\section{CHAPTER 2}

\section{PHARMACOKINETIC STUDIES ON THE MECHANISM OF RENAL SELECTIVITY OF THE VASODILATOR PRODRUG CGP 22979}

\subsection{INTRODUCTION}

The prodrug CGP 22979 (PD) is the N-acetyl- $\gamma$-L-glutamyl derivative of the hydralazine-like vasodilator CGP 18137 (D) (5-n-butyl,2-hydrazinopyridin) (see Fig. 1.4). The compound PD was developed for selective renal vasodilation (Hofbauer et al, 1985). On physiological grounds renal vasodilation is a rational method to treat essential hypertension (Struyker Boudier, 1980). The renall selectivity was reached by means of prodrug formation of D with the N-acetyl- $\gamma$-L-glutamyl group. Since renal tissue is rich in $\gamma$-glutamyl transpeptidase (GGT) (Albert et al., 196\%; Glenner et al., 1962), it was assumed that the vasodilator D will be predominantly released in the kidney and exert its action only there.

The principle of renal drug targeting via $y$-L-glutamyl prodrugs is based on the work of Orlowski et al. (Wilk et al. 1978; Orlowski et al., 1979). These authors showed enhanced renal concentrations of sulphamethoxazole following its administration as the $\gamma-\mathrm{L}-$ glutamyl or $\mathrm{N}$-acetyl- $\gamma$-L-glutamyl prodrug. The principle of renal sellectivity vila $\gamma-\mathrm{L}$-glutamyl prodrugs has since been demonstrated for a variety of compounds (Nagasawa et al., 1980; Magnan et al., 1982; Hofbauer et al., 1985).

Hemodynamic studies with PD in rats showed selective renal vasodilation to occur indeed. Upon chronic administration the blood pressure lowering effect parallelled the renal vasodilation (Smits and Struyker Boudier, 1985; Nievelstein et al. 1987). Administration of the active drug D, either acutely or chronically, resulted in a generalized vasodilation (Smits and Struyker Boudier 1985; $^{2}$ Nievelstein et al., 1987). These results are in support of the renal selectivity of PD.

However, target selectivity via the prodrug principle, although attractive, is not as simple as it seems. Computer simulations of selective delivery of active drug via 
a prodrug indicate that the goal can be obtained under extreme conditions only (Stella and Himmelstein, 1980; Smits and Thijssen, 1986): (a) the activating enzyme should occur almost exclusively in the target tissue, and (b) the active drug, once formed, has to be cleared very efficiently by the target organ.

In the case of the prodrug under study, a complicating factor in explaining its renal selectivity is that the site of action of the active drug is the blood vessel wall (Hofbauer et al., 1985). This means that D, once released from PD in the kidney, is very probably also systemically available.

We investigated the disposition of $\mathrm{D}$ in rats after $\mathrm{D}$ and $\mathrm{PD}$ administration to get more insight into the mechanism of the renal selectivity of PD.

\subsection{MATERIALS AND METHODS}

\subsubsection{Animals}

Male Wistar rats (270-300g, supplied by Winkelman, Borchen, FRG) were used. The animals had free access to lab food and drinking water.

\subsubsection{Materials}

The compounds CGP 18137 (D), CGP 22979 (PD) and the 3-chloro-analogue of D (CGP 33625) were a gift of Ciba-Geigy (Basel, Switzerland), $\gamma$-glutamyl transpeptidase (GGT, type II, EC 2.3.2.2, and acylase I, EC 3.5.1.14, were obtained from Sigma Chemicals. All other chemicals were of analytical grade and were supplied by Merck Chemicals (Merck, Darmstadt, FRG).

\subsubsection{Experiments}

Acute experiments with $\mathrm{D}$ were performed with pentobarbital anesthetized rats. Pentobarbital sodium $(60 \mathrm{mg} / \mathrm{kg}$ ) was injected i.p. The left femoral artery and the right femoral vein were provided with a PE-10 catheter. Compound D was administered i.v. via the femoral vein catheter. Blood $(150 \mu \mathrm{l})$ was sampled via the arterial catheter. Blood $(100 \mu 1)$ was transferred immediately into vessels containing $10 \mu \mathrm{l}$ of $5 \%$ p-methoxybenzaldehyde in methanol $(\mathrm{v} / \mathrm{v}), 100 \mathrm{ng}$ of the chloroanalogue of $\mathrm{D}$ and $100 \mu \mathrm{l}$ water. The samples were set aside in the dark.

Tissue distribution of $\mathrm{D}$ was studied in conscious animals. D or PD was administered i.v. via a tail vein. At fixed times the animals were sacrificed under light ether anesthesia by blood withdrawal from the descending aorta. Tissues (liver, kidney and other) were quickly removed, weighed and homogenized in 2 vols. of 
ice-cold $0.02 \mathrm{M}$ Tris- $\mathrm{HCl}$ buffer ( $\mathrm{pH} 7.4$ ) in glass vessels containing $20 \mathrm{mg} \mathrm{p}$ methoxybenzaldehyde.

Chronic administration of PD was performed by constant rate i.v. unfusion using the Alzet osmotic minipump (M 2001) as delivery device. The pump containing PD was implanted subcutaneously and connected to a catheter introduced into the jugular vein. The rats received $10 \mathrm{mg} \cdot \mathrm{kg}^{-1} \cdot \mathrm{day}^{-1}$ of $\mathrm{PD}$.

The formation of $\mathrm{D}$ out of $\mathrm{PD}$ in tissue homogenates was examined as follows. A mixture of $1 \mathrm{mM} \mathrm{PD}, 4 \mathrm{mM}$ p-methoxybenzaldehyde and $100 \mathrm{ng}$ of the chloroanalogue of D was prepared in $200 \mu \rrbracket 0.1 \mathrm{M}$ Tris-HCl buffer $\mathrm{pH} 8.0$ ). The mixture was heated to $37^{\circ} \mathrm{C}$ and the reaction was started by the addition of $50 \mu \mathrm{l}$ of tissue (kidney, liver) homogenate. Denaturated homogenate $\left(5 \mathrm{~min}\right.$ at $\left.100^{\circ} \mathrm{C}\right)$ served as control. The procedure to follow the formation of D out of PD by GGT and/or acylase was similar. The amount of enzymes in a reaction mixture were $1 \mathrm{U}$ and 200 U for GGT and acylase, respectively.

\subsubsection{Analysis of D}

The HPLC assay of hydralazin as described by Ludden et al. (1983) was adapted to assay $\mathrm{D}$. The chloro-analogue of $\mathrm{D}$ served as internal standard. The pmethoxybenzaldehyde treated samples were allowed to stand in the dark for at least $15 \mathrm{~min}$. The mixtures were extracted with $0.5 \mathrm{ml} \mathrm{n}$-hexane. $0.1 \mathrm{ml}$ of the hexane phase was analyzed by HPLC; stationary phase, Lichrosorb 5RP18, $150 \times 4.6 \mathrm{~mm}$ (Chrompack, The Netherlands); mobile phase, $10 \%$ acetic acid (pH 4.0 with ammonia)/acetonitrile, $35 / 65$, v/v; flow, $2 \mathrm{ml} / \mathrm{min}$; UV detection at $365 \mathrm{~nm}$. The retention times were $3.2 \mathrm{~min}$ and $4.1 \mathrm{~min}$ for internal standard and D, respectively.

\subsubsection{Statistics}

Data are presented as mean \pm SD. Groups were compared using Student's t-test. Differences were considered to be statistically significant for $\mathrm{p}<0.05$.

\section{RESULTS}

\subsubsection{Experiments with D}

To assay $D$ in biological samples it appeared to be necessary to add pmethoxybenzaldehyde instantaneously to the samples because of a rapid decline of $D$ upon standing; pilot experiments suggested the halflife of disappearance of $D$ to be less than $5 \mathrm{~min}$ in liver homogenates and blood. To get more insight in the 


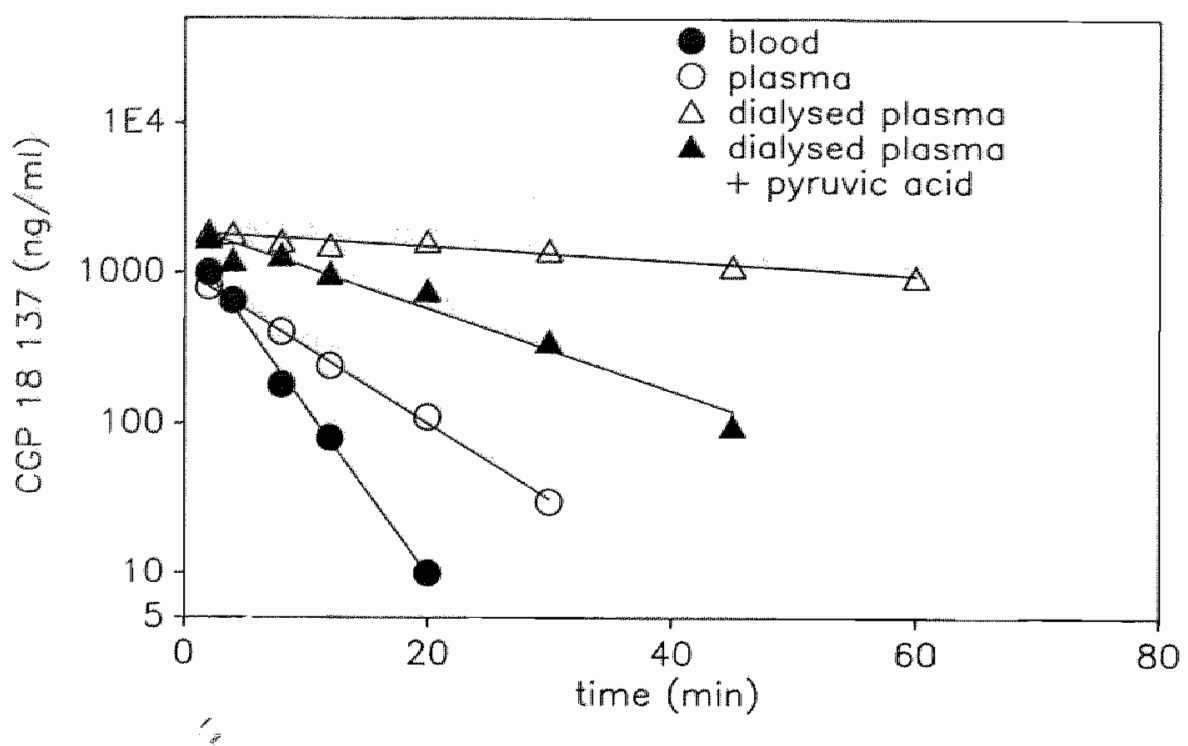

Flg. 2.1 In vitro disappearance of D in blood, plasma, dialyzed plasma and dialyzed plasma plus pyruvic acid.

A

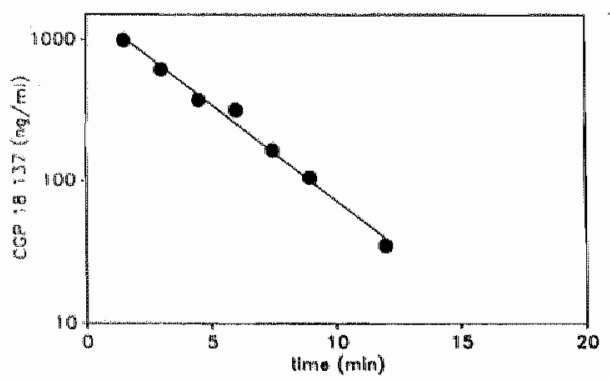

B

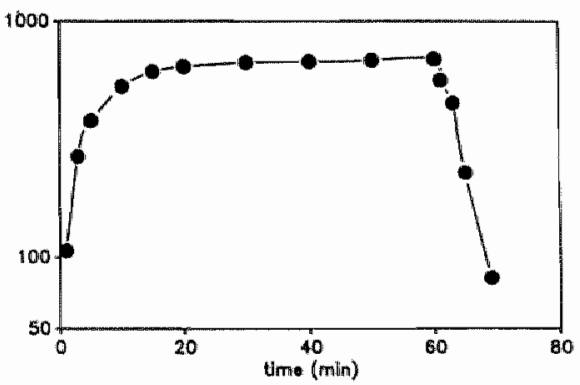

Flg. 2.2 Blood concentration vs. time curwes; $A$ following an i.v. bolus dose of $3 \mathrm{mg}^{-k^{-1}}{ }^{-1}$ of D; $B$ following an i.v. infusion of $0.1 \mathrm{mg} . \mathrm{kg}^{-1}$. min of $\mathrm{D}$ during $60 \mathrm{~min}$. 
mechanism of this elimination, in vitro experiments with blood and plasma were performed (Fig. 2.1). The data clearly show the rapid in vitro elimination of $D$ from blood and plasma (t1/2: 2.8 and 6 min for blood and plasma, respectively). The disappearance from blood was not due to uptake by erythrocytes. Dialyzed plasma was less active ( $\mathrm{t} 1 / 2$ about $60 \mathrm{~min}$ ) in eliminating $\mathrm{D}$. After the addition of ketobodies, i.e. pyruvic acid, to the dialyzed plasma, the ability to eliminate $\mathrm{D}$ was almost restored ( $\mathrm{t} 1 / 2$ about $9 \mathrm{~min})$. In phosphate buffer ( $\mathrm{pH}$ 7.4) D appeared to be stable for at least one hour. These results suggest that $\mathrm{D}$, in analogy with hydralazin (Ludden et al., 1982) reacts easily with ketones present in biological samples.

The concentration time course of $\mathbf{D}$ following its i.v. administration in rats is shown in Fig. 2.2A. As is seen, the elimination of $\mathrm{D}$ from the circulation was very rapid, $t 1 / 23.1 \pm 0.4 \mathrm{~min}(\mathrm{n}=4)$. A similar rate of decline of $\mathrm{D}$ in the blood was observed following the cessation of a 60 min constant rate i.v. infusion of D (Fig. 2.2B). This precludes distribution phenomena to be accountable for the high disappearance rate of $D$. Pharmacokinetic constants derived from the i.v. data are summarized in Table 2.1. Total blood clearance is high $(156 \pm 28 \mathrm{ml} / \mathrm{min})$ and exceeds cardiac output (about $100 \mathrm{ml} / \mathrm{min}$ ).

Table 2.1 Pharmacokinetic parameters of CGP 18137 following an i.v. bolus dose of $3 \mathrm{mg} \cdot \mathrm{kg}^{-1}$.

$\begin{array}{lll}\mathrm{t} 1 / 2 & 3.1 & \pm 0.4 \mathrm{~min} \\ \mathrm{CL} & 156 & \pm 28 \mathrm{ml} \cdot \mathrm{min}^{-1} \\ \mathrm{~V}_{\mathrm{d}} & 710 & \pm 1.7 \mathrm{ml} \\ \text { AUC } & 6.6 & \pm 1.8 \mu \mathrm{g} \cdot \mathrm{ml}^{-1} \cdot \mathrm{min}\end{array}$

Values are expressed as mean \pm SD of 4 experiments.

Table 2.2 Tissue concentrations of CGP 18137 (D) following an i.v. bolus dose of 3 $m g \cdot \mathrm{kg}^{-1} \mathrm{D}$

Tissue $\quad 15$ min $\quad 30$ min 60 min

$$
\mu g \cdot g^{-1}
$$

$\begin{array}{lccc}\text { Kidney } & 1.1 \pm 0.4 & 0.7 \pm 0.5 & 0.16 \pm 0.08 \\ \text { Liver } & 0.5 \pm 0.3 & 0.24 \pm 0.15 & 0.13 \pm 0.07 \\ \text { Ratio kidney/liver } & 2.7 \pm 1.5 & 3.0 \pm 1.9 & 1.3 \pm 0.2\end{array}$

Data are expressed as mean \pm SD of 3-4 experiments. 


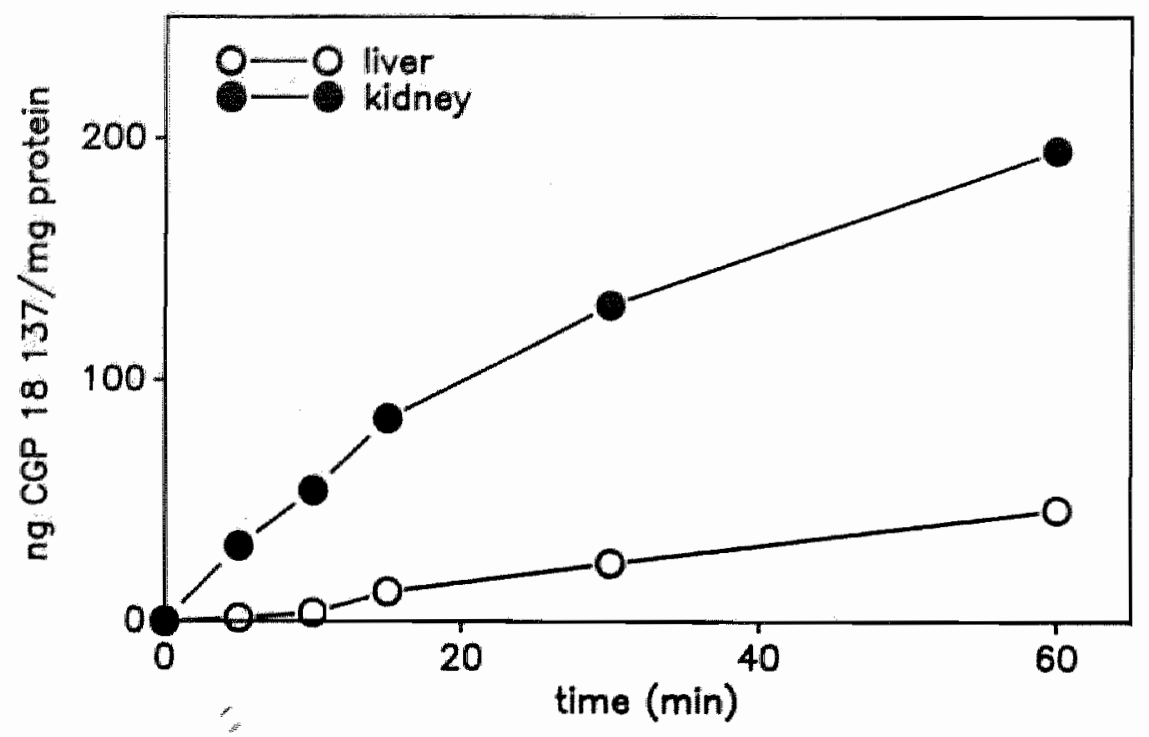

Flg. 2.3 In vitro conversion of PD by liver and kidney homogenates.

Table 2.3 Tissue concentrations of CGP 18137 (D) following iv. administration of CGP 22979 (PD)

Tissue $\quad 15 \mathrm{~min} \quad 30 \mathrm{~min} \quad 60 \mathrm{~min} \quad 120 \mathrm{~min}$

Following $30 \mathrm{mg} \cdot \mathrm{kg}^{-1}$ of $\mathrm{PD}$

$\begin{array}{lllll}\text { Kidney } & 9.6 \pm 1.2 & 8.0 \pm 4.3 & 2.7 \pm 1.2 & 0.6 \pm 0.1 \\ \text { Liver } & 2.1 \pm 0.1 & 1.2 \pm 0.7 & 0.8 \pm 0.4 & 0.2 \pm 0.1 \\ \text { Ratio kidney/liver } & 4.6 \pm 0.4^{*} & 7.8 \pm 1.9^{*} & 3.6 \pm 0.6^{*} & 3.0 \pm 0.7^{*}\end{array}$

Following $10 \mathrm{mg}^{-\mathrm{kg}^{-1}}$ of PD

$\begin{array}{lccc}\text { Kidney } & 2.3 \pm 0.3 & 1.5 \pm 0.5 & 0.19 \pm 0.09 \\ \text { Liver } & 0.39 \pm 0.06 & 0.5 \pm 0.2 & 0.02 \pm 0.02 \\ \text { Ratio kidney/liver } & 6.2 \pm 1.8^{*} & 3.0 \pm 0.3^{*} & -* *\end{array}$

Data are expressed as mean \pm SD of 3-4 experiments

* Significantly different from 1; p. $<0.05$.

* Not calculated due to very low liver concentrations. 
Liver and kidney distribution of $D$ at 15,30 and 60 min after its i.v administration is presented in Table 2.2. Whereas these tissues contained $D$, no $D$ was detected in blood. The data suggest a preference of $D$ for accumulation in the kidney over the liver. The differences, however, were not significantly different $(p>0.1)$.

\subsection{Experiments with PD}

The in vitro release of $\mathrm{D}$ from $\mathrm{PD}$ was investigated in liver and kidney homogenates (Fig. 2.3). As is seen the conversion rate was much higher in kidney homogenates: $5.3 \pm 0.5$ vs. $0.8 \pm 0.04$ ng.mg protein ${ }^{-1} \cdot \mathrm{min}^{-1}$. The capability of GGT and/or acylase to release D was also investigated. GGT alone failed to release any detectable D within 30 min of incubation. Acylase alone gave some D release (11 $\mathrm{ng} / 30 \mathrm{~min}$ ). However, the combination of both enzymes highly stimulated $\mathrm{D}$ release: $90 \mathrm{ng} / 30 \mathrm{~min}$.

The in vivo conversion of $\mathrm{PD}$ to $\mathrm{D}$ was investigated by estimating tissue $\mathrm{D}$ distribution after PD i.v. bolus administration and after 7 days administration by constant rate infusion. Bolus injection of PD (10 and $30 \mathrm{mg} / \mathrm{kg}$ ) resulted in significantly higher kidney D levels as compared to liver tissue (Table 2.3). No D could be detected in either blood, lung, spleen, intestine, muscle and testes. In pancreatic tissue, concentrations of $\mathrm{D}$ were found to be about half the liver concentrations per gram tissue. Following the chronic administration of PD $(10 \mathrm{mg} / \mathrm{kg}$.day during 7 days) $D$ was detected in kidney tissue $(130 \pm 45 \mathrm{ng} / \mathrm{g}$ tissue; $\mathrm{n}=5)$. In 2 out of 5 animals traces of $D$ were observed in liver homogenates. No $D$ could be detected in pancreas, intestine or lung tissue.

\subsection{DISCUSSION}

The present study demonstrates the renal selectivity of the prodrug PD on the basis of tissue distribution of the active drug $\mathrm{D}$ following $\mathrm{PD}$ administration.

The concept of target directed drug delivery via prodrugs is based on target tissue specific biochemical systems (transmembrane transport systems, transforming enzymes, etc.) that can be called upon for local release of the active drug. As non-target tissues lack these biochemcial systems or have only minor activities, the non-target sites in the body are secured from drug exposure. This prodrug concept has been used in the past with varying success (see for a review, Stella et al., 1985). Theoretical considerations supported by computer simulations show that target selectivity via prodrugs can be obtained under extreme conditions only (Stella and Himmelstein, 1980; Smits and Thijssen, 1986). One of the prerequisites is to prevent the redistribution of active drug from the target site where it is released. To achieve 
this goall, the active drug should be cleared by the target site or after its release it should be efficiently cleared by systemic routes.

From our results it is clear that the latter condition holds for the vasodilator $\mathrm{D}$. Drug $D$ is eliminated very rapidly from the circulation. This feature, without doubt, is responsible for the fact that $\mathrm{D}$ was not observed in the circulation following $\mathrm{PD}$ administration. The elimination probably is due to a chemical condensation reaction between the hydrazine moiety of $\mathrm{D}$ and ketobodies in the plasma. Similar reactions have been shown for hydralazine (Ludden et al., 1982).

The renal selectivity of PD as established before by hemodynamic experiments (Smits and Struyker Boudier, 1985) is supported by the finding of enhanced renal concentations of D following PD administration. The renal selectivity of PD is associated with the high renal GGT activity (Hofbauer et al., 1985). Indeed, the in vitro conversion of PD to D was the highest for kidney homogenates. However, as is evident from the relatively high liver levels of $\mathrm{D}$ following PD bolus injections (Table 2.3), renal selectivity of PD is only relative. Because D is unstable in blood, the accumulation of $D$ in the liver must be due to local release. In other words, enough active drug can be released in the liver from $\gamma$-glutamyl type prodrugs to provide non-target tissues with drug.

The fact that $\mathrm{D}$ accumulates in kidney and liver tissue following both $\mathrm{D}$ and $\mathrm{PD}$ administration indicates $D$ either to bind tightly to tissue components or to be stored intracellularly. Following PD administration this accumulation could also be a result of intracellular $\mathrm{D}$ formation. The latter supposes facilitated or carrier mediated transport of $\mathrm{PD}$. The renally bound $\mathrm{D}$ or the intracellularly accumulated $D$ is apparently at least partly available to the smooth muscles of the renal resistance vessels.

Thus far it is believed that the release of active drug from $\gamma$-L-glutamyl prodrugs in the kidney is due to cleavage by GGT. This enzyme, which is mainly present in the brush border membranes of (proximal) tubular cells, transfers $y$-glutamyl residues from donor peptides (e.g. GSH) to acceptor amino acids, dipeptides or water (Meister and Anderson, 1983). The products of this cleavage and transfer reaction are subsequently transported across the brush border membrane by transport processes. This implies release and reuptake of active drug mainly to occur on the luminal site of the nephron. Before being handled in this way, however, PD has to be deacylated (Orlowksi et al., 1979; Cook et al., 1987). The introduction of the $\mathrm{N}$-acetyl group on the L-glutamic acid residue is prompted by the studies of Orlowski et al. (1979). It was shown by these authors that $\mathrm{N}$-substitution of the glutamic acid residue enhanced the renal selectivity of the model prodrug, i.e. $\gamma$-L-glutamyl sulphamethoxazole. It was reasoned that the sequential combination of renal acylases and GGT apparently favors selectivity. This mechanism can only work if both acylase and GGT are operating at the brush border membrane.

Other mechanisms, however, can also be thought of. Recently a GSH transport system was characterized in the basolateral membranes of the proximal tubule (Lash and Jones, 1984; Inoue and Morino, 1985). This transport system probably can also handle GSH conjugates of xenobiotics (Lash and Jones, 1985; Kramer $e t$ al. 1987). Thus, one could speculate on transmembrane transport of intact PD via 
this $\mathrm{Na}+$ dependent GSH transporter. Intracellularly, D is released. A possible candidate for mediating the latter might be the cytosolic enzyme $\gamma$-glutamyl cyclotransferase (Orlowski and Meister, 1973). This enzyme is also highly active in the liver and could be responsible for the relatively high amounts of $D$ in this tissue.

In summary, the prodrug PD functions as a delivery device for the vasodilator D with preference for renal tissue. However, the prolonged pharmacodynamic selectivity is mainly due to the instability of $D$ in blood, thus preventing $D$, released for instance form liver tissue, to accumulate in the circulation.

\subsection{REFERENCES}

Albert, Z, Orlowski, M. and Szweczuk, A., Histochemical demonstration of gamma-glutamyl transpeptidase. Nature (Lond) 191: 767-768, 1961.

Cook, N.D., Upperton, K.P. Challis, B.C. and Peters, T.J., The donor specificity and kinetics of the hydrolysis reaction of gamma-glutamyl transferase. Biochim. Biophys. Acta 914: 240-245, 1987.

Glenner, G.G., Folk, J.E. and McMillan, P.J., Histochemical demonstration of a gamma-glutamyI transpeptidase-like activity. J. Histochem. Cytochem. 10:481-489, 1962.

Hofbauer, K.G., Sonnenburg, C., Stalder, R., Criscioni, L., Kraetz, J., Fuhrer, W. and Habicht, E., CGP 22979A, a renal vasodilator with natriuretic properties. J. Pharmacol. Exp. Ther. 232: 838-844, 1985.

Inoue, $M$. and Morino, $Y$., Direct evidence for the role of the membrane potential in glutathione transport by renal brush border membranes. J. Biol. Chem. 260: 326-331, 1985.

Kramer, A., Foureman, G., Greene, K.E. and Reed, D.J., Nephrotoxicity of S-(2-chloroethyl)glutathione in the Fischer rat. Evidence for $\gamma$-glutamyl transpeptidase independent uptake by the kidney. J. Pharmacol. Exp. Ther. 242: 741-748, 1987.

Lash, L.H. and Jones, D.P., Renal glutathione transport. J. Biol. Chem. 259; 14508-14514, 1984.

Lash, L.H. and Jones, D.P., Uptake of the glutathione conjugate S-(1,2-dichlorovinyl) glutathione by renal basal lateral membrane vesicles and isolated kidney cells. Mol. Pharmacol. 28: 278-282, 1985.

Ludden, T.M., McNay Jr, J.L., Shepherd, A.M.M. and Lin, M.S., Clinical pharmacokinetics of hydralazine. Clin. Pharmacokin. 7: 185-205, 1982.

Ludden, T.M., Ludden, L.K.,Wade, K.E. and Allerheiligen, S.R.B., Determination of hydrallazine in human whole blood. J. Pharm. Sci. 72: 693-695, 1983.

Magnan, S.D.J., Shirota, F.N. and Nagasawa, H.T., Drug latentiation by $\gamma$-glut amyl transpeptidase. J. Med. Chem. 25: 1018-1021, 1982.

Meister, A. and Anderson, M.E., Glutathione. Annu. Rev. Biochem. 52: 711-760, 1983.

Nagasawa, H.T., Elberling, J.A. and Shirota, F.N., Latentiated forms of the transport inhibitory $\alpha$-amino acid adamantine. J. Pharm. Sci. 69: 1022-1024, 1980.

Nievelstein, H.N.M.W., Smits, J.F.M. and Struyker Boudier, H.A.J., Long-term hemodynamic consequences of renal vasodilation in conscious spontaneously hypertensive rats. J. Hypertension 5 (suppl 5): 439-441, 1987.

Orlowski, M. and Meister, A., Gamma-glutamyl cyclotransferase: distribution, isozymic forms and specificity. J. Biol. Chem. 248: 2836-2844, 1973.

Orlowski, M., Mizoguchi, $\mathbf{H}$. and Wilk, S., N-acyl- $\gamma$-glutamyl derivatives of sulfamethoxazole as modells of kidney selective prodrugs. J. Pharmacol. Exp. Ther. 212: 167-172, 1979.

Smits, J.F.M. and Thijssen, H.H.W., Spatial control of drug action: theoretical considerations on the pharmacokinetics of target aimed drug deliwery. In: Rate controlled drug administration (ed: 
Struyker Boudier, H.A.J.). CRC Press, Boca Ratton, F1, USA, 1986, Pp 83-113.

Sinwits; J.M.M. and Struyker Boudier, H.AJ., Preferential renal vasodilator effects of CGP 22979A in conscious spontameously hypertensive rats. J. Pharmacol. Exp. Ther. 232: 845-848, 1985.

Stella, VJ. and Himmelstein, $K_{\text {J. }}$, Prodrugs and site specific drug delivery. J. Med. Chem. 23: $1275-1282,1980$.

Stella, WJ., Charman, W.N.A. and Naringrekar, V.H. Prodrugs, do they have advantages in clinical practice? Drugs $29: 455-473,1985$.

Struyker Boudier, H.A.J., Dynamic systems analysis as a basis for drug design: application to antihypertensive drug action. In: Drug design (ed: Ariëns, EJ.). Academic Press, New York, USA, 1980, pp 146-191.

Wilk, S. Mizoguchi, $\mathbb{H}_{\text {. }}$ and Orwloski M. Gamma-glutamyl dopa, a kidney specific dopamine precursor. J. Pharmacol. Exp. Ther. 206: 227-232, 1978. 


\section{CHAPTER 3}

\section{A STUDY ON THE MECHANISM OF ACTIVATION OF THE RENAL VASODILATOR PRODRUG CGP 22979}

\subsection{INTRODUCTION}

The renal selectivity of $\gamma$-L-glutamyl prodrugs, such as $\gamma$-glutamyl dopa and -dopamide (Wilk et al., 1978; Minard et al., 1980) is associated with the high activity of GGT in the kidney (Albert et al., 1961, Glenner et al., 1962). In the case of $\mathrm{N}$-acetylated $\gamma$-L-glutamyl prodrugs, however, the $\mathrm{N}$-acetyl group will have to be removed before the compound can act as a substrate for GGT (Cook et al., 1987). This was also observed for CGP 22979 (PD, see chapter 2), the $\mathrm{N}$-acetyl- $\gamma$-glutamyl prodrug of CGP 18137 (D, see for structural formula's Fig. 1.4).

The introduction of the $\mathrm{N}$-acetyl group in PD was inspired by the work of Orlowski et al. (1980), who showed that $\mathbf{N}$-acetyl- $\gamma=\mathbf{L}$-glutamyl sulfamethoxazole was far more renally selective than the $\gamma$-L-glutamyl prodrug. This effect was attributed to the combined action of GGT and a renal acylase. This explanation implies the following: (i) the conversion by kidney acylase is the rate-limiting step; (ii) the acylase and GGT should be localized in each other's close proximity. The latter means that, as GGT is membrane bound and has its active site extracellularly, the acylase should also be localized there, at either the basolateral or brush border membrane.

This model, however, is not the only possible explanation for the renal selectivity of $\mathrm{N}$-acetyl-y-glutamyl prodrugs. The tubular cells in the kidney contain several transport systems for anionic compounds (Somogyi, 1987), and recently, new insight has been acquired in the transport of glutathione and $\gamma$-glutamyl compounds across the basolateral membrane of the tubular cells (Lash and Jones, 1984). The prodrug 
used in this study is an anionic drug and contains a $\gamma$-glutamyl group. So, it could be possible that $\mathrm{PD}$ is transported into the proximal tubular cells. The cytosolic enzyme \%-glutamyl cyclotransferase (Orlowski and Meister, 1973) could be responsible for the intracellular conversion of $\mathrm{PD}$ to $\mathrm{D}$, with or without prior deacetylation.

In the present study we focussed upon the role of GGT in the activation of PD and the possibility of transport and intracellular conversion of PD in the kidney, thus being able to discriminate between these explanations for the renal selectivity of PD and to get more insight in the renal handling of this compound.

\subsection{MATERIALS AND METHODS}

\subsubsection{Animals}

Male Wistar rats (270-330 g, supplied by Winkelman, Borchen, West-Germany) were used. The animals had free access to food and tap water.

\subsubsection{Materials}

The compounds CGP 18137 (D), CGP 22979 (PD) and CGP 33625 (a 3-chloro analogue of D) were a gift of Ciba-Geigy (Basel, Switzerland). AT-125 (acivicin; $\mathrm{L}$-( $\alpha \mathrm{S}, 5 \mathrm{~S})-\alpha$-amino-3-chloro-4,5-dihydro-5-isoxazoleacetic acid) was a gift of Dr. de Koning Gans (Upjohn, The Netherlands). Glutathione (reduced form) was obtained from Merck Chemicals (Merck, Darmstadt, West-Germany), DLbuthionine- $(S, R)$-sulfoximine and probenecid were obtained from Sigma Chemicals. All other chemicals used were of analytical grade and were supplied by Merck Chemicals.

\subsubsection{Experiments}

In vivo experiments. The influence of transport and/or enzyme inhibition in the kidney on the tissue concentrations of $\mathrm{D}$ following PD administration was investigated as follows. The animals were pretreated with either saline $\left(2 \mathrm{ml} / \mathrm{kg}^{-1}\right.$ i.p. injection) or one of the following compounds, at the indicated time prior to PD administration (30 $\mathrm{mg} \mathrm{kg}^{-1}$, i.v.); buthionine sulfoximine (1 mmol. $\mathrm{kg}^{-1}$, i.p.) and glutathione ( 2 mmol.kg ${ }^{-1}$; i.p.) at $15 \mathrm{~min}$; probenecid $\left(0.5 \mathrm{mmol} . \mathrm{kg}^{-1}\right.$; i.p.) at $30 \mathrm{~min}$ 
and AT- 125 (0.1 mmol... ${ }^{-1}$; i.v.) at $90 \mathrm{~min}$. The times of pretreatment were chosen on the basis of the optimal effectiveness of the different inhibitors. The tissue distribution of $\mathrm{D}$ was examined $30 \mathrm{~min}$ following PD administration. The animals were killed under light ether anesthesia by blood withdrawal from the descending aorta. Liver and/or kidneys were quickly removed, weighed and homogenized in two volumes of ice-cold $0.02 \mathrm{M}$ Tris HCl buffer ( $\mathrm{pH}$ 7.4) in glass vessels containing $20 \mathrm{mg}$ p-methoxybenzaldehyde. An internal standard ( $200 \mathrm{ng}$ of the chloro analogue of D) was added to $200 \mu \mathrm{l}$ tissue homogenate and the samples were analyzed for D.

In vitro experiments. Tissue homogenates for the in vitro conversion of $\mathrm{PD}$ to $\mathrm{D}$ were prepared in two volumes of ice-cold $0.05 \mathrm{M}$ Tris $\mathrm{HCl}$ buffer $(\mathrm{pH} 8.0)$. Part of the homogenate was centrifuged at $10,000 \mathrm{~g}$ for $20 \mathrm{~min}$. The supernatant was centrifuged at $100,000 \mathrm{~g}$ for $60 \mathrm{~min}$ to prepare the cytosolic fraction and microsomes. The microsomes were washed twice by resuspending them in $0.05 \mathrm{M}$ Tris $\mathrm{HCl}$ buffer $(\mathrm{pH} 8.0$ ), followed by centrifugation at $100,000 \mathrm{~g}$. The final microsomal pellet was resuspended in the same buffer to give a concentration of about $10 \mathrm{mg}$ protein. $\mathrm{ml}^{-1}$.

PD conversion was assayed under the following conditions. The reaction mixtures (200 $\mu$ l total volume) contained: $1 \mathrm{mM} \mathrm{PD,} 4 \mathrm{mM}$ p-methoxybenzaldehyde, $200 \mathrm{ng}$ of the chloro-analogue of $\mathrm{D}$ as an internal standard and $0.05 \mathrm{M}$ Tris $\mathrm{HCl}$

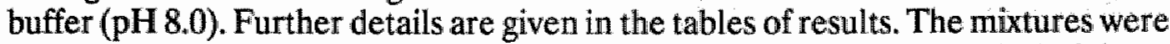
preincubated at $37^{\circ} \mathrm{C}$ and the reaction was started by the addition of $50 \mu \mathrm{l}$ of tissue homogenate, cytosolic fraction or microsomal suspension. All mixtures were incubated for $30 \mathrm{~min}$, reactions were terminated by heat denaturation ( 2 min at $100^{\circ} \mathrm{C}$ ). The appropriately denaturated $\left(5 \mathrm{~min}\right.$ at $\left.100^{\circ} \mathrm{C}\right)$ tissue fractions served as controls. Each incubation was performed in triplo.

\subsubsection{Analysis of D}

D was analyzed by a HPLC method essentially as described previously (chapter 2). In short, the p-methoxybenzaldehyde treated samples were extracted with $1 \mathrm{ml}$ hexane. The hexane was removed by evaporation under nitrogen and the residue was dissolved in acetonitrile/water and was analyzed by HPLC. Stationary phase: Lichrosorb 5RP 18 (150x4.6 mm, Chrompack, The Netherlands); mobile phase: $10 \%$ acetic acid ( $\mathrm{pH} 4.0$ with ammonia)/acetonitrile; 35/65, v/v. Flow rate: 2 ml.min ${ }^{-1}$, UV detection at $365 \mathrm{~nm}$. A reliable method to analyze PD was not available. 


\subsubsection{Statistics}

Data are presented as mean $\pm \mathrm{SD}$. Groups were compared using the Student's t-test. Differences were considered to be statistically significant for $\mathrm{p}<0.05$.

\subsection{RESULTS}

\subsubsection{In vivo metabolism of $P D$}

The renal handling of PD was investigated by pretreating the animals with several compounds which affect either the metabolism or transport of $\gamma$-glutamyl compounds (Table 3.1). In agreement with our previous observations (chapter 2), pretreatment with the GGT inhibitor AT- $125\left(0.1\right.$ mmol.kg ${ }^{-1}$ i.v., 90 min before PD administration), which is sufficient to inhibit $98 \%$ of GGT activity (Rankin and

Table 3.1 Influence of pretreatment with inhibitors on the tissue levels of $D$ following $P D$ administration ${ }^{\text {a }}$

$\begin{array}{lccc} & \text { Kidney }^{\mathbf{b}} & \text { Liver }^{\mathbf{b}} & \text { n } \\ \text { Saline } & 100 & 100 & 8 \\ \text { AT-125 }^{\mathbf{c}} & 74 \pm 18 & 87 \pm 9 & 4 \\ \text { Glutathione }^{\text {d }} & 33 \pm 14^{*} & 63 \pm 15^{*} & 4 \\ \text { Buthionine sulfoximine }^{\mathrm{e}} & 29 \pm 11^{*} & 60 \pm 30^{*} & 4 \\ \text { Probenecidf }^{\text {f }} & 61 \pm 20^{*} & 62 \pm 17^{*} & 4\end{array}$

a Tissue $D$ levels were determined at 30 min following i.v. administration of 30

b $\mathrm{mg} \cdot \mathrm{kg}^{-1} \mathrm{PD}$

Data ( $( \pm D)$ are presented as percent of saline control $(=7.9 \pm 0.9 \mu \mathrm{g} \mathrm{D.g}$ kidney ${ }^{-1}$ and $1.4 \pm 0.3 \mu \mathrm{g} . \mathrm{g}$ liver ${ }^{-1}$ )

c 0.1 mmol, $\mathrm{kg}^{-1}$, i.v., 90 min prior to $\mathrm{PD}$ administration

d 2 mmol.kg $\mathrm{kg}^{-1}$, i.p., 15 min prior to $P D$ administration

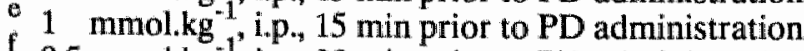

$0.5 \mathrm{mmol} . \mathrm{kg}^{-1}$, i.p., $30 \mathrm{~min}$ prior to PD administration

* Significantly different from saline control $(p<0.05)$. 
Curthoys, 1982; Kramer et al, 1987) resulted in lower liver and kidney concentrations of D. The differences, however, were not statistically significant. This suggests that GGT is not the major enzyme involved in the conversion of $P D$ to $D$ in vivo. Buthionine sulfoximine is a structural analogue of a $\gamma$-glutamyl amino acid which has been shown to interact with the uptake of $\gamma$-glutamyl derivatives by the kidney (Griffith et al., 1979; Anderson and Meister, 1983). Pretreatment with buthionine sulfoximine markedly decreased the levels of $D$ in the kidney. Liver $D$ levels were also depressed, although less than kidney levels.

Glutathione pretreatment also decreased kidney and liver concentrations of $\mathrm{D}$ ( $67 \pm 14$ and $37 \pm 15 \%$ reduction respectively).

Probenecid pretreatment led to a significant decrease in both liver and kidney $D$ levels of about $40 \%$.

\subsubsection{In vitro experiments}

To gain more insight into the site of conversion of PD and into the enzymes involved, PD was incubated in vitro with renal tissue. The conversion rates of PD were $26.1 \pm 11,1.4 \pm 0.4$ and $12.3 \pm 0.5 \mathrm{ng}$ of $\mathrm{D}$ formed $\mathrm{min}^{-1}$.mg protein ${ }^{-1}$ for kidney homogenate, microsomes and cytosol, respectively (Table 3.2). When acylase (500 U/incubation) was added to the microsomal assays, the conversion rate increased 30-fold. This indicates that the microsomal fraction, which contains GGT, does not contain acylase and confirms earlier observations that GGT cannot hydrolyze

Table 3.2 In vitro conversion rates of $P D$ to $D$

Tissue

Kidney homogenate

Kidney microsomes

Kidney microsomes + acylase ${ }^{a}$

Kidney cytosol

Kidney cytosol + acylase $^{a}$

Liver homogenate

Liver cytosol

Acylase

\section{ng D.min ${ }^{-1}$. mg protein $^{-1}$}

$$
\begin{aligned}
26.1 & \pm 11 \\
1.4 & \pm 0.4 \\
41 & \pm 4.5 \\
12.3 & \pm 0.5 \\
12.0 & \pm 1.5 \\
2.4 & \pm 0.6 \\
1.6 & \pm 0.3 \\
0.9 & \pm 0.2
\end{aligned}
$$

Each incubation was performed in triplicate; data are the mean \pm SD of $2=4$ experiments. Substrate concentration was $1 \mathrm{mM}$.

${ }^{a} 500 \mathrm{U}$ acylase per incubation 
Table 3.3 The effect of glutathione, buthionine sulfoximine and AT-125 on the in vitro conversion rates of $P D$

\section{Glutathione Buthionine sulfoximine}

Kidney homogenate

Kidney cytosol

Kidney microsomes + acylase

$$
\begin{aligned}
& 84 \pm 12 \\
& 65 \pm 12^{*} \\
& \text { ND }
\end{aligned}
$$

AT-125

$$
\begin{gathered}
83 \pm 8^{*} \\
84 \pm 4^{*} \\
\text { ND }
\end{gathered}
$$$$
65 \pm 7^{*}
$$$$
66 \pm 13^{*}
$$$$
27 \pm 12^{*}
$$

The data are presented as percentage $( \pm \mathrm{SD}$ ) of control conversion rates (see Table 3.2). Each incubation was performed in triplicate; data are the mean of 2-4 experiments. Incubations contained $5 \mathrm{mM}$ glutathione, $5 \mathrm{mM}$ buthionine sulfoximine or $0.25 \mathrm{mM} \mathrm{AT}-125$ and $1 \mathrm{mM}$ substrate.

* Significantly different from control; $\mathrm{p}<0.05$

ND: Not determined

N-acetyl- $\gamma$-L-glutamyl compounds (Cooket al., 1987; Drieman et al., 1988). Acylase added to the cytosol fraction did not enhance the conversion rate of PD to D. Acylase alone released only a minimal amount of $D$.

The addition of the GGT inhibitor AT- 125 caused a significant reduction in conversion rate of PD in all kidney fractions (Table 3.3). This effect was greatest in incubations containing microsomes and acylase: a reduction of $75 \%$. Homogenates and the cytosol fractions were inhibited by $35 \%$.

Addition of glutathione caused a significant reduction of PD conversion in incubations with cytosol of $35 \%$, and a non-significant reduction in incubations with homogenate. Buthionine sulfoximine caused both in homogenate and cytosol a small but significant reduction.

Liver preparations had a much lower activity as compared to kidney prepara-

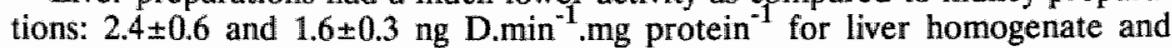
cytosol, respectively. This conversion could be blocked by AT-125: $50 \pm 9$ and $44 \pm 7 \%$ reduction, respectively. 


\subsection{DISCUSSION}

Gamma-glutamyl transpeptidase is one of the key enzymes of the $\gamma$-glutamyl cycle (Tate and Meister, 1985; Allison, 1985). Because of its high activity in the kidney and its ability to hydrolyze $\gamma$-glutamyl compounds, GGT has been thought of as a target enzyme for kidney selective release of active drug out of $\gamma$-glutamyl prodrugs. Examples hereof are mentioned in the introduction of this paper. In order to enhance the renal selectivity, acylation of the $\alpha$-amino group of the glutamyl moiety has been suggested (Orlowski et al., 1980). However, $\mathrm{N}$-acetylated $\gamma$ glutamyl prodrugs cannot be hydrolyzed by GGT, because a N-substituent makes the compound a very poor substrate for GGT (Cook et al., 1987), as has also been shown for PD (chapter 2), so the combined action of renal acylase and renal GGT would be necessary for kidney selectivity.

Besides being hydrolyzed by GGT, $\gamma$-glutamyl compounds as well as glutathione and glutathione-S-conjugates can be transported intactly into the proximal tubular cells (Orlowski and Wilk, 1978; Griffith et al., 1979; Rankin and Curthoys, 1982; Kramer et al., 1987). This uptake probably occurs via a sodium dependent, electrogenic and partly probenecid sensitive transporter system (Lash and Jones, 1984). As the intracellular enzyme $\gamma$-glutamyl cyclotransferase can hydrolyze the $\gamma$-glutamyl compounds (Orlowksi and Meister, 1973), membraneous transport with intracellular conversion instead of extracellular conversion by GGT might be the origin of the renal selectivity of $\mathrm{N}$-acetyl-L-y-glutamyl prodrugs.

To investigate which of these processes are responsible for the conversion of PD in vivo, we first examined the role of GGT by inhibiting this enzyme with AT-125. The dose used has been shown to be sufficient to inhibit approximately $98 \%$ of the renal GGT activity (Rankin and Curthoys, 1982; Abbot et al, 1984). In spite of this high degree of inhibition, no significant depression of kidney $D$ levels was seen. This indicates that GGT is not the source of the high renal D levels.

Pretreatment with probenecid prior to PD administration caused a significant reduction of about $40 \%$ in kidney concentrations of D. Probenecid inhibits the transport of pAH and other organic anions by a specific transport system (Mudge, 1980 ) and it has also been reported to inhibit uptake of $\gamma$-glutamyl compounds (i.e. glutathione) across renal basolateral membranes (Lash and Jones, 1984). So, our results suggest that PD is also transported actively and that this transport is rate limiting for the formation of $\mathrm{D}$.

Another indication for active or facilitated transport of PD is the observation that buthionine sulfoximine pretreatment lowers kidney D concentrations to approximately $30 \%$ of control values. The mechanism of interaction of buthionine sulfoximine with the uptake or conversion of $\gamma$-glutamyl compounds is not known, but it has been suggested that it interacts with the transport of $y$-glutamyl compounds by competition (Griffith et al., 1979; Anderson and Meister, 1983). The reduction of $D$ levels following glutathione pretreatment could be due to an interaction at the level of transport as well as conversion, either by glutathione itself 
or one of its metabolites.

Pretreatment with either probenecid, buthionine sulfoximine or glutathione also reduced liver levels of $\mathrm{D}$. The effect of probenecid on liver $\mathrm{D}$ concentrations was comparable to that on kidney, but the effect of glutathione and buthionine sulfoximine was much weaker (Table 3.1). These results could indicate the existence of two distinct transport systems: one probenecid sensitive and one sensitive to buthionine sulfoximine, the latter being more abundantly present in the kidney. It is also possible that only one transport system is active and that this system shows tissue-specific differences. The absence of detalled knowledge of the selectivity of anion transport systems in the liver precludes a choice between these alternatives. As we could not measure PD itself, but only D, the transport of PD into the kidney cannot be investigated in detail.

Once $\mathrm{PD}$ is intracellular, it can be converted to $\mathrm{D}$, as is shown by the results of the incubations with cytosol. Addition of acylase does not increase PD conversion, so it can be concluded that either the cytosol contains sufficient acylase, and that the conversion of the deacetylated $\mathrm{PD}$ to $\mathrm{D}$ is rate limiting, or that $\mathrm{PD}$ is converted directly, i.e. before deacetylation. A candidate for the cytosolic conversion of deacetylated PD to D would be $\gamma$-glutamyl cyclotransferase. Whether $\gamma$-glutamyl. cyclotransferase can also handle $\mathrm{N}$-acetylated $\gamma$-glutamyl compounds is not known. The fact that AT-125 inhibited the cytosolic PD conversion in vitro by $35 \%$ (in contrast to the in vivo results) might indicate that $\gamma$-glutamyl cyclotransferase is sensitive to AT-125, though much less so than GGT, or, more probably, that some GGT was present in the cytosolic preparations. Buthionine sulfoximine has only a minor inhibitory effect on in vitro systems, so the large effect seen in vivo is probably not due to enzyme inhibition.

From our results, we suggest the following model for the renal activation of PD. $P D$ is offered to the kidney via the plasma. A part is filtered by glomerular filtration. The filtered PD cannot be hydrolyzed by GGT at the brush border membrane and is therefore either excreted intact into the urine or taken up by the tubular cells. The non-filtered PD will partly be taken up by the proximal tubular cells through the basolateral membrane; possibly via the sodium dependent system described by Lash and Jones (1984) or by the pAH anion transport system. Once it is intracellular, PD is converted to $\mathrm{D}_{\text {, }}$ either directly or after deacetylation. The deacetylated prodrug as well as the active drug $D$ which is formed can be retained by the kidney cells and can also leak into either the tubular lumen or the blood. The D which reaches the blood vessel wall gives rise to a local vasodilation (Hofbauer et al., 1985) and is subsequently metabolized by a chemical reaction in the blood (chapter 2). To lower renal resistance, $D$ will have to reach resistance vessels. It can be imagined that $\mathrm{D}$ reaches the efferent and/or afferent arterioles of a nearby nephron through the interstitium when thïs drug leaks from a tubular cell.

In summary, we believe that the mechanism of the renal selectivity of $\mathrm{N}$-acetyl$\gamma=$ glutanityl prodrugs is less related to the action of GGT, but more to the combined action of a specific transport system and intracellular enzymes (probably acylase and/or $\gamma$ glutamyl cyclotransferase) in the renal proximal tubular cells. This transport will have to be investigated further (the next chapters deal with this topic). 
Further, it should be borne in mind that in order to be tissue selective, the liberated active drug will have to restrict its action to the site of formation. In the case of PD, this is achieved via a high clearance of the active drug by a chemical reaction in the blood (chapter 2).

\subsection{REFERENCES}

Abbot, W.A., Bridges, R.J. and Meister, A. Extracellular metabolism of glutathione accounts for its disappearance from the basolateral circulation of the kidney. J. Biol. Chem. 259; 15393-15400, 1984.

Albert, Z, Orlowski, M. and Szewczuk, A. Histochemical demonstration of gamma-glutanyl transpeptidase. Nature (London) 191: 767-768, 1961.

Allison, R.D. Gamma-glutamyl transpeptidase: kinetics and mechanism. In: Methods in enzynology (eds.: Colowick, S.P. and Kaplan, N.O.), Academic Press Inc., Orlando, 1985, vol. 113, pp. 419-437.

Anderson, M.E. and Meister, A. Transport and direct utilization of gamma-glutamyl sysi(e)ine for glutathione synthesis. Proc. Nat. Acad. Sci. USA 80: 707-711, 1983.

Cook, N.D., Upperton, K.P., Challis, B.C. and Peters, T.J. The donor specificity and kinetics of the hydrolysis reaction of gamma-ghtumyl transferase. Biochim. Biophys. Acta 914: 240-245, 1987.

Glenner, G.G., Folk, J.E and McMillan, P.J. Histochemical demonstration of a gamma-glutamyl transpeptidase-like activity. J. Histochem. Cytochem. 10: 481-489, 1962.

Griffith, O.W., Bridges, R.J. and Meister, A. Transport of gamma-glutamyl aminoacids: role of glutathione and gamma-glutamyl transpeptidase. Proc. Nat. Acad. Sci. USA 76: 6319-6322, 1979.

Hofbauer, K.G., Sonnenburg, C., Stalder, R., Criscioni, L., Kraetz, J., Fuhrer, W. and Habicht, E. CGP 22979A, a renal vasodilator with natriuretic properties. J. Pharmacol. Exp. Ther. 232: $838-844,1985$.

Kramer, R.A., Foureman, G., Greene, K.E. and Reed, D.J. Nephrotoxicity of S-(2-chloroeihyl) glutathione in the Fischer rat. Evidence for gamma-glutamyltranspeptidase independent uptake by the kidney. J. Pharmacol. Exp. Ther. 242: 741-748, 1987.

Lash, L.H. and Jones, D.P. Renal glutathione transport. J. Biol. Chem. 259: 14508-14514, 1984.

Minard, F.N., Grant, D.S., Cain, J.C., Jones, P.H., and Kyncl, J. Metabolism of gamma-glutamyl dopanide and its carboxylic acid esters. Brochem. Pharmacol. 29: 69-75, 1980.

Mudge, G.H. Inhibitors of tubular transport of organic compounds. In: The pharmacologic basis of therapeutics (eds.: Gilman, A.G., Goodman, L.S. and Gilman, A.), MacMillan, New York, 1980, 6th edition, pp. 929-934.

Orlowksi, M. and Meister, A. Gamma-glutamyl cyclotransferase; distribution, isozymic forms and specificity. J. Biol. Chem. 248: 2836-2844, 1973.

Orlowski, M. and Wilk, S. Synthesis of ophthalmic acid in liver and kidney in vivo. Biochem. J. 170: 415-419, 1978.

Orlowski, M., Mizoguchi, H. and Wilk, S. N-acyl-gamma-glutamyl derivatives of sulfamethoxazole as models of kidney selective prodrugs. J. Pharmacol. Exp. Ther. 212: 167-172, 1980.

Rankin, B.B. and Curthoys, N.P. Evidence for the renal paratubular transport of glutathione. FEBS Letters 147: 193-196, 1982.

Somogyi, A. New insights into the renal secretion of drugs. Trends Pharmacol. Sci. 8: 354-357, 1987.

Tate, S.S. and Meister, A. Gamma-glutamyl transpeptidase from the kidney. In: Methods of enzymology (eds.: Colowick S.P. and Kaplan, N.O.), Academic Press Inc., Orlando, 1985, vol. 113, pp. 400-419.

Wilk, S., Mizoguchi, H. and Orlowski, M. Gamma-glutamyll dopa, a kidney specific dopamine precursor. J. Pharmacol. Exp. Ther. 206: 227-232, 1978. 



\section{CHAPTER 4}

\section{THE HEMODYNAMIC CONSEQUENCES OF MANIPULATING THE RENAL UPTAKE AND CONVERSION OF CGP 22979}

\subsection{INTRODUCTION}

Renal vasodilation as a possible treatment of hypertension and renal failure has received considerable attention during the last years (Struyker Boudier, 1980; Ackerman et al, 1983; Hofbauer et al, 1985; Merlo et al., 1986). CGP 22979 (PD) was developed to act as a renal selective vasodilator prodrug (Hofbauer et al, 1980). Acute hemodynamic studies in conscious rats by Smits and Struyker Boudier (1985) showed that at low doses $\left(3.0-10 \mathrm{mg} \cdot \mathrm{kg}^{-1}\right)$ a selective renal vasodilation occurs, while at higher doses ( $30 \mathrm{mg} . \mathrm{kg}^{-1}$ ) a general vasodilation is found (Smits and Struyker Boudier, 1985).

Studies on the mechanism of activation of this prodrug are described in the chapters 2 and 3. Contrary to what was proposed earlier (Orlowski et al., 1980) it was found that $\gamma$-glutamyl transpeptidase (GGT) is not involved in the renal accumulation of $D$ in the kidney (chapter 3 ). Inhibitors of transport of $P D$ to the tubular cells, on the other hand, did affect the renal $D$ levels. On this basis, a model was proposed, in which the renal tubular uptake and intracellular conversion of PD plays an important role, contrary to conversion by GGT (Drieman et al., 1989). This model was primarily based upon in vitro studies and in vivo disposition studies. Renal uptake and conversion were investigated by pretreatment of the animals with enzyme and/or transport inhibitors prior to prodrug administration. Active drug (D) levels in the kidney were taken as a measure for the renal selectivity. It is, however, preferable to relate the inhibition of transport or conversion to a pharmacological effect rather than tissue concentrations of the active drug, especially if 
the concentration measurement is not in the same physiological compartment as the site of action.

To test our proposed mechanism of renal selectivity of $P D$ and in general of other $\mathrm{N}$-acetyl-y-glutamyl prodrugs, we investigated the influence of inhibition of renal D accumulation (i.e. buthionine sulfoximine and glutathione) and of the GGT inhibitor AT-125 on the regional hemodynamic responses (especially the renal vasodilator activity) of $\mathrm{PD}$ in rats.

\subsection{MATERIALS AND METHODS}

\subsubsection{Animals}

Male spontẩneously hypertensive (SHR) rats (250-300 g) were obtained from the central animal facilities of the University of Limburg. Animals had free access to standard lab food and tap water.

\subsubsection{Materials}

CGP 22979 and CGP 18137 were a gift of Ciba-Geigy (Basel, Switzerland). Acivicin (AT-125) was a gift of Upjohn (Ede, The Netherlands). DL-buthionine$(\mathrm{S}, \mathrm{R})$-sulfoximine was obtained from Sigma Chemicals and ghutathione (reduced form) from Merck Chemicals (Darmstadt, West-Germany).

\subsubsection{Surgery}

Under pentobarbitone anesthesia (50 mg.kg $\left.{ }^{-1}\right)$, miniaturized Doppler flowprobes were implanted on the left renal artery, superior mesenteric artery and abdominal aorta as described by Smits and Struyker Boudier (1985). Animals were also provided with polyethylene catheters for blood sampling and infusions in the abdominal aorta and vena cava via the left femoral artery and vein, and for blood pressure measurement in the abdominal aorta via the right femoral artery. The body temperature of the rats was kept constant at $37^{\circ} \mathrm{C}$. 


\subsubsection{Experimental procedures}

The animals were kept under anesthesia by a constant rate infusion of pentobarbitone ( $24 \mathrm{mg} \cdot \mathrm{kg}^{-1} \cdot \mathrm{h}^{-1}$ ). Once the body temperature was constant, the blood pressure and the blood flows through the renal artery and superior mesenteric artery and the abdominal aorta were measured as described previously (Smits and Struyker Boudier, 1985). When these parameters had been constant for at least 15 min, animals were pretreated intraperitoneally with saline $\left(2 \mathrm{ml} . \mathrm{kg}^{-1}\right)$, buthionine sulfoximine $\left(1 \mathrm{mmol} . \mathrm{kg}^{-1}\right)$ or glutathione $\left(2 \mathrm{mmol} . \mathrm{kg}^{-1}\right) 15 \mathrm{~min}$ prior to $\mathrm{PD}$ administration ( $3 \mathrm{mg} . \mathrm{kg}^{-\mathrm{P}}$ i.v.). Inhibition of $\gamma$-glutamyl transpeptidase (GGT) was accomplished by pretreating the animals with 0.1 mmol. $\mathrm{kg}^{-1}$ AT- 125 i.v. $90 \mathrm{~min}$ prior to PD administration. Blood pressure and blood flows were recorded during 90 min following PD administration.

In order to investigate the influence of pretreatment on the action of $D$, the same protocol was followed, except that a dose of $0.1 \mathrm{mg} \cdot \mathrm{kg}^{-1}$ of D was used in stead of 3 mg.kg ${ }^{-1}$ of PD.

\subsubsection{Statistics}

Results are expressed as mean \pm S.E.M. Groups were compared, using one-way analysis of variance. Differences were regarded to be significant when $\mathrm{p}<0.05$.

\subsection{RESULTS}

\subsubsection{Dose-effect relationship}

PD was injected i.v. in a dose of $0.3(\mathrm{n}=5), 1.0(\mathrm{n}=6)$, or $3.0(\mathrm{n}=7) \mathrm{mg}^{-1} \mathrm{~kg}^{-1}$ to control animals. The results are summarized in Fig. 4.1. Pretreatment values of MAP ranged between 130 and $150 \mathrm{~mm} \mathrm{Hg}$ and of haert rate between 360 and 400 bpm. The effects on renal blood flow reached a maximum at 30-40 min and did not diminish during the length of the experiment $(90 \mathrm{~min})$. The effect at $30 \mathrm{~min}$ was used for the comparison of the results with the tissue concentrations of $D$ measured in earlier experiments (chapter 3 ).

A dose-dependent increase in renal blood flow was found, while no significant decrease in blood pressure was observed. A dose of $10 \mathrm{mg} \cdot \mathrm{kg}^{-1}$ of PD was also tested (results not shown), but this dose caused a substantial decrease in mesenteric and 

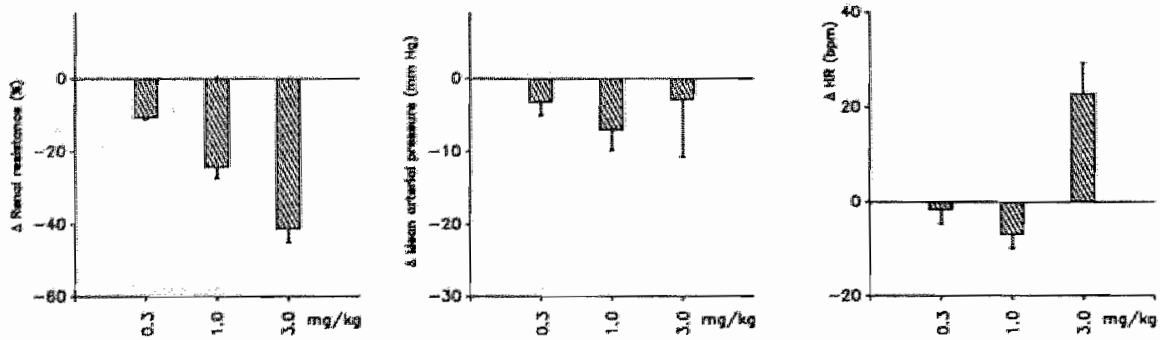

Fig 4.1 Effects of CGP 22979 (PD; 0.3-3.0 mg $\mathrm{kg}^{-1}$ ) on renal resistance (RR), mean arterial blood pressure (MAP) and heart rate (HR). Data are expressed as mean \pm S.E.M. (n = 5-7).
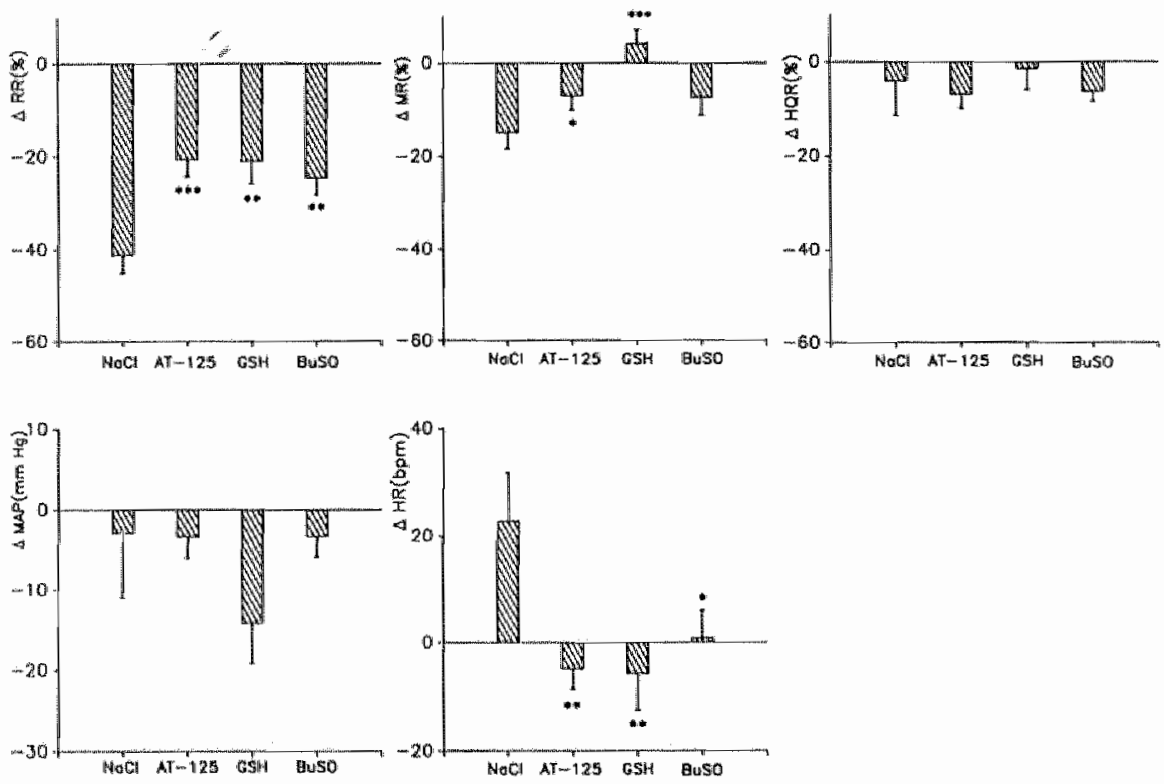

Flg. 4.2 The influtence of AT-125, buthionine sulfoximine (BuSO) and glutathione (GSH) on the hemodynamic responses to $\mathrm{PD}\left(3.0 \mathrm{mg} \cdot \mathrm{kg}^{-1}\right)$. Significances compared to saline controls: ${ }^{*} \mathrm{p}<0.05 ; *{ }^{*} \mathrm{p}<0.01 ; * * * \mathrm{p}<0.001$. 

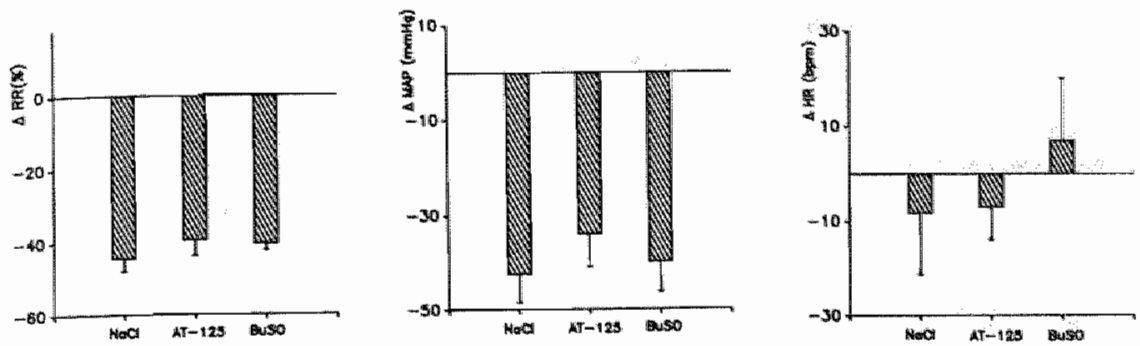

Fig. 43 The influence of AT-125 and buthionine sulfoximine (BuSO) on the hemodymamic responses to CGP 18137 (D; $0.1 \mathrm{mg}^{\mathrm{kg}}{ }^{-1}$ ).

hindquarter resistance and of blood pressure.

As the increase in renal blood flow was maximal at a dose of $3 \mathrm{mg} \cdot \mathrm{kg}^{-1}$ this dose was used to investigate the effect of transport or enzyme inhibitors on the regional hemodynamic responses to $\mathrm{PD}$.

\subsubsection{Effects of pretreatment on the action of D}

The rats were pretreated with saline, AT-125 or buthionine sulfoximine as described. At $\mathrm{t}=0 \mathrm{D}$ was injected i.v. in a dose of $0.1 \mathrm{mg} . \mathrm{kg}^{-1}$. This dose causes an effect on renal resistance comparable to $3 \mathrm{mg} \cdot \mathrm{kg}^{-1}$ of PD. The results are summarized in Fig. 4.2. At $30 \mathrm{~min}$, renal resistance was lowered by $40 \%$. No significant differences were found in either the AT-125 or the buthionine sulfoximine pretreated groups. These compounds had also no influence on the effect of $D$ on the blood pressure.

\subsubsection{Effects of pretreatment on the action of PD}

In these experiments a dose of $3 \mathrm{mg} \cdot \mathrm{kg}^{-1}$ was used. The results are summarized in Fig. 4.3. When compared to saline controls, all the substances used modified the renal response to $\mathrm{PD}$. The decrease in renal resistance was attenuated from $41 \pm 4 \%$ 
$(n=7)$ in the control group to $25 \pm 4 \%(n=7), 21 \pm 5(n=6)$ and $21 \pm 4(n=9)$ in the buthionine sulfoxmine, glutathione and AT-125 group, respectively, i.e. a reduction in effect of about $50 \%$.

PD also lowered the mesenteric resistance $(15 \pm 4 \%)$, although less dramatically than the renal resistance. This effect of PD was affected by the treatments used (50-100\% inhibition), though non-significantly in the case of buthionine sulfoximine. Hindquarter resistance and blood pressure did not change significantly.

\subsection{DISCUSSION}

The aim of the present study was two-fold (i) to investigate the influence of inhibition of PD uptake and/or subsequent intracellular conversion by buthionine sulfoximine or glutathione and of inhibition of GGT by AT-125 on the regional hemodynamic effects of PD; (ii) to correlate these effects with the effects of the same compounds on the tissue (kidney) concentrations of D following PD administration.

In chapter 3 it was shown that inhibition of GGT by AT-125 had no significant effect on the renal D levels. Therefore, AT- 125 was not expected to modify the renal response to PD. However, the present study shows that the renal response was $50 \%$ lower when GGT was inhibited. This modified response can only be due to a smaller amount of D at the site of action, as AT-125 does not interfere with the action of D (Fig. 4.2). The enzyme GGT is not able to hydrolyze PD in the absence of acylase (chapter 2), as is also described for other N-substituted $\gamma$-glutamyl compounds (Cooket al., 1987). This indicates that deacetylated PD reaches GGT. Deacetylated PD can originate from the cytosol of the renal tubular cells, from a membrane bound acylase near GGT itself, or from elsewhere in the body, e.g. the liver. The question of the origin of deacetylated PD cannot be solved without further experiments. These findings imply that the renal tissue concentration of $D$ in this case is not directly related to the concentration or amount of $D$ present at the site of action (which is the vascular wall of renal resistance vessels).

Glutathione and buthionine sulfoximine, as uptake and/or conversion inhibitors (Griffith et al, 1979; Anderson and Meister, 1983), decreased the renal resistance response by about $50 \%$. This effect is less than the effect of these compounds on the kidney $\mathrm{D}$ levels which are reduced by $70 \%$ (chapter 3 ). This difference can be explained by the above-mentioned finding that the intracellular D accounts for only a part of the renal response to PD, the latter also being dependent on GGT activity.

Glutathione and AT-125 also reduced the effect of PD on the mesenteric resistance significantly. As $\mathrm{D}$ has a very short half-life time in blood, and as even after a $10 \times$ higher dose of PD ( $30 \mathrm{mg} \cdot \mathrm{kg}^{-1}$ ) no D was found in the plasma (chapter 2 ), the decrease in mesenteric resistance can only be the result of local formation 
of $\mathrm{D}$. As the treatments reduced the response to $\mathrm{PD}$, i.e. the local amount of $\mathrm{D}$, it is possible that the same processes as in the kidney (uptake and intracellular conversion) occur. It is also possible that deacetylated $\mathrm{PD}$ from renal or hepatic origin is activated in the mesenteric tissue by GGT. The decrease in effect by pretreatment with glutathione is, in that case, a consequence of reduction in renal or hepatic release of deacetylated PD. This can only be investigated if PD and deacetylated PD can be analyzed.

In conclusion, the present study shows the following. The renal hemodynamic response and the kidney concentrations of $\mathrm{D}$ following $\mathrm{PD}$ administration correlate qualitatively. This illustrates the importance of transport into the renal tubular cells and intracellular conversion in the renal selectivity of $\mathrm{PD}$ as a vasodilator. Quantitatively, however, there is no complete correlation. This is caused by the action of GGT; this enzyme has a significant effect on the hemodynamic response to PD but not on the renal accumulation of D following PD administration. Future research will focus upon other $\mathrm{N}$-acetyl- $\mathrm{L}-\gamma$-glutanyl prodrugs as models for renal selective prodrugs, with special emphasis on the transport of the prodrug into the renal tubular cells as an important step in the mechanism of the renal selectivity.

\subsection{REFERENCES}

Ackerman, D.M., Blumberg, A.M., MacCafferty, J.P., Sherman, S.S., Weinstock, J., Kaiser, C., and Berkowitz, B. Potential usefulness of renal vasodilators in hypertension and renal disease: SKF 82 526. Fed. Proc. 42: 186-190, 1983.

Anderson, M.E. and Meister, A. Transport and direct utilization of gamma-glutamyl cyst(e)ine for glutathione synthesis. Proc. Nat. Acad. Sci USA 80: 707-711, 1983.

Cook, N.D., Upperton, K.P., Challis, B.C., and Peters, T.J. The donor specificity and kinetics of the hydrolysis reaction of $\gamma$-glutamyl transferase. Biochim. Biophys. Acta 914: 2240-245, 1987.

Griffith, $O . W_{\text {, Bridges, }} \mathrm{RJ}_{\mathrm{w}}$ and Meister, A. Transport of $\gamma$-glutamyl aminoacids. Role of glutathione and gamma-glutamyl transpeptidase. Proc. Nat. Acad. Sci. USA 76: 6319-6322, 1979.

Hofbauer, K.G., Sonnenburg, C., Stalder ${ }_{n}$, . $_{\text {, Criscioni }}$ L., Kraetz, J., Fuhrer, W., and Habicht, $\mathbb{E}$. CGP 22979 A, a renal vasodilator with natriuretic properties. J. Pharmacol. Exp. Ther. 232: 838-844, 1985.

Merlo, L., Ghirardi, P., Brusoni, B., Mussini, E., and Marchetti, G. Effects of ibopamine on systemic, pulmonary and regional hemodynamics. Drug Res. 36: 304-311, 1986.

Orlowski, M., Mizoguchi, $H_{\text {. }}$ and Wilk, S. N-acyl- $\gamma$-glutamyl derivatives of sulfamethoxazolle as models of kidney selective prodrugs. J. Pharmacol. Exp. Ther. 206: 227-232, 1980.

Smits, J.F.M. and Struyker Boudier, H.A.J. Preferential renal vasodilator effects of CGP 22979A in conscious spontaneously hypertensive rats. J. Pharmacol. Exp. Ther. 232: 845-848, 1985.

Struyker Boudier, H.A.J. (1980) Dynamic systems analysis as a basis for drug design: application to antihypertensive drug action. In: Drug design (ed.: Ariëns, EJ.), Academic Press; New York, 1980, pp. 146-191. 



\section{DISCUSSION AND CONCLUSIONS OF PART 1}

In chapter 2 it was shown that D accumulates in the kidney, and to a lesser extent in the liver and pancreas. This must be due to a high level of converting enzymes in these tissues, especially in the kidney. No D was found in other tissues.

The in vitro studies described in chapter 3 indicate that PD is converted mainly intracellularly. The effects of buthionine sulfoximine and glutathione on the tissue concentrations of $\mathrm{D}$ following in vivo $\mathrm{PD}$ administration indicate an active transport of PD into the kidney.

The fact that AT-125 had no effect on the accumulation of D in the kidney (chapter 3 ) but did have a significant effect on the renal blood flow (chapter 4) indicates that not only the intracellularly generated $D$ is responsible for the vasodilation due to PD administration. A part of the prodrug must be generated extracellularly. GGT is not able to convert PD directly (chapter 2), hence PD will have to be deacetyllated. This deacetylated PD can originate from the renal tubules or from elsewere in the body (probabely mainly from the liver).

The fact that $D$, generated in the kidney tubular cells is able to reduce the renal vascular resistance is probably due to the unique architecture of the kidney. D, released from one nephron, could diffuse via the interstitium to the afferent and/or efferent arteriolles of a nearby nephron. Such a mechanism can also explain why D which is formed in the liver has no effect on the hemodynamics. D, released from the liver cannot react immediately with resistance vessels, but will have to be transported first via the circulation to other resistance areas. Because of the rapid inactivation of $\mathrm{D}$ (chapter 2), this would only be possible when large amounts of $\mathrm{D}$ are released, i.e. when the dose of PD would be very high. Another explanation for the general vasodilation which occurs when high doses of PD are administered would be that deacetylated PD, released from for instance the liver, is converted by local GGT activity in some tissues. The generated $D$ would cause a local vasodillition at several sites in the body, thus causing a general vasodilation and decrease of mean arterial pressure.

In short, we propose that the renal selective effect of low doses of PD is caused by: (i) a kidney-selective uptake of PD. This active transport has been proven only indirectly in the previous chapters. In chapter 7 , however, experiments with kidney slices will provide direct evidence for an active transport of PD by the kidney; (ii) an intracellular conversion, the converting enzymes having higher activity in the kidney than in other tissues; (iii) a rapid deactivation of the active drug once it reaches the circulation.

The following model is proposed for the renal handling of PD (Fig. 4.4). The prodrug PD reaches the kidney via the plasma. A part is filtered by glomerular filtration and will be excreted in the urine. The non-filtered PD is partly taken up 
by the tubular cells (step 1). The intracellular PD is converted to D either directly or (more probably) in two steps by the the enzymes acylase (2) and $\gamma$-glutamyl cyclotransferase (3). The generated D can leak into the urine or the blood (4). The D which reaches the blood vessel wall causes a local vasodilation; due to the short halflife time of $D$ in the blood the vasodilation will be restricted to the kidney. Deacetylated PD (PD'), can originate from either the liver or the tubular cells (dotted arrow). PD' will be hydrolyzed rapidly by GGT (5); D which is generated by GGT can contribute to the renal vasodilation.

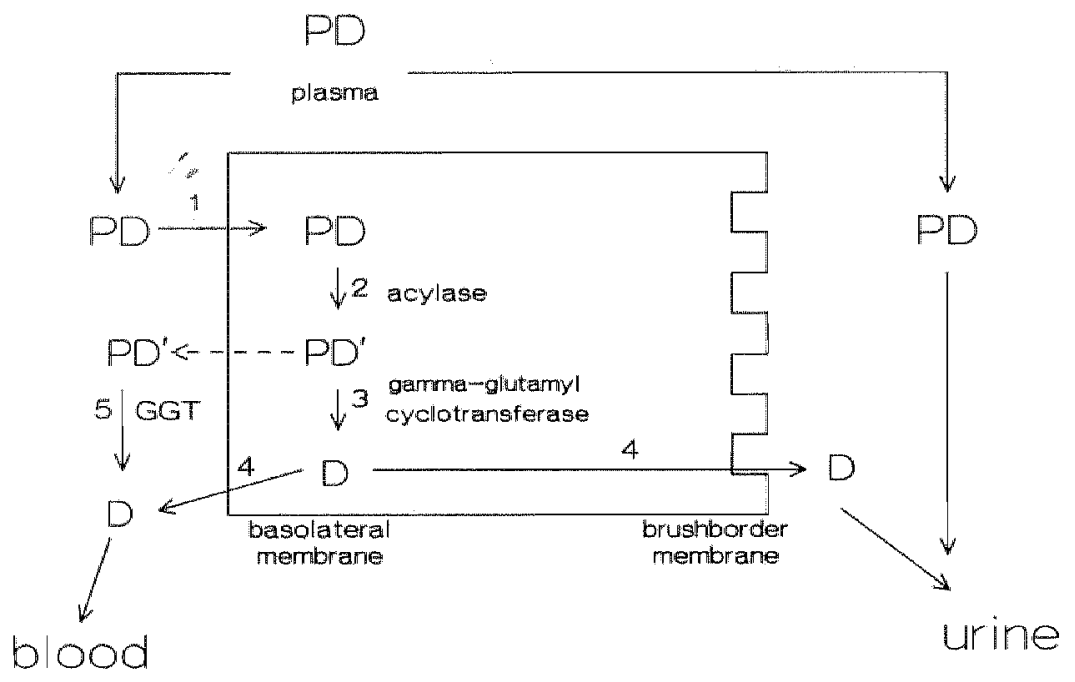

A model for the renal handling of CGP 22979 (PD). For explanation, see text. 


\section{PART II}

\section{THE ROLE OF CARRIER-MEDIATED TRANSPORT IN THE RENAL SELECTIVITY OF PRODRUGS}





\section{CHAPTER 5}

\section{CARRIER-MEDIATED TRANSPORT AND INTRACELLULAR CONVERSION AS DETERMINANTS IN THE RENAL SELECTIVITY OF N-ACETYL- $Y$-GLUTAMYL SULFAMETHOXAZOLE}

\subsection{INTRODUCTION}

Tissue specific drug delivery and action is a highly desirable goal in the development of new therapeutic modalities. The advantages are obvious: drugs act more salutary and lower doses can be used, thus minimizing systemic toxicity and unwanted side-effects. One of the approaches to tissue specific drug delivery is to design prodrugs, which are selectively cleaved in the target tissue. This approach appears simple, but it can only be employed effectively if a thorough knowledge of the (physicochemical, transport, metabolic and kinetic) properties of both prodrug and active drug is present. The role of these properties has been demonstrated with the aid of computer simulations (Stella and Himmelstein, 1980; Smits and Thijssen, 1986).

Recently, we studied the mechanism of the renal selectivity of CGP 22979 , an $\mathrm{N}$-acetyl-L- $\gamma$-glutamyl prodrug of the hydralazine-like vasodilator CGP 18137 (chapter 2-4) and proposed a model for this selectivity (see Fig. 4.4). Essential features of this model are: (a) active transport of the prodrug into the renal proximal tubular cells; (b) intracellular conversion of the prodrug; (c) rapid clearance of the active drug in the blood by a chemical reaction. The transport of the prodrug into the kidney could not be established directly but only indirectly, because only the active drug and not the prodrug could be analysed. It was not clear to what extent the enzyme $\gamma$-glutamyltranspeptidase (GGT) was involved in the renal selectivity 
of CGP 22979: inhibition of this enzyme by AT-125 did not influence the renal accumulation of the active drug but did cause a decrease in the renal response to the prodrug.

To be able to investigate the mechamism of activation and renal selectivity of $\mathrm{N}$-acetyl-L-y-glutamyl prodrugs in more detail a model compound was used: $\mathrm{N}$ acetyl-L - -glutamyl sulfamethoxazole and an analysis was developed in which sulfamethoxazole (SM), L-y-glutamyl SM (GSM) and N-acetyl-L-y-glutamyl SM (AGSM) could be measured simultaneously. The same compound has been used by Orlowski and co-workers $(1980)$ as a model compound for the renal specificity of L-y-glutamyl and $\mathrm{N}$-acylated L- $\gamma$-glutamyl prodrugs in mice. The tissue distribution of SM following i.p. injection of SM or one of its derivatives was reported (Orlowskiet al., 1980). Relatively higher SM concentrations in the kidney compared to liver and other tissues were found when SM was given as prodrug; only a small effect was seen in the case of GSM, but a large effect when SM was given as the $\mathrm{N}$-acetyl $\gamma$-glutamyl derivative. However, they did not report plasma SM concentrations or any prodrug concentration. The renal selectivity of AGSM was attributed to the combined action of a renal acylase and GGT (Orlowski et al, 1980). However, GGT is an enzyme located on the outer surface of the (brush border and basolateral) membrane (Horiuchi et al, 1978). This makes it unlikely that the conversion of the prodrug by this enyzme can generate high intracellular concentrations of active drug. It has also been found that GGT cannot hydrolyse $\mathrm{N}$-substituted $\gamma$-glutamyl compounds (Cook et al., 1987; chapter 2).

GGT is not the only enzyme able to hydrolyze $\gamma$-glutamyl compounds; the cytosolic enzyme $\gamma$-glutamyl cyclotransferase, another enzyme of the $\gamma$-glutaml cycle is also able to hydrolyze $\gamma$-glutamyl compounds (Orlowski and Meister, 1973), and it is possibly this enzyme in combination with an acylase that is responsible for the intracellular conversion of the $\mathrm{N}$-acetyl- - -glutamyl prodrug (chapter 3 ). As anionic compounds do not diffuse easily across biological membranes, an active transport or carrier system is needed to get the prodrug into the proximal tubular cells. A carrier system for glutathione, glutathione conjugates and for $\gamma$-glutamyl derivatives has been described (Anderson and Meister, 1983; Lash and Jones, 1983,1984; Monks and Lau, 1987). The possible role of GGT in the transport of glutathione conjugates is still debated (Kramer et al., 1987; Lau et al., 1988).

In this study we provide evidence for the existence of an active transport of the prodrug into the kidney tubular cells. The role of GGT in the transport and conversion of the prodrug is discussed. Also, the existence of an intracellular two-step conversion of the prodrug is demonstrated. 


\subsection{MATERIALS AND METHODS}

\subsubsection{Animals}

Male Wistar rats (270-300 g, supplied by Winkelman, Borchen, FRG) were used. The animals had free access to lab food and drinking water.

\subsubsection{Materials}

Sulfamethoxazole (SM), L-glutamic acid, and buthionine sulfoximine were supplied by Sigma Chemicals. L- $\gamma$-glutamyl SM (GSM) and N-acetyl-L-y-glutamyl SM (AGSM) were synthetized as described by Orlowski et al (1980). Both compounds gave a single peak on the HPLC system described in chapter 5.2.4, and gave a single spot on the following TLC system: stationary phase: Silica 60 F254 with concentration zone (Merck); solvent: butanol-acetic acid-water $=35-10-5, \mathrm{v} / \mathrm{v} / \mathrm{v} ; \operatorname{Rf}$ GSM $=$ $0.20, \mathrm{AGSM}=0.48$.

AT-125 (acivicin; L-( $\alpha S, 5 S)$ - $\alpha$-amino-3-chloro-4,5-dihydro-5-isoxazole acetic acid) was a gift of dr. De Koning Gans (Upjohn, The Netherlands).

All other chemicals were supplied by Merck and were of analytical grade.

\subsubsection{Experiments}

Liver and kidney homogenates were prepared in 3 volumes of ice-cold $0.05 \mathrm{M}$ Tris HCl buffer ( $\mathrm{pH} \mathrm{8.0)}$ ). Part of the homogenate was centrifuged at $10,000 \times \mathrm{g}$ for $20 \mathrm{~min}$. The supernatant was centrifuged at $100,000 \mathrm{xg}$ for $60 \mathrm{~min}$. The supernatant hereof was used as the cytosol in incubations.

The in-vitro conversion of AGSM was measured in incubations containing $1 \mathrm{mM}$ substrate and $0.05 \mathrm{M}$ Tris $\mathrm{HCl}$ buffer $(\mathrm{pH} 8.0$ ) in a total volume of $150 \mu \mathrm{l}$. The mixtures were pre-incubated at $37^{\circ} \mathrm{C}$ and the incubations were started by addition of $50 \mu$ cytosol or homogenate. Reactions were terminated by heat denaturation ( 2 min at $100^{\circ} \mathrm{C}$ ). The appropriately denaturated $\left(5 \mathrm{~min}\right.$ at $\left.100^{\circ} \mathrm{C}\right)$ tissue fractions served as controls. Each incubation was performed in triplicate.

For the in-vivo kinetic experiments with AGSM, animals were provided with a catheter in the left femoral vein and artery. The rats were allowed to recover for at least $24 \mathrm{hr}$. At the experimental day, AGSM $\left(50 \mu\right.$ mol. $\left.\mathrm{kg}^{-1}\right)$ was injected i.v. into the conscious animals and blood samples were taken at regular time intervals via the femoral artery catheter. Plasma samples were analyzed for SM, GSM and AGSM as described below.

Tissue distribution (liver, kidney and plasma) of SM, GSM and AGSM was 
examined at $20 \mathrm{~min}$ following i.p. injection of these compounds $\left(50 \mu \mathrm{mol} . \mathrm{kg}^{-1}\right.$ of SM or AGSM, $25 \mu \mathrm{mol} . \mathrm{kg}^{-1}$ of GSM). The animals were sacrificed under light ether anesthesia by blood withdrawal from the descending aorta. A blood sample was taken and liwer and kidneys were quickly removed, weighed and homogenized in 2 volumes of ice-cold saline.

Tissue distribution was also examined following pretreatment with buthionine sulfoximine (1 mmol.kg- i.p.) at $20 \mathrm{~min}$ or AT-1.25 (100 $\mu \mathrm{mol}^{-1} \mathrm{~kg}^{-1}$, i.v.) at $90 \mathrm{~min}$ prior to prodrug administration.

Cumulative urinary excretion of SM and its derivatives was measured following i.p. injection of SM, AGSM ( $50 \mu \mathrm{mol} . \mathrm{kg}^{-1}$ each) or GSM $\left(25 \mu \mathrm{mol} . \mathrm{kg}^{-1}\right)$.

\subsubsection{Analysis of SM and derivatives}

Plasma or tissue homogenate $(200 \mu \mathrm{l})$ was acidified with $100 \mu \mathrm{l} 0.1 \mathrm{~N} \mathrm{HCl}$ and diluted with water till $1.00 \mathrm{ml}$. The mixtures were extracted with $5.0 \mathrm{ml}$ of ethylacetate/petroleum ether $(40-60)=90 / 10$. The solvent was removed under a nitrogen stream and the residue was dissolved in $100 \mu \mathrm{l}$ of acetonitrile/ water (80/20 $\mathrm{v} / \mathrm{v})$ and analyzed by HPLC. Stationary phase: Lichrosorb 5RP18 $(150 \times 4.6 \mathrm{~mm}$, Chrompack, The Netherlands); mobile phase: $1 \%$ acetic acid/acetonitrile $=80 / 20$ v/v. Flow rate: $2 \mathrm{ml}^{-\mathrm{min}^{-1}}$. Detection: UV $260 \mathrm{~nm}$. Retention times: GSM: $2.1 \mathrm{~min}$; AGSM: $3.5 \mathrm{~min}$; SM: $4.1 \mathrm{~min}$ and N-acetyl SM: $4.8 \mathrm{~min}$.

\subsubsection{Statistics}

Data are presented as mean \pm SD. Groups were compared using Student's t-test. Differences were considered to be statistically significant for $\mathrm{p}<0.05$.

\subsection{RESULTS}

\subsubsection{In-vitro experiments}

The metabolism of AGSM by liver and kidney fractions is summarized in Fig. 5.1 and 5.2. The results of incubations with homogenates did not differ qualitatively from those with cytosol. Both SM and GSM were found.

In incubations with liver fractions, GSM was found in higher concentrations than 


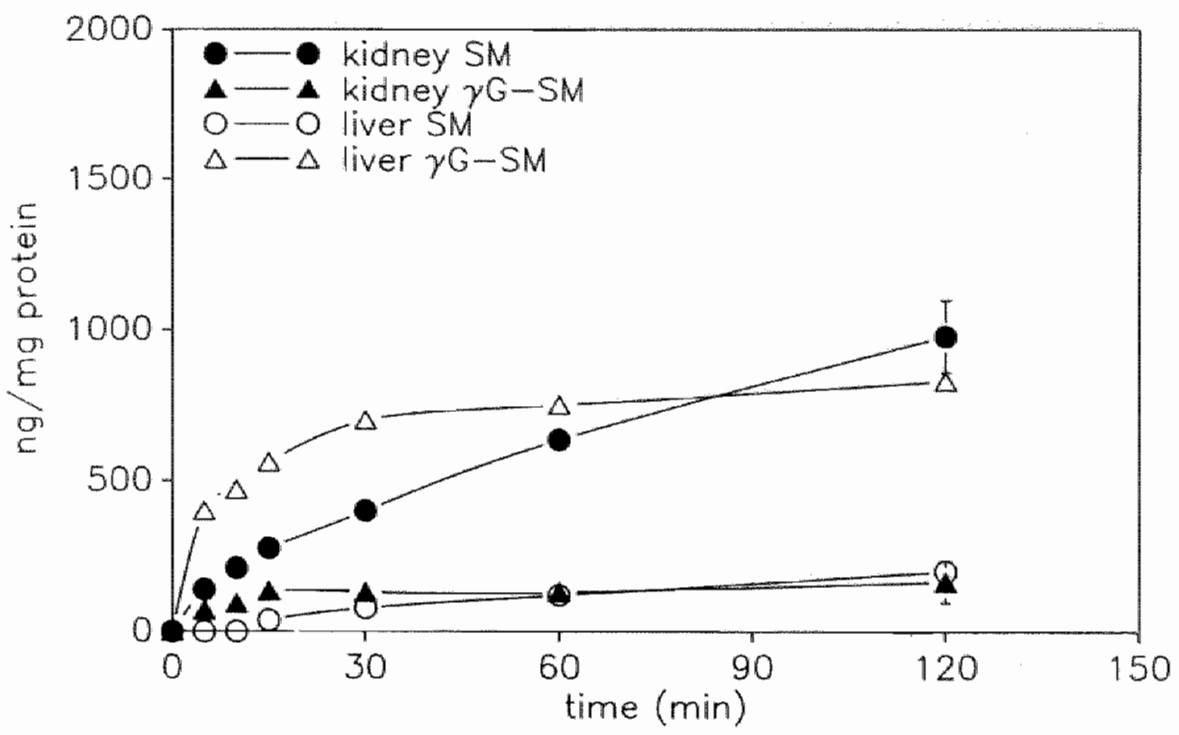

Fig. 5.1 The conversion of N-acetyl-L- $\gamma$-glutamyl SM by liver and kidney homogenates.

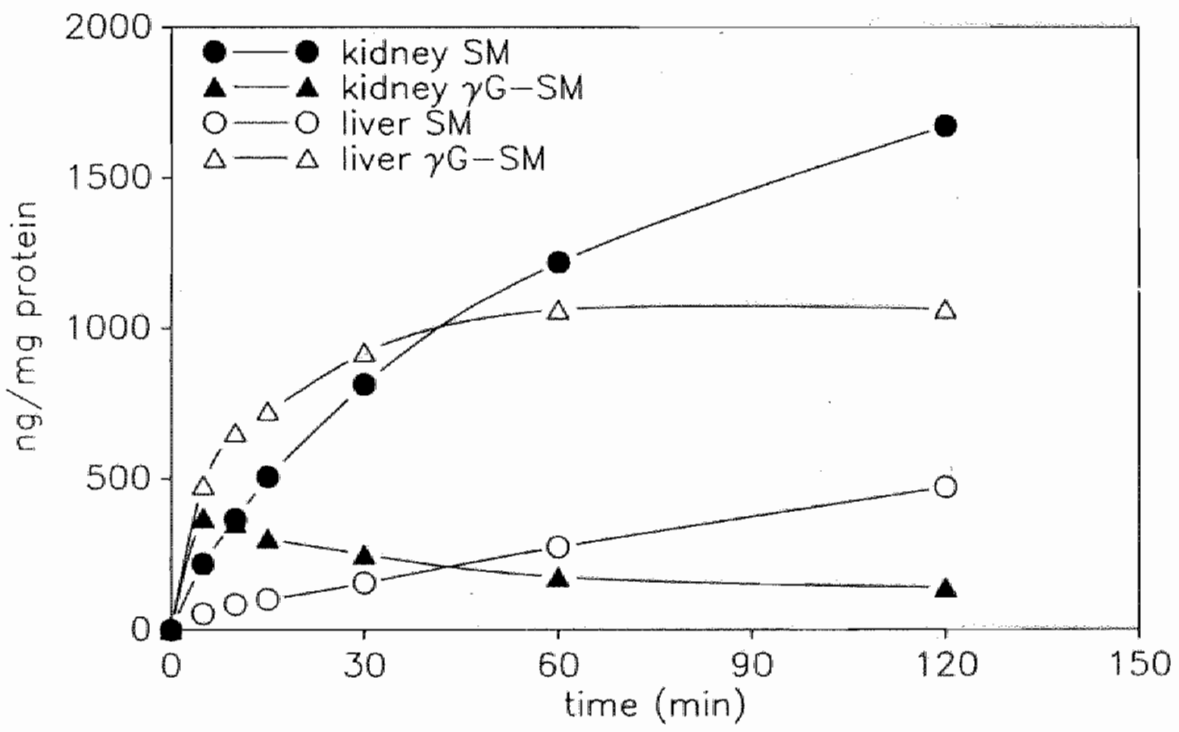

Ftg. 5.2 The conversion of N-acetyl-L- $\gamma$-glutamyl SM by liwer and kidney cytosol. 


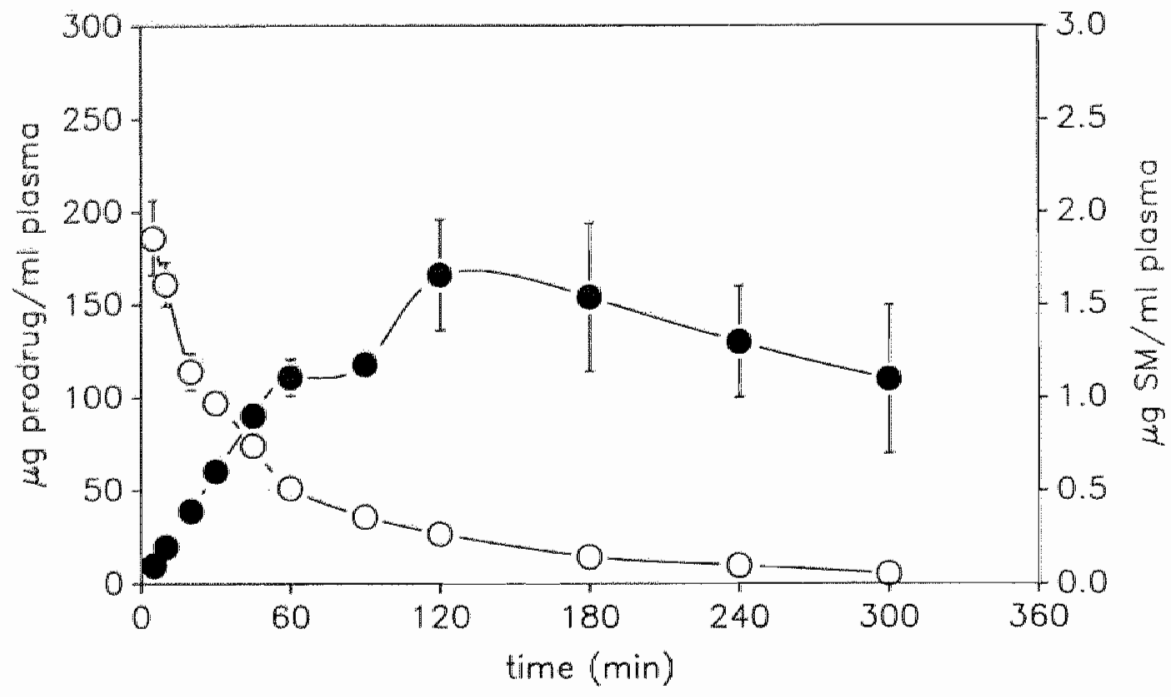

Fig 5.3 Plasma concentration versus time curve of $\mathrm{N}$-acetyl-L $\mathrm{y}$-glutamy\| SM and SM following an inv. bolus injection of $50 \mu \mathrm{mol} . \mathrm{kg}^{-1} \mathrm{~N}$-acetyl-L- $\gamma$-glutamyl $\mathrm{SM}_{\text {. }}$

$\mathrm{SM}$, whereas in kidney incubations the situation was reversed. This indicates that in the kidney the deacetylation of the prodrug is the rate-limiting step and in the liver the removal of the $\gamma$-glutamyl group. So, the overall reaction AGSM $\rightarrow$ SM occurs at higher rate in the kidney as in the liver.

\subsubsection{In-vivo experiments}

The plasma concentration time curve of AGSM and its active product SM are shown in Fig. 5.3. The kinetic parameters of AGSM calculated from these experiments are: terminal half-life time ( $\mathrm{t} 1 / 2$, computed by least-square regression analysis): $76 \pm 10 \mathrm{~min}$; plasma clearance (calculated via the area under the curve): $2.4 \pm 0.2 \mathrm{ml} \cdot \mathrm{min}^{-1} \cdot \mathrm{kg}^{-1}$; volume of distribution: $260 \pm 20 \mathrm{ml} . \mathrm{kg}^{-1}$. Free SM appeared slowly in the plasma; maximum levels of SM were observed at $120 \mathrm{~min}$.

The tissue distribution of SM at 20 min following administration of SM or one of its derivatives is shown in Table 5.1. Following SM administration, the concentration of SM is highest in plasma; kidney and liver concentrations are only $15-20 \%$ of plasma concentration. The same pattern is seen following GSM administration, but following AGSM, a reversal of the pattern is seen: high kidney SM concentrations, in comparison to plasma and liver. 
Table 5.1 Concentrations of SM in kidney, liver and plasma at 20 min following L.p. administration of SM, GSM and AGSM.

\begin{tabular}{|c|c|c|}
\hline$\underset{\left.\mu \mathrm{mol} . \mathrm{kg}^{-1}\right)}{\text { SM }}$ & $\begin{array}{l}\text { L-y-glutamyl SM } \\
\left(25 \mu \mathrm{mol}^{-\mathrm{kg}^{-1}}\right)\end{array}$ & $\begin{array}{c}\mathbf{N} \text {-acetyl-L- } \gamma \text {-glutamyl SM } \\
\left(50 \mu \mathrm{mol}^{-1} \mathrm{~kg}^{-1}\right)\end{array}$ \\
\hline
\end{tabular}

SM ( $\mu$ g.g tissue ${ }^{-1}$ )

$\begin{array}{llll}\text { Plasma } & 48 \pm 6(100) & 14 \pm 1.5(100) & 0.34 \pm 0.10(100) \\ \text { Kidney } & 10 \pm 1.5(21) & 3.6 \pm 0.3(26) & 3.1 \pm 0.9(912)^{*} \\ \text { Liver } & 7.3 \pm 1.1(15) & 2.1 \pm 0.4(15) & 0.22 \pm 0.07(65)^{*}\end{array}$

Data are expressed as mean \pm SD of 3-6 experiments. Values in parenthesis are relative concentrations compared to plasma, arbitrarily set as 100 .

* Significantly different $(p<0.05)$ from relative concentrations following SM administration.

Table 5.2 The influence of buthionine sulfoximine and AT-125 pretreatment on the tissue distribution of AGSM ${ }^{\mathrm{a}}$.

$$
\text { AGSM ( } \left.\mu \text { g.g tissue }{ }^{-1}\right)^{b}
$$

\section{Plasma}

Saline

Buthionine sulfoximine AT-125

$$
\begin{aligned}
& 73 \pm 6(100) \\
& 77 \pm 10(105) \\
& 74 \pm 5(101)
\end{aligned}
$$

Kidney

Liver

a animals were sacrificed 20 min after AGSM administration ( $50 \mu$ mol. $\mathrm{kg}^{-1}$ i.p.).

b Data are expressed as mean \pm SD of 3-4 experiments. Values in parenthesis are relative concentrations compared to saline pretreatment.

* Significantly different $(p<0.05)$ from saline pretreatment.

\# Significantly different $(p<0.05)$ from plasma concentrations. 
The tissue distribution of AGSM and the influence of pretreatment with buthionine sulfoximine and AT-125 are shown in Table 5.2. Buthionine sulfoximine pretreatment reduced the prodrug concentration in the kidney with 35\%. In these experiments the concentration of SM was also measured. Buthionine sulfoximine pretreatment reduced SM concentrations in all tissues significantly $(p<0.05)$ : in plasma $35 \pm 7 \%$, in liver $50 \pm 10 \%$ and in kidney $72 \pm 8 \%$ reduction.

The cumulative urinary excretion $(0-20 \mathrm{hr})$ of SM and derivatives was found to be as follows: after AGSM: $72 \pm 8 \%$ of dose unchanged and $2 \pm 1 \%$ as SM; after GSM: no unchanged drug and $26 \pm 5 \%$ of dose as SM; after SM: $42 \pm 8 \%$ excreted unchanged. In all urine samples $\mathrm{N}$-acetyl $\mathrm{SM}$ was also found.

\subsection{DISCUSSION}

In this study we investigated the mechanism of the renal selectvity of $\mathrm{N}$-acetyl$\gamma$-glutamyl prodrugs, with special emphasis on selective transport and intracellular conversion, using $\mathrm{N}$-acetyl- $\gamma$-glutamyl sulfamethoxazole and the deacetylated prodrug, GSM, as model compounds. The choice of this compound is based upon the work of Orlowski and co-workers (1980), who investigated the possibility of targeting SM to the kidney via GSM and acylated derivatives hereof.

SM is a polar drug and does not easily pass biological membranes: the plasma concentration of SM following i.p. administration is about 5x higher than kidney or liver SM concentrations (Table 5.1). The use of the L-y-glutamyl group as "promoiety" does not improve this situation; SM concentrations in the kidney remain much lower than in the plasma. This can be explained as follows. GGT has its active site on the extracellular side of the membrane (Horiuchi et al, 1978). This enzyme is found both at the brush border membrane and the basolateral membrane (Tate and Meister, 1985). The GGT at the brush border membrane can hydrolyze the filtered part of GSM. The released SM will be excreted into the urine. The GGT at the basolateral membrane will hydrolyze GSM extracellularly. Thus, SM is not released into the tubular cells but into the blood. This is equivalent to an intraarterial infusion of SM and causes no kidney selectivity because of the low extraction ratio of SM by the kidney (cfr. Daemen et al., 1988).

On the other hand, the use of the N-acetyl-L- $\gamma$-glutamyl group as "promoiety" has a large effect on the kidney selectivity of SM (Table 5.1). The plasma concentration of the active drug and consequently the systemic availability, is greatly reduced when AGSM is administered in an equimolar dose compared to SM. The kidney concentration of SM is also reduced, but less dramatically than plasma concentrations ( $31 \%$ vs. $0.7 \%$ of control values, respectively). So, this prodrug causes a large selectivity for the kidney by reducing systemic availability of SM (the released SM is retained by the kidney). 
Orlowski et al. (1980) gave the following explanation for the difference in renal selectivity between GSM and AGSM. GSM is an excellent substrate for GGT. The rapid hydrolysis in other tissues than the kidney would contribute to the loss of kidney selectivity. The introduction of the $\mathrm{N}$-acetyl group slows down the conversion by tissue homogenate and, as the kidney is rich in $\mathrm{N}$-acyl aminoacid deacylases, this would contribute to the renal selectivity. Our plasma and tissue data suggest that the difference between GSM and AGSM lies in the site of conversion: extracellularly for GSM (by the enzyme GGT) and intracellularly in the case of AGSM.

Recently, we suggested another mechanism for the renal selectivity of $\mathrm{N}$-acetyl$\gamma$-glutamyl prodrugs (chapter 3 and 4 ) and the results of the present study confirm our model. The prodrug is transported into the proximal tubular cell (actively or facilitated). Consequently, it is converted via a two-step reaction into the active drug.

The experiments with the kidney slices, described in chapter 7, provide direct evidence for the existence of a carrier mediated transport system: slice concentrations of AGSM are 2.5 times higher than the AGSM concentrations in the medium (Table 7.1). This ratio does not take into account the amout of prodrug which is converted in the slices; as this amount is relatively high (approximately $30 \%$ of the AGSM slice concentration) the capacity of the slices to accumulate AGSM is probabely larger than the value observed. In vivo, the kidney concentrations of AGSM are also higher than plasma concentrations, contrary to the kidney SM concentrations foilowing SM administration (Table 5.2). Buthionine sulfoximine inhibited the accumulation of AGSM both in vivo as in vitro in incubations with kidney slices. This compound has previously been described as an inhibitor of the transport of $\gamma$-glutamyl compounds (Griffith et al., 1979; Anderson and Meister, 1983). From these experiments it cannot be concluded whether one or more carrier systems are involved in the transport of $\mathrm{N}$-acetyl- $\gamma$-glutamyl prodrugs.

To investigate the intracellular conversion of the prodrug, AGSM was incubated in vitro with cytosol or homogenate of kidney or liver (Fig. 5.1 and 5.2). In all incubations, GSM could be detected. So, a two-step conversion of the prodrug occurs indeed: first the prodrug is deacetylated and subsequently the $\gamma$-glutamyl group is removed. However, it cannot be excluded that a direct hydrolysis of the $\mathrm{N}$-acetyl- $\gamma$-glutamyl group occurs concurrently. In the kidney, the deacetylation seems to be the rate-limiting step, as the concentrations of GSM remain low. This compound is accumulated in incubations with liver homogenate or cytosol, indicating that here the hydrolysis of the $\gamma$-glutamyl group is the rate-limiting step.

In vivo, no GSM could be detected following AGSM administration. This is explained by the fact that any deacetylated prodrug which leaks into the general circulation will be converted by GGT. Free SM appears only slowly in the plasma, probably due to a leakage from the kidney (Fig. 5.3). The results of the urinary excretion of SM and its derivatives are another illustration of the finding that GSM and AGSM are metabolized in a different way. GSM is not excreted unchanged, but largely as SM and acetyl SM, the major metabolite of SM. AGSM is excreted largely unchanged, and only to a small extent as free SM or acetyl SM.

The results of this study confirm the model we proposed recently (chapter 3 and 
Fig 4.4), especially on the transport of the $\mathrm{N}$-acetyl $\gamma$-glutamyl prodrug and its site of conversion. Also, we can now propose a more detailed scheme for the intracellular conversion (Fig. 5.4). In our view, this model can be generalized to other $\mathrm{N}$-acetyl-L-y-glutamyl compounds. In short: the $\mathrm{N}$-acetyl-L-y-glutamyl prodrug (PD) is delivered to the kidney via the plasma. A part is filtered by glomerular filtration and excreted into the urine or possibly taken up via the brush-border membrane (step 1). Another part can be taken up via the basolateral membrane (1). Once intracellularly, PD can be deacetylated (PD') by acylase (2) and hydrolysed by $\gamma$-glutamyl cyclotransferase (3) to the active drug (D). This drug can be retained by the kidney cells, metabolised, excreted into the urine or into the blood (4). The nature of this transport is still unknown to us at the moment. It cannot be ruled out that the deacetylated prodrug (PD') is transported out of the tubular cells into either blood or urine. If so, it will be hydrolysed quickly by GGT, which would cause some loss of selectivity.

The activation of $\mathbf{L}-\mathrm{y}$-glutamyl compounds is quite different and these prodrugs are not suitable as kidney selective prodrugs, unless other features are present (such as is the case with $\mathrm{L}-\gamma$-glutamyl dopa, which needs to be decarboxylated following the hydrolysis of the $\gamma$-glutamyl group; Wilk et al, 1978).

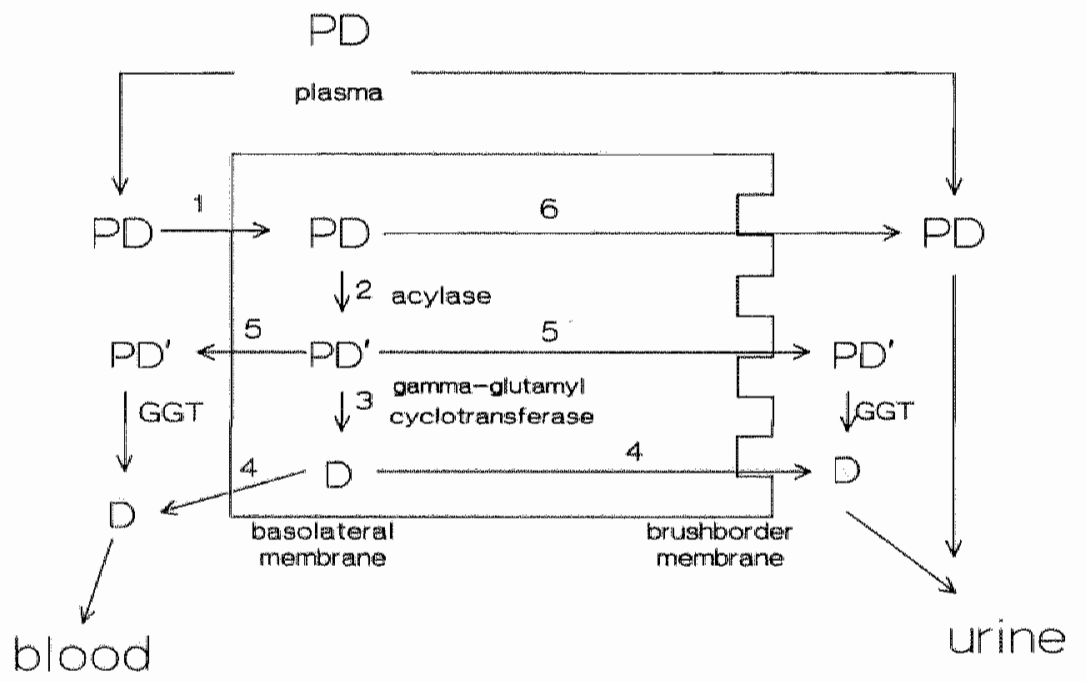

Fig.5.4 A model for the renal handling of N-acetyl-L- $\gamma$-glutamyl prodrugs (PD). Arrows correspond to: (1) uptake of PD by the proximal tubular cells via the basolateral membrane; (2) deacetylation of PD by acylase; (3) hydrolysis of the deacetylated prodrug (PD') by $\gamma$-glutamyl cyclotransferase; (4) transport of the active drug (D) into urine or blood; (5) transport of PD' into urine or blood; (6) transport of PD into the tubular lumen. 


\subsection{REFERENCES}

Anderson, M.E. and Meister, A. Tramsport and direct utilization of gammaglutanyl syst(e)ine for glutathione synthesis. Proc. Nat. Acad. Sci. USA 80: 707-711, 1983.

Cook, N.D., Upperton, K.P., Challis, B.C. and Peters, T.J. The donor specificity and kinetics of the hydrolysis reaction of $\gamma$-glutamyl transferase. Biochim. Biophys. Acta 914: 240-245, 1987.

Daemen, M.J.A.P., Vervoort-Peters, H.T.M. and Thijssen, H.H.W., Pharmacokinetic evaluation of local drug delivery: the intratesticular and intrarenal administration of acenocoumarol in the rat. J. Pharm. Pharmacol. 40: 283-285, 1988.

Dass, P.D. and Welbourne, T.C. Effect of AT-125 on in situ renal $\gamma$-glutamyltransferase activity. FEBS letters 144: $21-24,1982$.

Griffith, O.W., Bridges, R.J. and Meister, A. Transport of gamma-glutamyl aminoacids" role of glutathione and gamma-glutamyl transpeptidase. Proc. Nat. Acad. Sci. USA 76: 6319-6322, 1979.

Horiuchi, S., Inoue, M. and Morino, Y. Gamma-glutanyl transpeptidase: sidedness of its active site on renal brush border membrane. Eur. J. Biochem. 87: 429-437, 1978.

Kramer, R.A., Foureman, G., Greene, K.E. and Reed, D.J. Nephrotoxicity of S-(2-chloroethyl)glutathione in the Fisher rat: evidence for $\gamma$-glutamyl transpeptidase independent uptake by the kidney. J. Pharmacol. Exp. Ther. 242: 741-748, 1987.

Lash, L.H. and Jones, D.P. Transport of glutathione by renal basal-lateral membrane vesicles. Biochem. Biophys. Res. Commun. 112: 55-60, 1983.

Lash, L.H. and Jones, D.P. Renal glutathione transport. Characteristics of the sodium-dependent system in the basal-lateral membrane. J. Biol. Chem. 259: 14508-14514, 1984.

Lau, S.S., McMenamin, M.G. and Monks, T.J. Differential uptake of isomeric 2-bromodihydro* quinone-glutathione conjugates into kidney slices. Biochem. Biophys. Res. Commun. 152: 223-230, 1988.

Monks, T.J. and Lau, S.S. Renal transport processes and glutathione conjugate-mediated nephrotoxicity. Drug Metab. Disp. 15; 437-441, 1987.

Orlowski, M. and Meister, A. Gamma-glutamyl cyclotransferase; distribution, isozymic forms and specificity. J. Biol. Chem. 248: 2836-2844, 1973.

Orlowski, M., Mizoguchi, H. and Wilk, S. N-acyl-gamma-glutamyl derivatives of sulfamethoxazole as models of kidney selective prodrugs. J. Pharmacol. Exp. Ther. 212: 167-172, 1980.

Smits, J.F.M. and Thijssen, H.H.W. Spatial control of drug action: theoretical considerations on the pharmacokinetics of target-aimed drug deliwery. In: Rate-controlled drug administration and action (ed: Struyker-Boudier, H.A.J.). CRC Press, Florida, pp 83-113, 1986.

Stella, V.J. and Himmelstein, K.J. Prodrugs and site specific drug delivery. J. Med. Chem. 23: $1275-1282,1980$.

Tate, S.S. and Meister, A. Giamma-glutamyl transpeptidase from the kidney, In: Methods of enzymology (eds: Colowick, S.P. and Kaplan, N.O.), vol. 113, pp 400-419. Academic Press Inc., Orlando, 1985.

Wilk, S., Mizoguchi, H. and Orlowski, M. Gamma-glutamyl dopa, a kidney specific dopamine precursor. J. Pharmacol. Exp. Ther. 206: 227-232, 1978. 



\section{CHAPTER 6}

\section{LIMITS TO THE TRANSPORT OF N-ACETYL-Y- GLUTAMYL PRODRUGS}

\subsection{INTRODUCTION}

In the previous chapters it has been shown that the derivatization of the primary amino group of a drug with an $\mathrm{N}$-acetyl- $\gamma$-glutamyl group can lead to a selective delivery of the active drug in the kidney. The basis hereof is a combination of a selective transport and intracellular enzymatic conversion in the renal tubular cells (see chapter 5). To investigate the merits of this prodrug approach, it would be more ideal if the active drug has an intracellular site of action. We therefore searched for a drug which would meet the following requirements:" (i), its structure should contain a primary amino group; (ii), the site of action of the drug should be intracellularly; (iii), the drug should either serve a therapeutically relevant goal or be suitable as a tool in pharmacologic research. It was found that 4'-aminowarfarin (4-AW) met those requirements.

4-AW is an active metabolite of acenocoumarin in the rat (Thijssen et al., 1985). Acenocoumarin inhibits the enzyme vitamin- $K$ epoxide reductase, which regenerates vitamin $K$ from vitamin $\mathrm{K}$-2,3-epoxide. The enzyme is part of the vitamin $\mathrm{K}$ cycle which resides in the endoplasmatic reticulum of the hepatocyte and of other tissue cells, such as kidney, brain and testis (Friedman et al., 1982; de Boer-van den Berget al., 1986). In the liver, the enzyme is involved in the production of vitamin $\mathrm{K}$ dependent clotting factors. The physiologic functions of the extrahepatic vitamin K-dependent systems are still unknown. Because 4-hydroxycoumarin anticoagulants accumulate preferentially in the liver (Thijssen and Baars, 1987), it is not possible to investigate the function of the extra-hepatic vitamin $\mathrm{K}$-dependent systems by inhibiting these with warfarin or acenocoumarin. If a renal selective warfarin prodrug would be available, it would be possible to investigate 


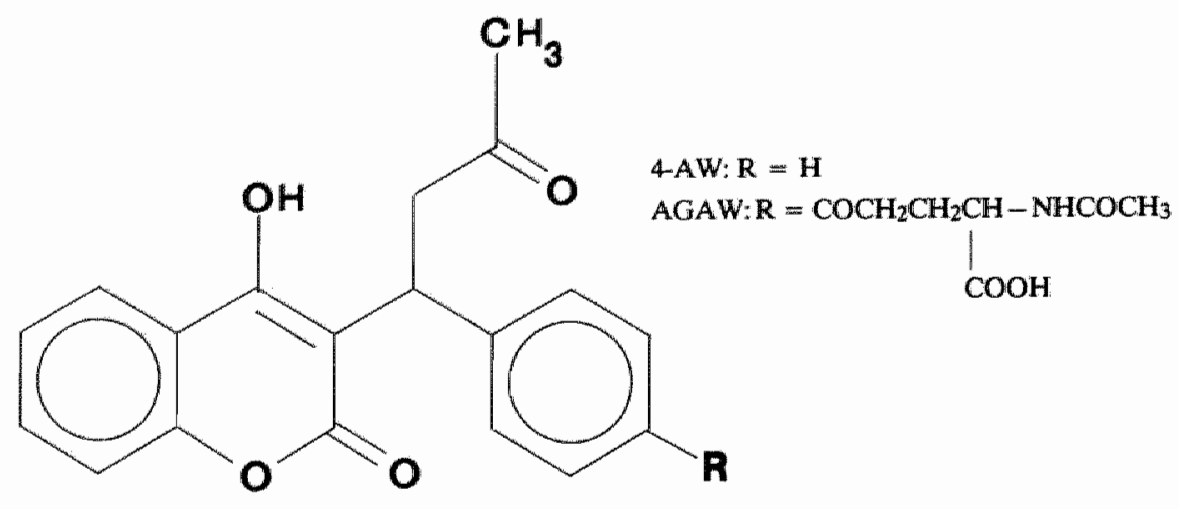

Fig. 6.1 Stuctural formulas of 4-AW and AGAW.

the physiologic function of the renal vitamin $\mathrm{K}$ cycle. Therefore, the $\mathrm{N}$-acetyl $-\gamma-$ glutamyl prodrug of 4-AW was designed (Fig 6.1).

In short, the aim of this studie was three-fold: (i) to investigate the renal selectivity of $\mathrm{N}$-acetyl- $\gamma$-glutamyl 4'-aminowarfarin (AGAW), (ii) to correlate the tissue concentrations of the active drug with an intracellular biochemical parameter and (iii) to evaluate the physiological function of the renal vitamin $\mathrm{K}$ cycle.

Unfortunately, AGAW appeared to have no kidney selective effects. This was due to a lack of transport into the kidney and to an extensive biliary excretion, as the results will show. Therefore, the pharmacokinetic features of the prodrug, with emphasis on liver transport, were further evaluated.

\subsection{MATERIALS AND METHODS}

\subsubsection{Animals}

Male Wistar rats (270-300 g, supplied by Winkelman Borchen, FRG) were used. The animals had free access to lab food and drinking water. 


\subsubsection{Materials}

4'-Aminowarfarin (4-AW) was prepared by reduction of acenocoumarin (a gift from Ciba-Geigy, Basel, Switzerland) with $\mathrm{SnCl}_{2}$. The identiy was checked by comparing the product with 4-AW synthetized before (Thijssen et a, 1983a).

Gamma-glutamyl aminowarfarin (GAW) was prepared by the general method of King and Kidd (1949) as modified by Orlowski et al. (1980). Phtaloyl-L-glutamic anhydride ( $6.8 \mathrm{mmol}$ ) was dissolved in $20 \mathrm{ml}$ glacial acetic acid/tetrahydrofuran $(50 / 50 \mathrm{v} / \mathrm{v})$ and heated to $60^{\circ} \mathrm{C} .4-\mathrm{AW}(6.2 \mathrm{mmol}, 2 \mathrm{~g})$ was added and the mixture was kept at $60^{\circ} \mathrm{C}$ for $30 \mathrm{~min}$. After cooling to room temperature, the mixture was left standing for $2 \mathrm{hr}$ whereafter the solvent was removed under reduced pressure. The residue was suspended in ethylacetate and the solvent was removed till virtually all acetic acid was remowed. The residue was dissolved in methanol and $0.65 \mathrm{ml}$ hydrazine hydrate and $0.65 \mathrm{ml}$ triethylamine were added. The mixture was left standing at room temperature for $48 \mathrm{hr}$. The precipitate which had formed was removed by filtration. The filltrate was evaporated under reduced pressure. The residue was dissolved in $30 \mathrm{ml}$ water and applied to the top of a Dowex-1-acetate column (AG 1-X8, 200-400 mesh $20 \times 250 \mathrm{~mm}$, Biorad).

The column was washed with $500 \mathrm{ml}$ water and eluted with $500 \mathrm{ml}$ of subsequently $0.1,0.3,0.5,1.0$ and $2.0 \mathrm{M}$ acetic acid. Fractions were screened on filter paper for ninhydrin-positive material and analyzed with TLC (Silica 60 F254 with concentration zone, Merck; solvent butanol-acetic acid-water $=35-10-5, \mathrm{v} / \mathrm{v} / \mathrm{v})$. GAW eluted at $2 \mathrm{M}$ HAc. GAW containing fractions were pooled and evaporated under reduced pressure. The compound was recrystallized by dissolving in a small amount of $0.1 \mathrm{M} \mathrm{NaOH}$ and subsequent acidification to $\mathrm{pH}=5$. A light-yellow product separated which gave a single ninhydrin-positive spot on the TLC system $(\mathbb{R f}=0.35)$ and a single peak on the HPLC system described under $6.2 .5, \mathbb{R} t=2.5$ min. Yield: $785 \mathrm{mg}$ (1.8 $\mathrm{nmol}, 28 \%)$.

N-acetyl-L-y-glutamyl 4-AW (AGAW) was prepared by dissolving $600 \mathrm{mg}$ (1.38 mmol) GAW in $20 \mathrm{ml}$ of $0.5 \mathrm{M}$ sodium carbonate. The solution was cooled on ice and $1.5 \mathrm{mmol}$ of acetic acid anhydrid was added dropwise under continuous stirring during $20 \mathrm{~min}$. The mixture was stirred for an additional $20 \mathrm{~min}$, then the pH was adjusted with $6 \mathrm{~N} \mathrm{HCL}$ to about $\mathrm{pH}=1$. The mixture was extracted with ethylacetate and the organic phase was collected. The solvent was removed under reduced pressure and a crystalline product was obtained: $520 \mathrm{mg}$ (1.05 mmol, $76 \%$ ). The compound gave a single spot on the TLC system $(R f=0.55)$ and a single peak on the HPLC system $(\mathrm{Rt}=3.6 \mathrm{~min})$.

\subsubsection{In-vitro experiments}

Liver and tissue homogenates were prepared in 3 volumes of ice-cold $0.05 \mathrm{M}$ Tris-HCl buffer, $\mathrm{pH}=8.0$. For the preparation of microsomes, the homogenate was centrifuged at $10,000 \mathrm{x}$ f for $20 \mathrm{~min}$. The supernatant was centrifuged at $100,000 \mathrm{xg}$ 
for $60 \mathrm{~min}$. The supernatant hereof was used as the cytosol in incubations. The pellet was washed and resuspended in the Trus- $\mathrm{HCl}$ buffer and centrifuged at $100,000 \mathrm{x} \mathrm{g}$ for $60 \mathrm{~min}$. This procedure was repeated and the remaining microsomal pellet was resuspended in the Tris-HCl buffer to a concentration of $10-20 \mathrm{mg}_{\text {protein.ml }}{ }^{-1}$.

The in-witro conversion of AGAW was measured in incubations containing $1 \mathrm{mM}$ substrate and $0.05 \mathrm{M}$ Tris-HCl buffer $(\mathrm{pH}=8)$ in a total volume of $200 \mu 1$. The mixtures were preincubated at $37^{\circ} \mathrm{C}$ and the incubations were started by addition of $50 \mu \mathrm{l}$ cytosol, homogenate or microsome suspension. Reactions were terminated by heat denaturation $\left(2 \mathrm{~min}\right.$ at $100^{\circ} \mathrm{C}$ ). The appropriate denaturated $(5 \mathrm{~min}$ at $\left.100^{\circ} \mathrm{C}\right)$ tissue fractions served as controls. Each incubation was performed in triplicate.

Plasma protein binding of AGAW was determined as follows. Rat plasma (0.8 $\mathrm{ml}$ ), containing $50 \mu \mathrm{g} \cdot \mathrm{ml}-1 \mathrm{AGAW}$ was dialyzed against a buffer (0.067 M Sörensen phosphate $\mathrm{pH}=7.4$ and $0.9 \% \mathrm{NaCl}$ ) in a dialysis chamber during 5 hour at $370 \mathrm{C}$. The concentrations of AGAW in both plasma and buffer were determined as described under 6.2.5. The experiment was performed in triplicate.

\subsubsection{In-vivo kinetics}

Animals were provided with a catheter in the left femoral vein and artery. The rats were allowed to recover for at least $2.4 \mathrm{hr}$. At the experimental day, $10 \mathrm{mg} . \mathrm{kg}^{-1}$ AGAW was injected i.v. into the conscious animals and blood samples were taken at regular time intervals via the femoral artery catheter. Plasma samples were analyzed for 4-AW, GAW and AGAW as described below.

The tissue distribution (liver, kidney and plasma) of AGAW was examined at 30 and $60 \mathrm{~min}$ following its i.p. injection (10 $\left.\mathrm{mg} \cdot \mathrm{kg}^{-1}\right)$. Animals were sacrificed under light ether anesthesia by blood withdrawal from the descending aorta. A blood sample was taken and liver and kidney were quickly removed, rinsed in ice-cold saline, blotted dry, weighed and homogenized in 2 volumes of ice-cold saline.

Cumulative urinary excretion $(0-20 \mathrm{hr})$ of AGAW and its metabolites was determined following i.p. injection of $10 \mathrm{mg} \cdot \mathrm{kg}^{-1}$ AGAW.

Biliary excretion of AGAW was investigated as follows. Animals were anesthetized with $60 \mathrm{mg} . \mathrm{kg}^{-1}$ pentobarbital sodium i.p. and provided with a polyethylene catheter in the femoral vein for i.v. injections and infusions, in the femoral artery for blood sampling and a silastic catheter in the bile duct. The body temperature of the animals was kept constant at $37^{\circ} \mathrm{C}$. At $\mathrm{t}=0,10 \mathrm{mg} \cdot \mathrm{kg}^{-1}$ of $\mathrm{AGAW}$ was injected. i.v. Bile was collected during $6 \mathrm{hr}$ in fractions varying from $15 \mathrm{~min}$ at the start to 1 hr at the end of the experiment. At the end of each collection interval, a blood sample was taken $(200 \mu \mathrm{l})$. In some experiments, rats were pretreated with buthionine sulfoximine $\left(1 \mathrm{mmol} . \mathrm{kg}^{-1}\right.$ at $\left.\mathrm{t}=-5 \mathrm{~min}\right)$, probenecid $\left(1 \mathrm{mmol} . \mathrm{kg}^{-1}\right.$ at $\mathrm{t}=-5 \mathrm{~min})$ or were given a continuous infusion of indocyanine green $\left(25 \mu \mathrm{g} \cdot \mathrm{min}^{-1}\right)$ from $t=-15$ to $t=120 \mathrm{~min}$. Plasma and bile samples were analyzed for 4-AW and AGAW as described below. 


\subsubsection{Analysis of 4-AW and derivatives}

Samples $(100 \mu \mathrm{l})$ were buffered to $\mathrm{pH}=4.5$ with a $0.5 \mathrm{M}$ sodium acetate buffer $(100 \mu 1)$ and extracted with ethylacetate $(1 \mathrm{ml})$. The ethylacetate fraction was then extracted with $0.2 \mathrm{ml} 1 \mathrm{~N} \mathrm{HCl}$. The acidic phase contains 4-AW; AGAW and GAW remain in the ethylacetate fraction. The ethylacetate is evaporated and the residue takken up in $100 \mu \mathrm{l}$ eluens and analyzed on the following HPLC system: column, Lichrosorb 5RP $18,150 \times 4.6 \mathrm{~mm}$; eluens, $0.5 \%$ acetic acid/acetonitrile $=2.85 / 1 \mathrm{v} / \mathrm{v}$, $\mathrm{pH}=4.20$; flow, $2 \mathrm{ml}^{-m^{-1}}$; detection: UV $303 \mathrm{~nm} ; \mathrm{Rt}: \mathrm{GAW}=2.5, \mathrm{AGAW}=3.6$ min. 4-AW is analyzed by injecting $10 \mu$ of the acidic fraction into the same HPLC system, but using the following eluens: $0.1 \%$ acetic acid/ acetonitrile $=3.31 / 1 \mathrm{v} / \mathrm{v}$, $\mathrm{pH}=4.76$; flow $=1.0 \mathrm{ml} \cdot \mathrm{min}^{-1}, \mathrm{Rt}: 4-\mathrm{AW}=4.7 \mathrm{~min}$. Concentrations were calculated from the peak-hights with the use of calibration curves.

\subsection{RESULTS}

The formation of 4-AW out of AGAW by kidney and liver fractions is shown in Table 6.1. Kidney fractions are able to release 4-AW about 10 times faster than the corresponding liver fractions. Kidney cytosol is the most active in the conversion of AGAW; kidney microsomes on the other hand are only able to convert the prodrug in significant amounts when acylase is added. These results are consistent with those found earlier using the N-acetyl-L- $\gamma$-glutamyl prodrug CGP 22979 (chapter 3).

Table 6.1 The conversion of $A G A W$ to $4-A W$ by liver and kidney fractions in vitro

Tissue fraction

Kidney homogenate

cytosol

microsomes

+ acylase

Acylase

Liver homogenate

cytosol

microsomes ng 4-AW.mg protein ${ }^{-1} \cdot \mathrm{min}^{-1}$

$$
\begin{aligned}
14.9 & \pm 0.3 \\
25.4 & \pm 0.6 \\
2.3 & \pm 0.2 \\
23.3 & \pm 2
\end{aligned}
$$

$0.2 \pm 0.05$

$10.2 \pm 0.4$

$3.2 \pm 0.2$

$0.3 \pm 0.1$

Data expressed as mean \pm SD of 2 experiments in triplicate. 


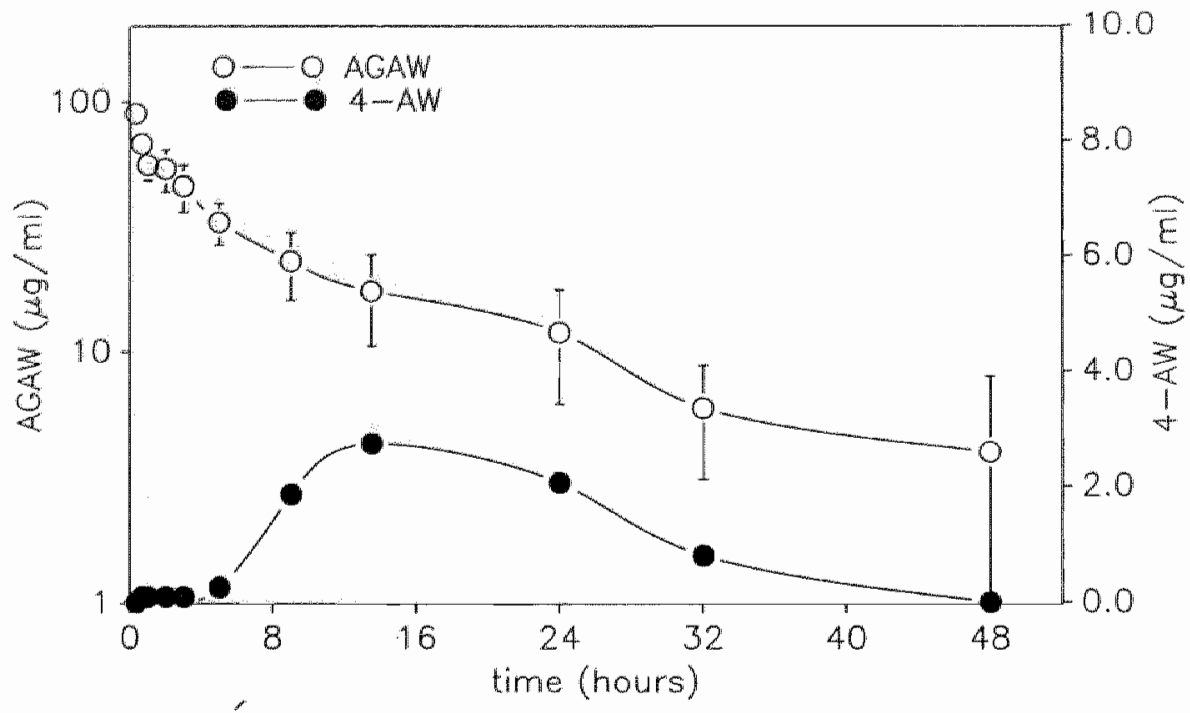

Fig. 6.2 Plasma concentration versus time curve of AGAW (open circles) and 4-AW (filled circles) after injection (i.v.) of $10 \mathrm{mg} \cdot \mathrm{kg}^{-1} \mathrm{AGAW}$.

Table 6.2 Tissue distribution of AGAW and 4-AW following $10 \mathrm{mg}^{\mathrm{k}} \mathrm{kg}^{-1} \mathrm{AGAW}$ i.v. at 30 and $60 \mathrm{~min}$

$\mathrm{AGAW}^{30 \text { min }}$ 4-AW $\left(\mu \mathrm{g} \cdot \mathrm{ml}^{-1}\right)^{\mathrm{AGAW}}{ }^{60 \mathrm{~min}}$ 4-AW

\begin{tabular}{|c|c|c|c|c|c|}
\hline Plasma & 104 & \pm 8 & $0.02 \pm 0.01$ & $83 \pm 3$ & $0.12 \pm 0.01$ \\
\hline Kidney & 10.8 & \pm 0.5 & $0.02 \pm 0.01$ & $9.7 \pm 0.5$ & $0.12 \pm 0.01$ \\
\hline Liver & 10.1 & \pm 0.5 & $0.02 \pm 0.01$ & $7.1 \pm 0.3$ & $0.094 \pm 0.01$ \\
\hline
\end{tabular}


The plasma concentrations of AGAW and 4-AW following an i.v. bolus dose of $10 \mathrm{mg} \cdot \mathrm{kg}^{-1}$ AGAW are shown in Fig. 6.2. AGAW appeared to display biphasic exponential kinetics. Total clearance (CL, calculated by $\mathrm{CL}=\mathrm{D} / \mathrm{AUC}$ were $\mathrm{D}=$ dose of AGAW and AUC = area under the plasmaconcentration vs time curve) was found to be $0.23 \pm 0.03 \mathrm{ml} \cdot \mathrm{min}^{-1} \cdot \mathrm{kg}^{-1}$ (mean $\pm \mathrm{SD}, \mathrm{n}=3$ ). Terminal halflifetime, calculated by the least-square method from $t=8-48 \mathrm{hr}$, was $11 \pm 3 \mathrm{hr}$ (correlation coefficient of individual logarithmic plots: 0.98). Plasma concentrations of 4-AW were low during the first $8 \mathrm{hr}$ (approximately $100 \mathrm{ng}^{-1} \mathrm{ml}^{-1}$ ) but raised from $\mathrm{t}=8 \mathrm{hr}$ to reach maximum concentrations (approximately $3 \mu \mathrm{gg} \cdot \mathrm{ml}^{-1}$ ) between 14 and $24 \mathrm{hr}$.

The tissue distribution of AGAW at 30 and at $60 \mathrm{~min}$ is given in Table 6.2. At both time points, AGAW concentrations in kidney (and liver) were only about $10 \%$ of those in plasma. This suggests that AGAW is not transported into the tubular cells, or only to a limited extent. The 4-AW concentrations are low, both in the kidney and in the plasma. To check whether AGAW is excreted largely unchanged into the urine, the cumulative $(0-20 \mathrm{hr})$ urinary excretion of the prodrug was measured. Only $4 \%$ of the prodrug was recovered in the urine, and $2 \%$ was found to be excreted as 4-AW and acetylated 4-AW (AA).

It is known that a high protein binding of a drug can reduce the urinary excretion rate via carrier-mediated transport mechanism, see for instance Russel et al. (1987). Therefore, the protein binding of AGAW was determined; it appeared that $90 \pm$ $3 \%$ was bound to plasma protein $(n=3)$.

An explanation for the late appearance of 4-AW in the plasma could be that AGAW undergoes an enterohepatic recycling. The biliary excretion of AGAW was measured to investigate this possibility (Fig. 6.3). It appeared that $50 \%$ of the dose was excreted unchanged into the bile within $3 \mathrm{hr}$. The biliary clearance, $\mathrm{CLb}_{\mathrm{b}}$ calculated by $C L_{b}=V e b / C_{p}\left(C_{p}=\right.$ concentration of $A G A W$ in the plasma in $\mu \mathrm{g} \cdot \mathrm{ml}^{-1}$ and $\mathrm{Veb}_{\mathrm{e}}=$ excretion rate of $\mathrm{AGAW}$ in the bile in $\mu \mathrm{g} \cdot \mathrm{min}^{-1}$ ) was found to decrease in the first $3 \mathrm{hr}$ but remained fairly constant during the rest of the experiment: $\mathrm{Cl}_{b}=$ $0.53 \pm 0.03 \mathrm{ml} \cdot \mathrm{min}^{-1} \cdot \mathrm{kg}^{-1}$ at $\mathrm{t}=0-15 \mathrm{~min}, \mathrm{Cl} b=0.22 \pm 0.03 \mathrm{ml} \cdot \mathrm{min}^{-1} \cdot \mathrm{kg}^{-1}$ at $\mathrm{t}=3-6$ hr. The biliary AGAW concentrations in the first 15 min samples were at least 10 times higher than the average plasma concentration of AGAW in the same period.

The biliary excretion could not be inhibited by a bolus injection of buthionine sulfoximine or a continuous infusion of indocyanine green, but was inhibited effectively by a bolus dose of probenecid (Fig. 6.3). The bile flow was constant in all experiments from $\mathrm{t}=0-4 \mathrm{hr}$ : approximately $24 \mu \mathrm{l} / \mathrm{min}$ in control animals and 31 $\mu \mathrm{l} / \mathrm{min}$ in probenecid pretreated animals; from $\mathrm{t}=4-6 \mathrm{hr}$ the bile flow gradually decreased. The plasma concentrations obtained in these experiments are shown in Fig. 6.4. The area under the curve (AUC) from $t=15-240$ min was increased significantly $(p<0.01)$ following probenecid pretreatment: from $0.7 \pm 0.1$ (saline) to $1.1 \pm 0.1 \mu \mathrm{g} . \mathrm{hr} . \mathrm{ml}^{-1} \cdot \mathrm{kg}^{-1}$ (probenecid).

The biliary excretion rate of AGAW was fairly constant following probenecid pretreatment (approximatly $6.5 \mu \mathrm{g} \cdot \mathrm{min}^{-1} \cdot \mathrm{kg}^{-1}$ ), in contrast to control experiments (Fig 6.3). 


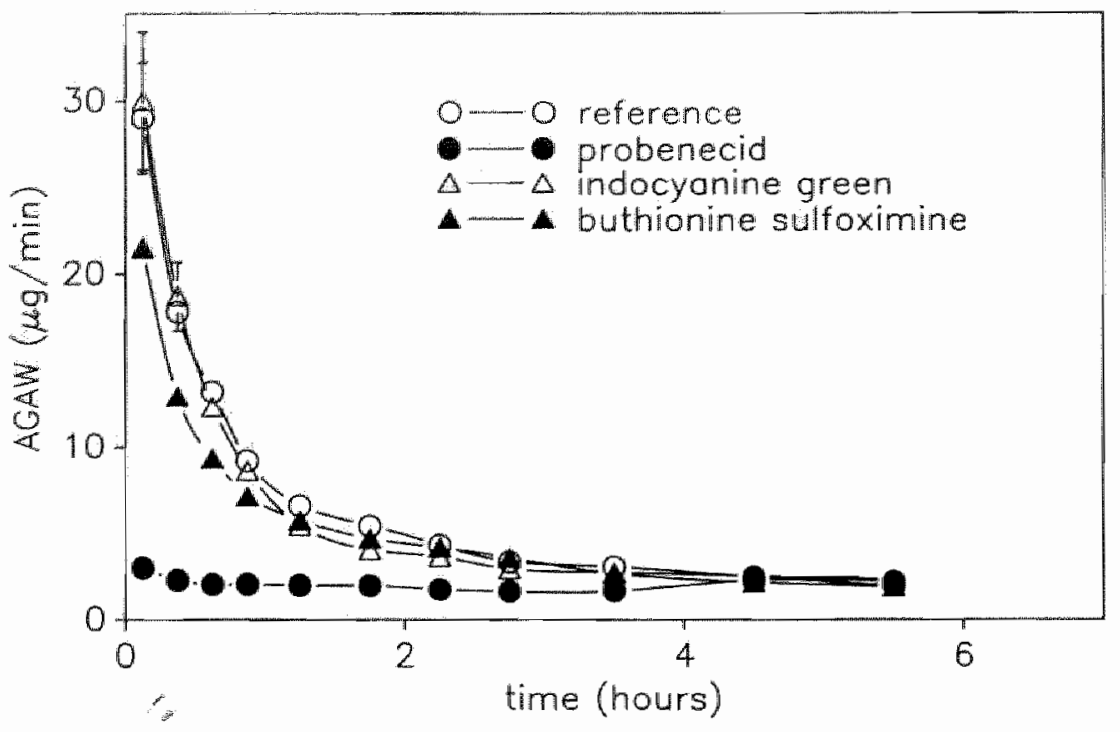

Fig.6.3 Biliary excretion rate of AGAW. The influence of pretreatment with probenecid, indocyanine green and buthionine sulfoximine.

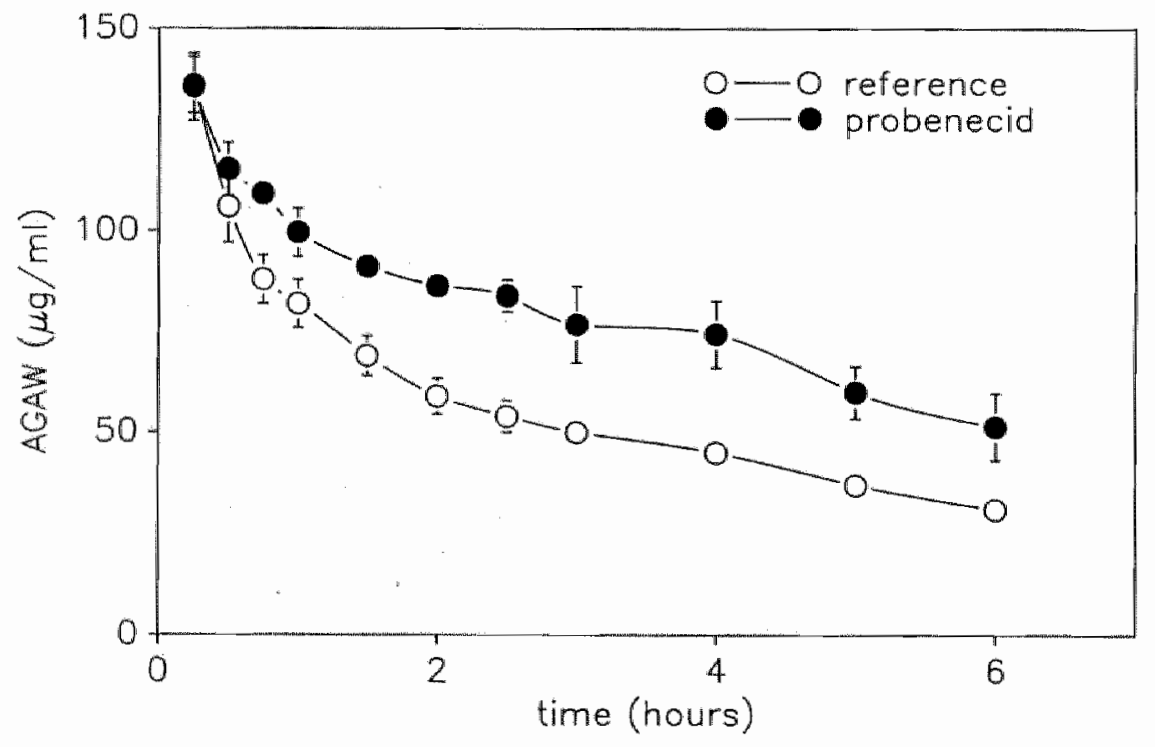

Flg. 6.4 The influence of probenecid on the plasmaconcentrations of AGAW. 


\subsection{DISCUSSION}

On basis of the model described in Fig 5.4 the prodrug AGAW was designed to act as a selective inhibitor of the renal vitamin $K$-epoxide reductase system. In vitro, it was found that the kidney cytosol is able to release the active drug at a rate comparable to the rate of conversion of other $\mathrm{N}$-acetyl- $y$-glutamyl prodrugs (chapter 3 and 5). As expected, the kidney microsomes were not able to convert the prodrug, unless acylase was added. These results are consistent with the concept that the prodrug is not converted directly by $\gamma$-glutamyl transpeptidase but is converted intracellularly by an acylase and (probabely) $\gamma$-glutamyl cyclotransferase. In vivo, however, no accumulation of either prodrug or active drug in the kidney occurred. This is in contrast to the results obtained with CGP 22979 (chapter 2) and $\mathrm{N}$-acetyl- $\gamma$-glutamyl sulfamethoxazole (AGSM; chapter 5).

Furthermore, AGAW was not excreted into the urine in any significant amount, which contrasts to the urinary excretion of AGSM (Chapter 5). These results indicate that AGAW is not transported into the tubular cells. Apparently, the use of an $\mathrm{N}$-acetyl-L- - -glutamyl group as "promoiety" does not necessarily guarantee renal selectivity. Hence, there are limits to the structure of the active drug which preclude its transport as an $\mathrm{N}$-acetyll- $\gamma$-glutamyl prodrug; structure-transport relationship studies are required to get more insight into that matter. A second explanation could be that the carrier-mediated tubular uptake is diminished by the high plasma protein binding of the warfarin prodrug. However, if the plasma concentrations of AGAW in Table 6.2 are corrected for protein binding, it appears that AGAW is distributed between plasma, liver and kidney in a ratio of approximately 1 , indicating no accumulation in the kidney. Also for other compounds the tubular excretion is dependent upon the unbound concentration and not on the total plasma concentration, e.g. phenolsulfonphthalein (Russel et al., 1987).

Remarkably, the liver appeared to be an efficient transporter of AGAW. This is not so much reflected in high liver concentrations of AGAW or 4-AW (Table 2), but in the substantial excretion of AGAW into the bile: $50 \%$ of the dose was excreted into the bile within $3 \mathrm{hr}$. In some of the bile collection experiments, liver biopsies were taken (appr. $100 \mathrm{mg}$ at $\mathrm{t}=1 \mathrm{hr}$ ); no significant amounts of AGAW were found. These results indicate that the transport of AGAW from the liver cells into the bile acts as a sink, as has also been described for other compounds (e.g. p-aminoacetyl hippuric acid; Rollins et al , 1980). These findings are in contrast with the transport behaviour of the $\mathrm{N}$-acetyl-y-glutamyl prodrugs studied previously (chapter 5 and 7) and of 4-AW (Thijssen et al, 1983b): these compounds are not or only to a limited extent excreted into the bile.

The biliary excretion of AGAW could not be inhibited by buthionine sulfoximine (which is able to imhibit the transport of AGSM into the tubular cells, chapter 5 and 7) or indocyanine green (which is excreted actively into the bile by a carrier system and can interfere with the carrier-mediated biliary excretion of other compounds; Meijer et al., 1984, 1988), but was inhibited effectively by pretreatment with 
probenecid (Fig. 6.3). Probenecid is known to inhibit carrier-mediated transport of anions not only in the kidney, but also in other tissues; for instance, the biliary excretion of methotrexate is inhibited by probenecid (Kates and Tozer, 1978); chapter 3 shows that the transport of CGP 22979 into the liver is also reduced to some extent by probenecid. In two of the probenecid pretreated rats a liver biopsy was taken (at $\mathrm{t}=1 \mathrm{hr}$ ). As in the control rats, no significant concentrations of AGAW were found ( $<<$ plasma concentrations). This indicates that the influx of AGAW into the hepatocytes is inhibited by probenecid; whether the efflux of AGAW from the hepatocytes into the bile is inhibited as well cannot be inferred from these experiments.

As the concentration of AGAW in the bile was typically 10 times higher than in the plasma in the first hour of the experiment, these results indicate an active transport of AGAW into the bile. The fact that the plasma protein binding of the prodrug is very high indicates that the hepatic transport carrier must be very effective. The biliary clearance $(\mathrm{Cl} b)$ is not constant, but declines in time. One of the explanations for this finding could be the existence of a stereoselective transport system in the liver: the prodrug consists of a mixture of 2 diastereoisomers: $\mathrm{N}$-acetyl$\mathrm{L}-\gamma$-glutamyl $\mathrm{R}, \mathrm{S}$-aminowarfarin. It is possible that only one of these enantiomers is transported actively into the bile. As time increases, the plasma concentration of the high-clearance enantiomer decreases relatively to the low-clearance enantiomer, causing the total $\mathrm{Cl}$ to decrease. The inhibition of the bilibary excretion by probenecid renders interesting results in this respect: the excretion is largely inhibited but the remaining biliary excretion rate is fairly constant at a comparable level as in the last phase $(\mathrm{t}=3-6 \mathrm{hr})$ of the control experiments, indicating, if the above mentioned explanation is correct, a selective inhibition of the excretion of the high-clearance enantiomer. Attempts have been made to separate both enantiomers and quantitate the relative contributions of these enantiomers to the biliary clearance. Unfortunately, they have not yet succeeded but new efforts will be made.

The late appearance of 4-AW in the plasma can be explained by enterohepatic recycling of AGAW and (partial) activation during reuptake of AGAW, or by absorbtion of 4-AW, produced from AGAW by the intestinal flora.

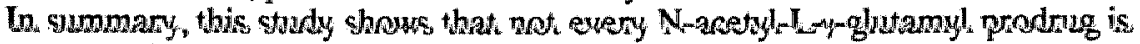
transported into the tubular cells. More research will have to be carried out to determine the structural requirements for tubular transport of these prodrugs. It was also shown that protein binding is an important factor which can influence the renal selectivity of prodrugs. The liver appears to have a very efficient carrier system which transports AGAW to the bille. The results show that fusion of an $\mathrm{N}$-acetyl- $\gamma$ glutamyl group with 4-AW renders a combination which has transport properties that neither 4-AW or any $\mathrm{N}$-acetyl- $\gamma$-glutamyl prodrug studied sofar possesses. 


\subsection{REFERENCES}

De Boer-van de Berg, M.A.G., Thijssen, H.H.W. and Vermeer, C. The in vivo effects of acenocoumarol, phenprocoumon and warfarim on vitamin $\mathrm{K}$ epoxide reductase and vitamin $\mathrm{K}$ dependent carboxylase in various tissues of the rat. Biochim. Biophys. Acta 884: 150-157, 1986.

Friedman, P.A., Mitch, W.E. and Silva, P. Localization of renal vitamin K dependent $\gamma$-glutamyl carboxylase to tubular cells. J. Biol. Chem. 257: 11037-11040, 1982.

Kates, R.E. and Tozer, T.N. Biliary excretion of methotrexate in rats and its inhibition by probenecid. J. Pharm. Sci. 65: 1348-1352, 1987.

King, F.E. and Kidd, D.A. A new synthesis of glutamine and of $\gamma$-dipeptides of glutamic acid from phtalylated intermediates. J. Chem. Soc. (Lond ) 3315-3319, 1949.

Meijer, D.K.F., Blom, A. Weitering, J.G. and Hornsveld, R. Pharmacokinetics of the hepatictransport of organic anions: influence of extra- and intrahepatic binding on hepatic storage of dibromosulfophtalein and interactions with indocyanine green. J. Pharmacokin. Biopharm. 12: 43-65, 1984.

Meijer, D.K.F., Weert, B. and Vermeer, G.A. Pharmacokinetics of biliary excretion in man. VI. Indocyanime green. Eur. J. Clin. Pharmacokin. 35: 295-303, 1988.

Orlowski, M., Mizoguchi, H. and Wilk, S. N-acyl- $\gamma$-glutamyl derivatives of sulfamethoxazole as models of kidney selective prodrugs. J. Pharmacol. Exp. Therap. 212: 167-172, 1980.

Rollins, D.E., Freston, J.W. and Woodbury, D.M. Transport of organic anions into liver cells and bile. Biochem. Pharmacol. 29: 1023-1028, 1980.

Russel, F.G.M., Wouterse, A.C. and Van Ginneken, C.A.M. Renal clearance of phenolsulfonphtalein and the interaction with probenecid and salicyluric acid. J. Pharnacokinet. Biopharm. 15: 349-368, 1987.

Thijssen, H.H.W. and Baars, L.G.M. Hepatic uptake and storage of warfarin. The relation with the target enzyme vitamin K 2,3-epoxide reductase. J. Pharmacol. Exp. Ther. 243: 1082-1088, 1987.

Thijssen, H.H.W., Baars, L.G. and Reijnders, M.J. Analysis of acenocoumarin and its amino and acetamido metabolites in body fluids by high-performance liquid chromatography. J. Chromatogr. 274: 231-238, 1983a.

Thijissen, H.H.W., Baars, L.G. and Reijnders, M.J. Acenocoumarol and its amino and acetamido metabolites. Comparative pharmacokinetics and pharmacodynamics in the rat. J. Pharm. Pharmacol. 35: 793-798, 1983b.

Thijssen, H.H.W., Baars, L.G.M. and Drittij-Reijnders, M.J. Stereoselective aspects in the pharmacokinetics and pharmacodynamics of acenocoumarol and its amino and acetamido derivatives in the rat. Drug Metab. Disp. 13: 593-597, 1985. 



\section{CHAPTER 7}

\section{THE USE OF KIDNEY-SLICES IN THE ASSESSMENT OF RENAL SELECTIVITY OF N-ACETYL-L-Y-GLUTAMYL PRODRUGS}

\subsection{INTRODUCTION}

The renal accumulation of an active drug following its administration as a prodrug can be assessed in vivo in rats. This requires the determination of concentrations of active drug in the kidney, in the plasma and in other, strategically chosen tissues following administration of the prodrug as well as the active drug in a sufficient number of animals. Though these experiments are nescessary in the assessment of the renal selectivity of a given prodrug, it is not the most efficient way to screen a large number of compounds for renal selectivity. A rapid in vitro method would be preferable. In this thesis it has been demonstrated that a combination of a renal selective carrier mediated transport and a selective conversion in the renal tubular cells lies at the basis of the renal selectivity of $\mathrm{N}$-acetyl- $\gamma$-glutamyl prodrugs. So, a combination of two in vitro systems, one for the screening of carrier-mediated transport and one for the determination of intracellular conversion, would be nescessary. In the previous chapters it has been shown that incubations with kidney cytosol are quick, easy and reliable; this seems to be the method of choice in the assessment of the ability of the kidney to activate the prodrugs. For the determination of transport of prodrugs into the tubular cells, several in vitro methods have been described. The use of basolateral membrane vesicles or isolated tubular cells is too elaborate and requires the precence of a radioisotope in the prodrug. The latter is also a significant drawback of the use of cultured tubular cells. The evaluation of tubular transport with kidney slices appears to be relatively simple and fast (see Smith et al., 1982 and Lau et al., 1988). In this chapter the use of rat 
renal slices in the determination of the uptake of $\mathrm{N}$-acetyl- $\gamma$-glutamyl prodrugs is evaluated.

\subsection{MATERIALS AND METHODS}

Kidney slices were prepared as follows. Male Wistar rats (270-330 g, supplied by Winkelman, Borchen, FRG) were killed by cervical dislocation. Kidneys were removed and placed in ice-cold phosphate buffer ( $\mathrm{pH}$ 7.4). Slices were prepared by cutting the kidney with single-sided razor blades, fixed in series (distance between blades: $0.8 \mathrm{~mm}$ ), and the slices were kept in phosphate buffer on ice till a sufficient number was prepared. The ability of the slices to accumulate organic anions was studied by the method described by Smith et al. (1982). In short, renal slices (75-150 $\mathrm{mg}$ ) were incubated in $4 \mathrm{ml}$ of a phosphate buffer ( $\mathrm{pH} 7.4$ ), containing $7.4 \mathrm{mM}$ phosphate, $96.7 \mathrm{mM} \mathrm{NaCl}, 40 \mathrm{mM} \mathrm{KCl}, 0.74 \mathrm{mM} \mathrm{CaCl} 2,10 \mathrm{mM}$ lactate and $75 \mu \mathrm{M}$ para-aminohippuric acid (PAH) or SM, GSM, AGSM, CGP 22979 or AGAW. The mixtures were incubated at $25^{\circ} \mathrm{C}$ for $90 \mathrm{~min}$ under $100 \% \mathrm{O}_{2}$ and agitated at 100 cycles/min. At the end of the incubation, the kidney slices were removed, gently blotted dry on filter paper and weighed.

Slices, used for the determination of PAH accumulation were homogenized in $3 \mathrm{ml}$ of $10 \%$ trichloroacetic acid (TCA). Subsequently the volume was adjusted to $10 \mathrm{ml}$ with distilled $\mathrm{H}_{2} \mathrm{O}$. This mixture was centrifuged and $2 \mathrm{ml}$ hereof was analyzed for PAH by the method of Smith et al. (1945). The incubation medium (1 ml) was treated with $4 \mathrm{ml} 3.75 \%$ TCA; $1 \mathrm{ml}$ hereof was analyzed for PAH.

Slices, used for the determination of the uptake of SM or one of its derivatives, were homogenized in $2 \mathrm{ml}$ of $1 \mathrm{~N} \mathrm{HCl}$ and centrifuged; $200 \mu \mathrm{l}$ of the mixture was transferred into a small $3 \mathrm{ml}$ glass tube and the solvent evaporated under a nitrogen stream. The residue was dissolved in $200 \mu \mathrm{l} \mathrm{H} 2 \mathrm{O}$-acetonitrile $(4 / 1 \mathrm{v} / \mathrm{v})$ and analyzed as described in chapter 5.2.4. The incubation medium (1 ml) was treated with $1 \mathrm{ml}$ $2 \mathrm{~N} \mathrm{HCl} ; 200 \mu \mathrm{l}$ of this mixture was likewise analized for SM, GSM and AGSM. In some experiments, enzyme or transport inhibitors were added $(0.1-1 \mathrm{mM})$ : probenecid, AT-125 or buthionine sulfoximine. The accumulation into the kidney slices is expressed as the ratio of the amount taken up per gram slice and the amount present per ml incubation medium.

The uptake of CGP 22979 and AGAW by kidney slices was determined likewise. AGAW was analyzed as described in chapter 6.2 .5 ; CGP 22979 was analyzed on the same HPLC-system as AGAW, using a detection wavelength of $312 \mathrm{~nm} ; \mathrm{Rt}=1.7$ $\min$.

Data are expressed as mean \pm SEM. Groups were compared using Student's $t$-test. Differences were considered to be statistically significant for $p<0.05$. 


\subsection{RESULTS}

The ability of the kidney slices to accumulate organic anions was investigated with PAH as a check on the functional integrity of the slices; a slice to medium ratio of PAH of $9.4 \pm 0.3(n=9)$ was found. This is comparable to the ratio found by other investigators (Lau et al., 1988) and indicates that the slices were viable and functionally intact.

Table 7.1 Uptake of PAH and $N$-acetyl- $\gamma$-glutamyl prodrugs by rat kidney slices.

$\begin{array}{lcc}\text { substrate }^{\mathbf{a}} & \text { ratio }^{\mathbf{b}} & \text { n } \\ \text { PAH } & 9.4 \pm 0.3 & 9 \\ \text { AGSM } & 2.5 \pm 0.2 & 9 \\ \text { CGP 22979 } & 3.4 \pm 0.4 & 6 \\ \text { AGAW } & 1.0 \pm 0.2 & 6\end{array}$

a All substrates at $75 \mu \mathrm{M}$ concentration.

b Ratio is expressed as the amount of substrate per gram kidney slice devided by the amount of substrate per $\mathrm{ml}$ medium, average \pm SEM.

AGSM and CGP 22979 accumulated in the slices: the ratios were found to be $2.5 \pm 0.2$ and $3.4 \pm 0.4$ respectively (see Table 7.1 ). AGAW did not accumulate in the slices (ratio $=1.0 \pm 0.2$ ).

The uptake and metabolism of AGSM by the kidney slices was investigated in more detail. In incubations with AGSM, SM was found in the slices (approximately $20 \%$ of AGSM slice concentrations) as well in the incubation medium, the slice to medium ratio of SM was found to be $6.3 \pm 1.0$. Deacetylated AGSM (GSM) was found only in the slices (approximately $10 \%$ of AGSM slice concentrations). The influence of several inhibitors on the accumulation of AGSM was tested; probenecid had the largest effect, AT- 125 and buthionine sulfoximine also caused a statistically significant decrease in uptake of AGSM (see Table 7.2).

When GSM was used as a substrate, all GSM appeared to be converted to SM at $90 \mathrm{~min}$, the generated SM was found only in the medium. When pretreated with AT- $125(1.0 \mathrm{mM})$, this conversion was largely inhibited; about $20 \% \mathrm{SM}$ and $80 \%$ GSM were found in the medium. No significant accumulation of these compounds in the slices occurred. 
Table 7.2 The influence of enzyme and transport inhibitors on the accumulation of AGSM in kidney slices.

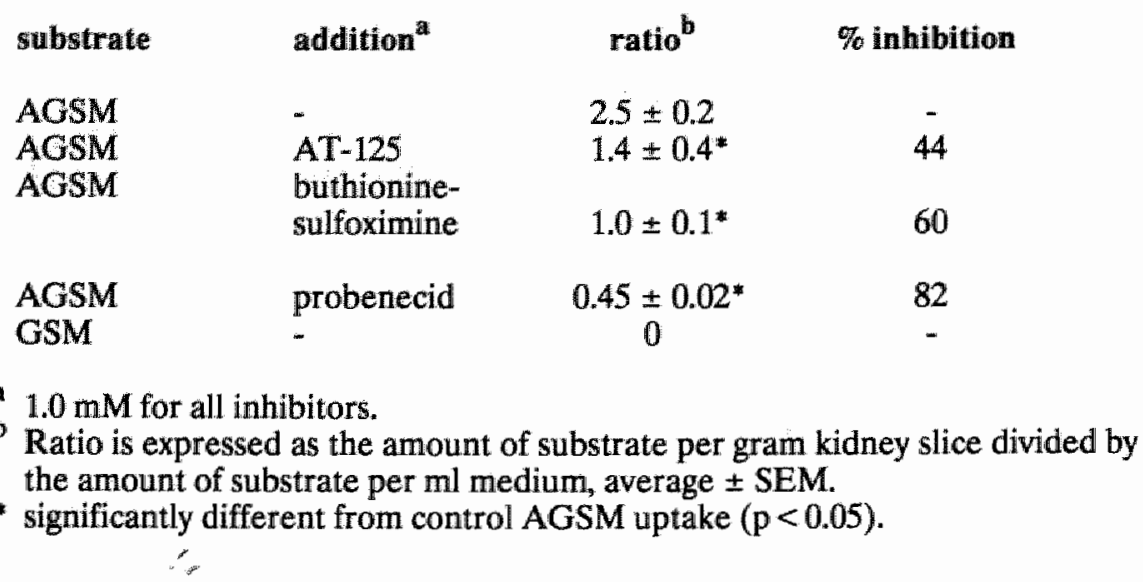

\subsection{DISCUSSION}

These experiments provide direct evidence for the existence of a carrier mediated transport system for the transport of certain $\mathrm{N}$-acetyl- $\gamma$-glutamyl prodrugs: slice concentrations of AGSM and CGP 22979 are significantly higher than concentrations in the medium. AGAW does not accumulate in the slices; this is in accordance with the fact that it is not kidney selective (chapter 6). Evidently, the results of these slice experiments reflect the in vivo selectivity of the prodrugs tested.

The presence of probenecid, an inhibitor of the general anion (or PAH) transport system, was very effective in inhibiting the accumulation of AGSM in kidney slices: $82 \%$ inhibition. This effect is large compared to the effect of probenecid on the accumulation of CGP 18137 following in vivo administration of CGP 22979 (40\% decrease, see chapter 3 ). This could be due to a relatively higher concentration of probenecid in the slice incubation medium than the concentration used in vivo. Another explanation is that the $\mathrm{N}$-acetyl-y-glutamyl prodrugs are transported via more than one carrier (e.g. the PAH and the glutathione transport system); in that case the relative contribution of the separate carrier systems is different for different substrates. Buthionine sulfoximine also inhibits the accumulation, although to a lesser degree at the same concentration as probenecid. Buthionine sulfoximine has previously been described as an inhibitor of the transport of $\gamma$-glutamyl com- 
pounds (Griffith et al., 1979; Anderson and Meister, 1983), besides its action as a glutathione-synthesis inhibitor. The inhibition of prodrug uptake by buthionine sulfoximine in kidney slices is comparable to the inhibition found in wivo (chapter 3 and 5).

AT-125, an irreversible GGT inhibitor, decreased AGSM uptake by $45 \%$. The mechanism through which the inhibition takes place is not yet clear. AT-125 is an effective GGT inhibitor in the concentration used (Dass and Wellbourne, 1982; Lash and Jones, 1984), so if the decrease in uptake was due to the GGT inhibition, a much larger decrease in uptake would have been expected. AT-125 is, however, not only a GGT inhibitor, but at higher concentrations also a more general alkylating agent. Lash and Jones (1984) have demonstrated that the transport of glutathione in renal basolateral membrane vesicles is inhibited at concentrations 5-10 times those required for GGT inhibition. Thus, it seems more probable that the reduction in accumulation of AGSM in the kidney slices is due to a non-specific transport inhibition rather than to the inhibition of GGT. This is supported by the results of the in vivo tissue distribution data: no decrease in kidney accumulation of AGSM is found following pretreatment with AT-125 at a dose which is sufficient to inhibit GGT. Buthionine sulfoximine, on the other hand, had both in vivo and in vitro an inhibitory action.

In short, it can be concluded that a carrier system exists by which AGSM, CGP 22979 and probabely also other $\mathrm{N}$-acetyl- $\gamma$-glutamyl prodrugs are transported. Whether one or more carriers are involved in this transport remains to be established.

It was possible to determine not only the uptake of AGSM in the kidney slices, but also the conversion of this prodrug: both deacetylated AGSM (GSM) and SM could be measured. This is once more proof for the existence of a two two-step conversion. More important, however, it shows that kidney slices can be used not only to evaluate the uptake of the prodrug but also its intracellular conversion and the ability of the slices to retain the active drug. This means that not only the transport, but also the metabolic activity of the slices is intact.

In conclusion, it can be stated that incubations of prodrugs with kidney slices is a suitable method to screen of prodrugs for kidney selective drug delivery.

\subsection{REFERENCES}

Anderson, M.E. and Meister, A. Transport and direct utilization of gamma-glutamyl syst(e)ine for glutathione synthesis. Proc. Nat. Acad. Sci. USA 80: 707-711, 1983.

Dass, P.D. and Wellbourne, T.C. Effect of AT-125 on in situ renal $\gamma$-glutamyltransferase activity. FEBS letters 144: 21 24, 1982 .

Griffith, O.W. Bridges, RJ. and Meister, A. Transport of $\gamma$-glutamyl aminoacids: role of glutathione and $\gamma$-glutamyl transpeptidase. Proc. Nat. Acad. Sci. USA 76: 6319-6322, 1979. 
Lash, L.H, and Jones, D.P. Renal glitathione transport. Characteristics of the sodium-dependent system in the basal-1ateral membrane. I. Bid. Chem. 259: 14508-14514, 1984.

Lau, S.S. McMentamin, M.G. and Monks, TJ. Differential uptake of isomeric 2-bromodihydroquinone-glutathione conjuggates into kidney slices. Biochem. Biophys. Res. Commun. 152: 223-230, 1988.

Smith, $H$.W., Finkelstein, $N_{n}$ Aliminosa, $L_{r,}$ Crawford, $B$, and Graber, $M$. The renal clearance of substituted hippuric acid derivatives and other aromatic acids in dog and man. J. Clin. Invest. 24: 388, 404, 1945.

Smith, J.H., Braselton, W.E., Tonsager, S.R., Mayor, G.H. and Hook, J.B. Effects of vanadate on organic ion accumullation in rat renal cortical slices. J. Pharmacol. Exp. Ther. 220: 540-546, 1982. 


\section{DISCUSSION AND CONCLUSIONS OF PART 2}

The second part of this thesis shows the importance of carrier mediated transport in the renal selectivity of $\mathrm{N}$-acetyl- $\gamma$-glutamyl prodrugs. The studies on CGP 22979 (part 1 of the thesis) only suggested the existence of a carrier mediated transport; the studies on AGSM in chapter 5 and the experiments with kidney slices (chapter 7) provide direct evidence for the existence of such a system.

The aim of this chapter is to evaluate the importance of a number of pharmacokinetic parameters on the renal selectivity by carrier-transported prodrugs. The following model was used for this purpose:

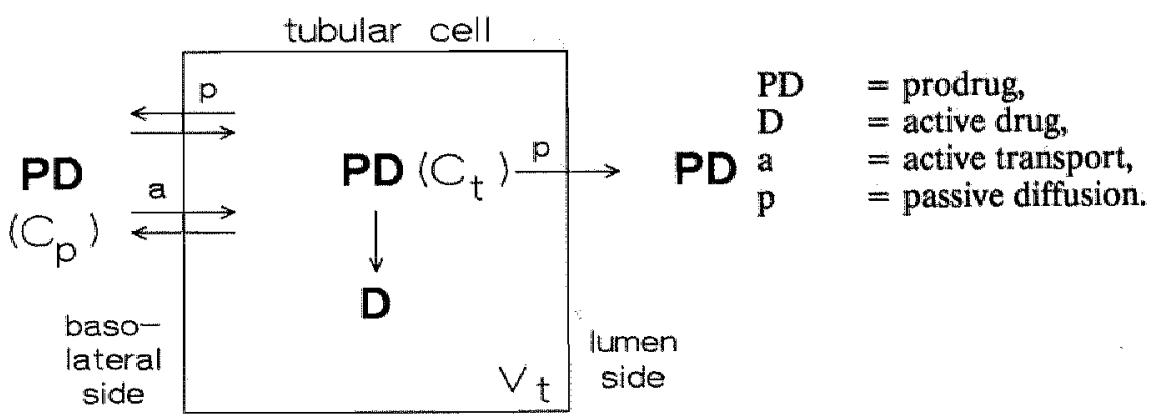

The mass balance equations for the kidney (target tissue) and for non-target tissue can be given:

$$
\begin{aligned}
& v_{t} \cdot \frac{d C_{t}}{d t}=C_{p} \cdot \frac{T_{m}}{k_{T}+C_{p}}-\frac{v_{m, t} \cdot C_{t}}{k_{m}+C_{t}}-C_{t} \cdot v_{t} \cdot k_{e}-\left(\frac{C_{t}}{R_{t}}-C_{p}\right) \cdot v_{t} \cdot k_{d} \\
& v_{n t} \cdot \frac{d C_{n t}}{d t}=v_{n t} \cdot k_{d} \cdot\left(C_{p}-\frac{C_{n t}}{R_{n t}}\right)-\frac{v_{m, n t} \cdot C_{n t}}{k_{m}+C_{n t}}
\end{aligned}
$$


where:

$\mathrm{V}=$ tissue volume,

$\mathrm{C}=$ (unbound) concentration of prodrug,

$K_{e}=$ elimination rate constant

$\mathrm{T}_{\mathrm{m}}=$ (apparent) transport maximum of the carrier system,

$\mathrm{KT}=$ (apparent) Michaelis-Menten constant for transport of the prodrug,

$V_{m}=$ maximum enzymatic conversion rate,

$\mathrm{K}_{\mathrm{m}}=$ Michaelis-Menten constant for the drug conversion enzyme,

$\mathrm{kd}=$ rate constant for passive diffusion of the prodrug across membranes,

$\mathbf{R}=$ (apparent) tissue distribution coefficient of the prodrug $\left(=\mathrm{C} / \mathrm{C}_{\mathrm{p}}\right.$ in steady state when no active transport would occur),

indexes used:

$t=$ target tissue,

nt $=$ non-target tissue,

$\mathrm{p}=$ plasma.

In this discussion, the factors influencing the distribution of the prodrug are stressed. The properties of the active drug which are necessary to achieve selectivity have been extensively discussed (Stella and Himmelstein, 1980, 1982; Smits and Thijssen, 1986; see also chapter 1.4.3).

In this model the following is assumed: (i) the uptake of the prodrug is not perfusion rate limited. If the latter is the case, and if the transport system occurs exclusively in the target tissue, a high degree of accumulation will be achieved. (ii) The conversion of the prodrug occurs both in target and in nontarget tissue, by the same enzyme.

The mass balance equations show the following. It is important that $\mathrm{kd}_{\mathrm{d}}$ is small compared to $T_{m}$ and to $V_{m, t}$. The first means that the passive diffusion or leakage from the target site must be small compared to the active uptake (or rather, the carrier system must have a high capacity), otherwise only a small degree of accumulation can be achieved and non-target tissue will also be supplied with prodrug. If the passive diffusion of the prodrug is much faster than the enzymatic conversion, no significant accumulation of the active drug in the target tissue compared to non-target tissue will be obtained.

The most important factor that determunes the selectivity of the system is the precence of the transport carrier in non-target tissue. The influence hereof can be shown using the appropriate mass balance equations:

$v_{t} \cdot \frac{d C_{t}}{d t}=C_{p} \cdot \frac{T_{m, t}}{R_{T}+C_{p}}-\frac{V_{m, t} \cdot C_{t}}{k_{m}+C_{t}}-\left(\frac{C_{t}}{R_{t}}-C_{p}\right) \cdot v_{t} \cdot k_{d}$ 
and

$V_{n t} \cdot \frac{d C_{n t}}{d t}=C_{p} \cdot \frac{T_{m, n t}}{K_{T}+C_{p}}-\frac{V_{m, n t} \cdot C_{n t}}{K_{m}+C_{n t}}-\left(\frac{C_{n t}}{R_{n t}}-C_{p}\right) \cdot V_{n t} \cdot k_{d}$

During steady-state, $\mathrm{dC} / \mathrm{dt}=0$. When only the transport of the prodrug is considered and not the conversion, and $R_{t}=R_{n t}=a$, the equations can be rearranged to:

$\frac{C_{t}-a C_{p}}{C_{n t}-a C_{p}}=\frac{T_{m, t}}{V_{t}} \cdot \frac{V_{n t}}{T_{m, n t}}$

It can be seen that the accumulation of the prodrug in the target tissue is directly related to the ratio of the transport maxima per tissue volume unit. This holds only when the uptake in the target tissue is not perfusion rate limited; in case of perfusion rate limited uptake the selectivity is sharply decreased by the presence of a transport system in non-target tissue. The accumulation is not dependent on the $\mathrm{KT}$ of the carrier system, due to the fact that the same carrier is assumed to be present in all tissues. If the carrier in the target tissue is different from that in other tissues, the accumulation is also dependent upon the ratio of the $\mathrm{KT}_{\mathrm{T}} \mathrm{s}$.

When the conversion of the prodrug into the active drug is also taken into account, the following remarks can be made. When the prodrug conversion is fast in all tissues except the plasma (i.e. $\mathrm{T}_{\mathrm{m}} / \mathrm{K}_{\mathrm{T}}<<\mathrm{V}_{\mathrm{m}} / \mathrm{K}_{\mathrm{m}}$ ), no high intracellular prodrug levels will be reached. The intracellular active drug levels will reflect the transport capacity of the tissues for the prodrug (provided that the active drug is retained by the kidney).

When the prodrug conversion is much slower than the transport (i.e. when $\mathrm{T}_{\mathrm{m}} / \mathrm{KT}_{\mathrm{T}}>>\mathrm{V}_{\mathrm{m}} / \mathrm{K}_{\mathrm{m}}$ ), the conversion rate is dependent upon intracellular prodrug concentrations. $C_{t}$ should therefore be kept at an optimal level, i.e. near $\mathbf{K}_{\mathrm{m}}$. This can be achieved by controlling $C_{p}$. When $C_{p}$ increases so that $C_{t}$ reaches high values $\left(>>\mathrm{K}_{\mathbf{m}}\right.$ ), only a small increase in drug formation at the target site can be achieved. At the same time, $C_{n t}$ is also increased, causing a relatively larger increase in nontarget active drug concentrations and a decrease in selectivity. Hence, $C_{p}$ will have to be kept low in order to achieve the highest selectivity. Ideally, the drug exerts its intracellular action at low concentrations. In that case an optimal use of the biochemical (transport) possibilities of the target tissue can be made.

When the ratio $T_{m, t} / T_{m, n t}$ is not high enough to achieve the desired level of selectivity, a tissue selective conversion can be very helpful. This is illustrated by the results obtained with the $\mathrm{N}$-acetyl- $\gamma$-glutamyl prodrugs tested.

In short, the following conclusions can be drawn from chapter 5-7. The importance of tissue-specific conversion in drug targeting via prodrugs has long been recognized. Many prodrugs have been designed on the basis of an elevated en- 
zymatic activity in the target tissue (see chapter 1). But enzymatic activity in non-target tissue can cause a considerable loss of selectivity. This thesis shows that a tissue selective carrier-mediated transport helps considerably in achieving siteselectivity. A combination of a tissue-sellective transport and a tissue-selective conversion appears to give the best results, even if the tissue selectivity of the enzymatic conversion is far from ideal (cfr. the hepatic conversion of CGP 22979 and AGSM).

The structural requirements for renal transport of $\mathrm{N}$-acetyl-L- - -glutamyl prodrugs will have to be investigated in more detail. But with the available information it can already be concluded that these prodrugs constitute one of the most promising approaches to drug targeting to the kidney. 


\section{CHAPTER 8}

\section{GENERAL DISCUSSION AND OUTLOOK}

\subsection{INTRODUCTION}

The experimental section of this thesis demonstrates that carrier-mediated transport into the tubular cells is a crucial step in the renal selectivity of $\mathrm{N}$-acetyl$\gamma$-glutamyl prodrugs. In chapters 3 and 4 , for instance, it is shown that inhibiting the transport of the prodrug CGP 22979 into the kidney reduces both the renal concentrations of the active drug and the pharmacologic effect. A disadvantage of this prodrug is that its site of conversion does not coincide with the site of action..

In chapter 7 the transport of several $\mathrm{N}$-acetyl- $\gamma$-glutamyl compounds into kidney slices is described. It was found that the transport of the non renal selective (chapter 6) prodrug AGAW is limited, compared to the other prodrugs tested. This is also an illustration of the importance of tissue selective transport in the targeting of drugs via prodrugs. In this thesis, only one class of renal selective prodrugs was investigated. It can be imagined that other classes of prodrugs are also able to achieve selectivity via carrier-mediated transport, either in the kidney or in another tissue.

Tissue selective carrier-mediated transport can become an important route to achieve site-selectivity for intracellularly acting drugs, especially when the intracellular process to be affected is not tissue selective. A lot of research into the biochemical background of diseases is presently carried out. The involvement of, for instance, second messenger systems, DNA-transcription, RNA translation and post-translational protein changes in the development and progress of diseases is being investigated. It can be imagined that in the near future new agents will become available that interact with these processes. As these processes are general and not specific for particular tissues, the new drugs can only have a therapeutic action if they are delivered to the site of action only. The design of transport prodrugs seems 
to be a promising approach to such a site-selectivity. An elevated level in the target cells of the enzyme which activates the prodrug will enhance the selectivity.

It is, of course, more elegant (and practical) if the active drug itself is transported selectively into the target cells. This might be achieved by some antineoplastic agents, for instance nucleoside analogues (Sirotnak and Barrueco, 1987). An elegant example of selectivity via transport is the uptake of catecholamines and related drugs by nerve endings. But in practice, when a drug is developed that can interact with the desired biochemical system, it seems easier to develop a prodrug with affinity for a specific transmembrane carrier than to change the structure of the active drug so, that it remains active and acquires affinity for the transport system. A prerequisite is of course that a tissue- or celltype-specific transport system is present. Much more research will have to be done to discover tissue-specific transport systems.

The aim of this chapter is to discuss the possibilities and limitations of the prodrug approach for the tissue selective targeting of drugs, not only to the kidney but to any tissue with biochemical properties which distinguish it from other tissues.

The tissue selective action of prodrugs can be divided into four steps: (i), transport of the prodrug to the site of action; (ii), conversion of the prodrug into the active drug at the site of action; (iii), interaction of the drug with a receptor; (iv), site-retention or clearance of the active drug by the target site. Each of these steps can offer possibilities to and impose limitations upon the selectivity of prodrugs and will be discussed in separate paragraphs, with emphasis on the tissue transport. The last part of this discussion will deal with the clinical relevance of targeting drugs to the kidney.

\subsection{TRANSPORT OF PRODRUGS}

\subsubsection{Passive transport}

The transport of a polar drug across a biological membrane can be improved by the design of a lipophilic prodrug. In this way the brain can be reached via the blood-brain barrier (BBB). When the prodrug reaches the brain, it should be converted into the active drug. This can be a problem since the metabolic capacity of the brain is rather limited. An example hereof is the increased brain permeability of $\gamma$-amino butyric acid (GABA) esters (Shashoua et al., 1984; Hesse et al., 1988). These prodrugs were only to a limited extent converted to the active compounds in the brain, with the exception of the cholesteryl ester of GABA.

The monobenzoyl and dibenzoyl esters of dopamine were tested for their ability to deliver dopamine to the brain (Tejani-Butt et al., 1988). The monobenzoyl ester 
was not able to cross the BBB, as opposed to the dibenzoyl ester. The dibenzoyl ester, however, was not converted to dopamine in the brain, whereas upon intrathecal administration the monobenzoyl ester was converted.

Recently, a lipophilic prodrug of glycine was described (milacemide, Youdim et al., 1988); this compound caused enhanced concentrations of glycine in the brain and increased the seizure treshold in response to hyperbaric oxygen.

However, enhancement of the lipophilicity of a drug improves the transport across all membranes and does not increase selectivity, hence this is generally not a useful method for the targeting of drugs. Only if enhancement of the lipophilicity is combined with at least one other metabolic quality, selectivity can be achieved. A very interesting example of this is the work of Bodor and co-workers (Bodor et al., 1975, 1976; Bodor and Brewster, 1983) on redox delivery systems, see chapter 1.4.5.

Enhancing the lipophilicity is, however, no guarantee for improved transport across the BBB. Cyclosporin, a very lipophilic peptide, was shown to have only very limited access to the brain (Cefalu and Pardridge, 1985), probably due to its large size and molecular weight.

Lipophilic esters of pilocarpine are used as topical prodrugs in the treatment of glaucoma (Bundgaard et al., 1985, 1986), but the active drug is partly systemically available as well, thus causing unwanted side effects. The accessability to both the target site and the rest of the body is enhanced by designing a lipophilic ester.

It can be concluded that enhancing the lipophilicity by the formation of a prodrug is not a useful approach to site specific drug delivery.

\subsubsection{Carrier-mediated transport}

The use of a tissue specific transport system offers unique possibilities to direct a prodrug to the target tissue or target cells. Although much work has been done on the characterisation of several transport systems, the knowledge on tissue specific transport systems is far from complete. Research has focussed upon a number of tissues, for instance: kidney, liver, brain, tumors, reticulo-endothelial cells, erythrocytes, gastro-intestinal barrier, and other tissues. Some of these tissues will be evaluated with regard to their transport capabilities.

Kidney. Largely because of its excretory function, the kidney is able to transport many different substances via carrier-mediated transport. The transport systems for inorganic ions will not be discussed here because of their obvious lack of affinity for (organic) prodrugs. The following reviews deal with the renal secretion of drugs: Brater (1980), Bekersky (1987), Somogyi (1987) and Van Ginneken and Russel (1989).

The transport systems can be devided into those with an excretory function, operating in the direction of the tubular lumen, and those with a reabsorptive 
function, operating at the brush-border membrane in the direction of the surrounding capillaries. The excretory systems are especially active in the transport of organic anions (Möller and Sheikh, 1983; Russel, 1988; Russel et al., 1989a,b) and cations (Berndt, 1981; Rennick, 1981). At least three distinguishable systems appear to be active in the transport of organic anions (review: Ullrich and Rumrich, 1988): the p-aminohippuric acid (PAH) system, the dicarboxylic acid system and the sulfate system.

The anion transport carrier systems are located at the basolateral membrane. The transport of the anions out of the cells into the tubular lumen occurs mainly by passive diffusion, thus causing accumulation of the transported compound in the tubular cell.

The system that has been studied most thoroughly so far is the PAH transport system (for reviews see Haberle (1981), Möller and Sheikh (1983), Shimada et al. (1987) and Ullich et al. (1988)). This transport system, located at the basolateral membrane of the proximal tubulus, appears to accept a wide range of organic anions, such as benzoates, captopril, indomethacin, penicillins, probenecid, sulfonamides and thymidin (Russel, 1988). The structural requirements for transport via this system have been described, as well as the substrate specificity of the sulphate and the dicarboxylate transport systems (UlIrich and Rumrich, 1988). With the aid of these transport systems it seems possible for a large variety of prodrugs to enter the renal tubular cells.

Another transport system is the so called $\gamma$-glutamyl transport system, which is able to transport glutathione, $\gamma$-glutamyl amino acids and possibly other $\gamma$-glutamyl compounds (Griffith et al., 1979; Rankin and Curthoys, 1983; Lash and Jones, 1983, 1985; Monks and Lau, 1987). The substrate specificity of this system has not yet been investigated in detail, and the occurrence of this transport system in other tissues has, to our knowledge, hardly been investigated. This system is not only responsible for the excretion of $\gamma$-glutamyl compounds, but also for the toxicity of some (but not all) glutathione conjugates (Monks et al., 1985; Monks and Lau, 1987; Schaeffer and Stevens, 1987; Anders et al., 1988; Commandeur et al., 1988).

For instance, it has been demonstrated that the renal toxicity of S-(2-chloroethyl)glutathione is dependent on a probenecid-sensitive transport system (Kramer et al., 1987). In contrast, the nephrotoxicity of S-2-bromohydroquinone-glutathione was dependent on degradation to the corresponding cysteine adduct and was not sensitive to probenecid (Kramer et al., 1987). The influence of other transport inhibitors and the interaction of other compounds, known to be transported by a single transport system, on the transport of glutathione conjugates was not investigated in this study.

The N-acetyl-L- $\gamma$-glutamyl prodrugs, studied in this thesis, are also shown to be transported into the kidney. The transport is probenecid-sensitive and can be inhibited by $\gamma$-glutamyl analogues as buthionine sulfoximine and glutathione. These data indicate an involvement of the glutathione transport system, described by Lash and Jones $(1983,1985)$ in the transport of these prodrugs. But as probenecid is a general anion transport inhibitor, it is also possible that the prodrugs studied are transported (partly) by the PAH transport system. We propose that the glutathione 
transporter is responsible for the renal selectivity of $\mathrm{N}$-acetyl- - -glutamyl prodrugs; other carrier systems (such as the PAH carrier) might be responsible for a part of their renal transport.

The cation transport system in the kidney is clearly distinct from its anionic counterpart (Rennick, 1981). Examples of endogeneous compounds which are transported by this system are: catecholamines, cholline, histamine and guanidine. Examples of drugs are: amiloride, atropine, isoproterenol, morphine, procaine, quinine, tetraethylammonium (see for review: Rennick, 1981). This carrier mediated transport system appears to be located at the brush border membrane and operates in the direction of the tubular lumen as opposed to the anion transport systems. The cations enter the tubular cells via the basolateral membrane by "gated channels" (Rennick, 1981; Somogyi, 1987), or by active transport (Schäli et al., 1983; Tarloff and Brand, 1986). Contrary to the transport by the anion carrier system, no accumulation of cations occurs in the tubular cells, due to the efficiency of the brushborder membrane carrier system. This implies that the cation transport system is not a useful target for renal selective prodrugs.

Transport in the other direction, i.e. from the tubular lumen via the tubular cells to the surrounding capillaries, occurs as well. Substances like amino acids (Murer, 1982; Brosnan, 1987; Röigaard-Petersen, 1988; Saier et al., 1988), dipeptides (Ganapathy et al., 1981; Kramer et al., 1988; Skopicki et al., 1988), sugars (Widdas, 1988) and nucleosides (LeHir and Dubach, 1984, 1985; Nelson et al., 1988) are transported via this route. These transport systems are highly specific for their substrates, but they also occur in other tissues than the kidney. Hence, these systems do not seem very suitable for the site-specific transport of prodrugs.

Filtered proteins are reabsorbed from the tubular lumen by endocytosis (Park, 1987), followed by hydrolysis in lysosomes. Small proteins with covalently bound drugs can be envisaged as kidney-directed drug delivery systems, provided that complete hydrolysis occurs and that a substantial part of the released active drug is available in the cytosol of the tubular cells, i.e. that not almost all the drug is excreted across the basolateral membrane.

Receptor-mediated uptake in the renal tubulus has been described for adenosine deaminase (Schrader et al., 1988). This enzyme is bound by complexing proteins, located at the surface of microvilli in the proximal tubule. The enzyme-protein complex is consequently translocated into the tubular cells and degraded. Possibly, other enzymes or low-molecular weight proteins are also reabsorbed by receptormediated transport. Because of its higher efficiency compared to simple endocytosis, receptor-mediated transport could be an effective route to deliver enzyme-drug complexes to the renal tubular cells.

Liver. The transport into hepatocytes of many endogenous compounds as well as drugs has been investigated. For instance, the transport of sugars (Widdas, 1988); amino acids (Saier et al., 1988); organic anions (e.g. bromosulfophtalein (BSP), indocyanine green (ICG), Meijer et al., 1984; Tazuma et al., 1988); cations (Bencini et al., 1988; Mol et al., 1988); glutathione (GSH) conjugates (Sorrentino et al., 1987); 
bilirubine, bile salts and other cholates (Boyer, 1980; Stacey, 1988); and of folates (Goldman, 1971) has been well documented.

An example of a drug which is transported by the follate carrier system is methotrexate (MTX). MTX is transported into hepatocytes (Gewirtz et al., 1980), as well as out of the liver cells into the bile (Kates et al., 1976). Both transport steps can be inhibited by probenecid (Kates and Tozer, 1978).

Probenecid and benzylpenicillin are also transported into hepatocytes. The uptake of benzylpenicillin is inhibited by probenecid (and vice versa), but paraaminohippuric acid or para-acetylaminohippuric acid had no effect (Terasaki et al., 1986; Tsuji et al., 1986). Taurocholic and cholic acid had a non-competitive inhibitory effect. These studies show that this hepatic anion transport system is clearly distinct from the renal PAH transport system, although an overlap in substrate specificity exists.

Another transport route which can be recruited to deliver drugs to the liver is via the low-density lipoprotein (LDL) receptor (van Berkel et al., 1986). A drug can be incorporated in the lipoprotein and via receptor recognition and internalization of the complex the drug could be delivered intracellularly. It is also possible to target modified lipoproteins to the different cell types of the liver via modifications of the lipoprotein ( (an Berkel et al., 1986).

Although the transport into the liver has been described for a large number of drugs, only a few transport systems have been well defined and characterized; structure-transport relationships for separate carrier systems are not known in detail (cfr. kidney; Ullrich and Rumrich, 1988). Therefore, it is not yet possible to predict whether a (pro)drug will be transported actively into the liver. More basic research in this direction will have to be carried out.

The targeting of drugs to the liver is not usually a highly desirable goal, except in cases of, for instance, hepatic infections or malignancies. It seems more important to keep drugs out of the liver to avoid hepatotoxicity or metabolic activation. If it is attempted to target a prodrug to a tissue which is less highly perfused than the liver, it is particularly important to bear the transport and metabolic capabilities of the liver in mind.

Brain. The BBB is an effective shield of the brain against unwanted substances. The endothelial cells of the capillaries in the brain have epithelial-like tight junctions, there are hardly any intracellular spaces and pinocytosis is rare (Brightman, 1977). For these reasons, drugs or other circulating substances can only gain access to the brain by four different mechanisms (Pardridge, 1985): (a) pore mediation, a route which is only available for water; (b) lipid solubility (see above), which can only ensure transport if the molecules are not too large; (c) carrier mediated transport, a route used for the transport of water soluble nutrients; (d) receptor mediated transcytosis of circulating peptides via peptide-specific transport systems on both the lumenal and antilumenal membranes of brain capillaries (Pardridge et al., 1985; Pardridge, 1986).

So far, the following nutrient and hormone carrier systems have been charac- 
terized (Pardridge, 1979, 1983; Aoyagi et al, 1988; Kalaria a a, 1988; Oldendorf et al., 1988; Shimon et al., 1988; Spector, 1988; Tews et al., 1988; Tovar et al., 1988): hexose, monocarboxilic acid, neutral amino acid, amine, basic amino acid, nucleoside, purine base and thyroid hormone.

An example of improved delivery to the brain via carrier mediated transport is L-dopa (Bianchine, 1980). This prodrug enters the brain via the neutral amino acid carrier and is converted in the brain, but also in other tissues, to dopamine. In this case, no selectivity is observed, only an enhanced concentration of dopamine in the brain (compared to an i.v. administration of equimolar dopamine).

The peptide receptors can accomplish the transport of peptides across the $\mathrm{BBB}$ (Pardridge, 1986). This transport is called receptor mediated transcytosis. The following events are described to take place (Pardridge, 1986): receptor mediated endocytosis, diffusion through the cytoplasm and receptor mediated exocytosis. Receptors have so far been found for the following peptides: insulin-like growth factor 1 and 2, transferrin, atriopeptin and angiotensin II (Pardridge et al., 1985; Speth et al., 1985; Frank et al., 1986; Chabrier et al., 1987).

Both the carrier mediated and the receptor mediated transport systems are highly specific for their endogenous substrates. Three strategies for directing drugs to the brain seem possible: (a) designing a drug with both pharmacological activity and affinity for a nutrient carrier system, (b) designing a prodrug by coupling a nutrient or nutrient analogue to a drug, (c) designing a prodrug by coupling a drug to an endogenous peptide, for instance insulin or transferrin. A large problem seems to be that even if a prodrug has a reasonable affinity for a transport system at the $\mathrm{BBB}$ in vivo, the liver might extract and metabolise a substantial fraction of the circulating prodrug.

An elegant in vitro method to investigate the transport capabilities of the $\mathrm{BBB}$ is the use of bovine brain microvessel endothelial cell monolayers (Audus and Borchardt, 1987; van Bree et al., 1988).

Tumors. Differences in transport capabilities between tumor cells and normal tissue cells would provide an excellent opportunity to target (pro) drugs to tumor tissue. Some of the substances, of which the transport into tumors via carriers has been investigated are: methotrexate (Goldman, 1971; Sirotnak, 1981; Gewirz and Holt, 1985; Price et al., 1988) via the folate carrier system in murine leukemia cells and Ehrlich ascites tumor cells, and other folate analogues (Sirotnak et al, 1988); glutamine antimetabolites (6-diazo-5-oxo-l-norleucine and acivicin (Huber et al., 1988)); amino acids (McCormick and Johnstone, 1988); histamine (Nakaya and Tasaka, 1988); organic anions (di Virgilio et al., 1988).

In a recent review Sirotnak and Barrueco (1987) discussed the role of membrane transport in the pharmacologic action of nucleoside analogues. Erythrocytes and (perhaps) other mammalian cells possess a single nucleoside transport system which has a broad substrate specificity, but some other mammalian cells, including some tumor cells, possess more than one transport system. These authors found an enhanced transport of FAraA in murine tumor cells compared to proliferative 
intestinal epithelial cells, due to the existence of two nucleoside transport systems in the tumor: a highly saturable (low transport $\mathrm{K}_{\mathrm{m}}$ ) and a poorly saturable (high transport $\mathrm{K}_{\mathrm{m}}$ ) one, whereas the intestinal cells only possess the poorly saturable transport system. The highly saturable system offers possibilities for achieving site-specific transport. A combination of a nucleoside analogue as antitumor agent and a selective inhibitor of the general transport system (for protection of the non-tumor tissues) might cause tumor-selective transport and action.

Althougha large number of studies have been published on the transport of drugs into tumor cells, it requires more data on the existence and chracteristics of similar transport systems in other tissues if site-selectivity via tumor-selective transport is to be achieved.

A complicating factor in the accumulation of drugs in tumor cells is the presence of excretory transport systems. Such systems may be responsible for the multidrug resistance which can develop in the treatment of metastases (Gerlach et al., 1986; Gottesman and Pastan, 1988). Lonidamine can interfere with the active transport of adriamycin out of Ehrlich ascite tumor cells (Floridiet al., 1988) and thus enhance the uptake of adriamycin of these cells. Cytochalasin B and D inhibit the outward transport of vincristine and daunomycin in drug-resistent tumor cell lines (Tsuruo and Lida, 1986).

\subsubsection{Conclusion}

Most tissues have not been systematically investigated with respect to their transport capacities. The presence of some transport systems has been demonstrated in a large number of tissues, including glucose (Widdas, 1988), nucleosides (Plagemann et al., 1988), water-soluble vitamins (Rose, 1988). These transport systems may be suitable targets to achieve site-specific transport, if multiple systems are found with different transport characteristics, as is the case with the nucleoside transporters (Sirotnak and Barrueco, 1987).

It may be imagined that a prodrug can be targeted to, for instance, the myocardium, a tissue that is rich in glucose (Sokoloff et al., 1979; Wijns et al, 1988) and fatty acid (Hütter et al, 1984) transporter systems, by using a difference in substratespecificity between the myocardium and other tissues, and by profiting from the fact that the heart needs large quantities of these fuels. More investigations into the structure-transport relationships of substrates for the different carrier systems and a thorough comparison between the characteristics of the carriers from different tissues will have to be carried out if the targeting of prodrugs via a site-specific carrier system is to be successful. This requires the avallability of good in vitro test systems, such as freshly isolated or cultured tissue cells, perfused organs, tissue slices or the use of membrane vesicles. These are available for a number of tissues, but for other tissues they will have to be developed. 


\section{CONVERSION OF PRODRUGS}

In this thesis, it has already been stated that an optimal combination of sitespecific transport and site-specific conversion is one of the requirements for a tissue selective prodrug. It is not necessary for both to be $100 \%$ site-specific, but the combination should be optimal. The tissues that are metabolically most active are: liver, kidney, pancreas and tumor. Therefore, most site-specific drug delivery is directed to one of these tissues.

Primary requirements are that the prodrug is stable in the plasma and that it has no large first-pass metabolism (since for chronic administration and patient acceptance the prodrug should preferabely be orally administered). These requirements impose a number of limitations upon prodrugs. For instance, gludopa $(\gamma-\mathrm{L}$ glutamyl-L-dopa) is an efficient renal vasodilator with few side-effects (Wilk et al., 1978; Minard et al., 1980; Jeffrey et al, 1988a,b,c), but its availability upon oral administration is poor. The mechanism of the renal selectivity of gludopa is not yet understood. This prodrug is converted by $\gamma$-glutamyltranspeptidase to L-dopa and subsequently by a decarboxylase to dopamine. The results obtained with $\gamma$-glutamylsulfamethoxazole (chapter 5) indicate that the $\gamma$-glutamyl prodrugs are not transported into the tubular cells. Possibly the renal selectivity of gludopa is due to the high extraction ratio of the released dopamine by the kidney and the short halflife time of dopamine in vivo.

Another dopaminergic prodrug, ibopamine ( $N$-methyl-3,4-O-diisobutyryl dopamine, Casagrande et al., 1985), is orally available but is not kidney-selective, due to its hydrolysis by circulating esterases. Therefore, it is marketed as an "inodilator", a drug with both positive inotropic and renal vasodilatory action for the treatment of congestive heart failure.

Epinine-4-O-phosphate, a prodrug of epinine ( $\mathrm{N}$-methyl dopamine), does possess renal vasodilatory action at doses where no cardiac side effects are observed (Casagrande et al., 1988). This drug was developed on the basis of the relatively high alkaline phosphatase activity in the kidney as a renal selective prodrug (see chapter 1.4.6). This enzyme is associated with the brushborder membrane of the tubules (Guder and Ross, 1984). It seems most probable that the selectivity of this prodrug is mainly due to a relatively high conversion in the kidney, combined with a high affinity of the kidney for the released drug.

An example of a prodrug which does not owe its site-specificity to a site-specific enzymatic conversion, but which selectivity is due to an acid-catalysed activation is omeprazol (Wallmark, 1986; see also chapter 1.4.5).

However, site-specific conversion due to an elevated level of a particular enzyme in other tissues than liver or kidney will generally be hard to achieve because of the large blood flow and metabolic activity in the liver and kidney. In that case, the use of a selective transport system in the target tissue and a more generally distributed enzyme as a route to achieve site-selectivity appears to give a better chance of success. 
Based upon its high blood flow, transport capabilities and high levels of metabolic enzymes, the kidney seems the pre-eminent tissue for drug targeting via prodrugs.

\section{8,4 DRUG-RECEPTOR INTERACTION}

When a specific transport system is used to deliver a drug intracellularly, it is necessary for the target receptor or enzyme to be located intracellularly as well. If the target of the active drug is not located intracellularly, as is the case with CGP 22979 , extra metabolic features are necessary to restrict the (side)effect(s) of the drug to the desired site, for instance a very short half-life compared to the rate of leakage from the tissue (see chapter 2).

The chance to enhance site specificity via a tissue-specific intracellular receptor by means of prodrugs seems low. If a receptor is tissue specific, an active drug can usually be designed which is able to reach the target site and interact with the receptor; no prodrug is needed. The brain is an exception to this because of the efficiency of the BBB; a lipophilic prodrug will be a solution in that case.

Many of the intracellularly occuring biochemical processes, such as second messenger systems, DNA-transcription, RNA-translation and post-translational protein changes are not tissue-specific. When a pharmacological intervention in one of these processes at a specific (pathologic) tissue is needed, targeting via a specific transport utilizing prodrug can be a solution.

\subsection{SITE RETENTION}

The necessity of retention or clearance of the active drug by the target tissue once it is released from the prodrug has been reviewed extensively by Stella and Himmelstein (Stella and Himmelstein, 1980, 1982; Stella et al., 1985; see also chapter 1.4.3). In short, an effective site-specific prodrug cannot be made of an active drug which has good access to the tissue, i.e. when the drug can pass biological membranes at a reasonable rate. In that case, the active drug will redistribute from the site of formation and even if all other variables are perfect, i.e. absolute site-specific conversion and good access of the prodrug to the target site, only a minimal benefit of the prodrug can be expected. If the parent drug has poor access to the target site, on the other hand, the use of such a prodrug would result in large 
advantages. These observations imply, as stated by Stella and Himmelstein (1980), that most currently used therapeutic agents will not benefit much from further targeting via prodrugs, for the very fact that they are already capable of reaching their site of action.

\subsection{CLINICAL POSSIBILITIES FOR KIDNEY-SELECTIVE PRODRUGS}

When a disease is due to pathologic processes which are located primarily in the kidney, the targeting of drugs to the kidney via prodrugs is clinically highly relevant. The effect on the kidney can be enhanced by increasing the local drug concentration; the side effects can be minimized by reducing systemic drug concentrations. Targeting of drugs to the kidney offers in particular new possibilities to the pharmacologic treatment or prevention of the following diseases: (i) (acute) renal failure (ARF); (ii) kidney transplantation; (iii) focal glomerulosclerosis.

ad (i). An increase in renal blood flow can not only protect against ARF and acute tubular necrosis (ATN), but can also be used as part of the treatment of ARF (Nortman and Franklin, 1984; Kjellstrand et al., 1988). A general vasodilation is not wanted because of the blood pressure lowering effect, so a renal selective vasodilation is requested. Besides a renal vasodilatory action, dopamine also has a positive inotropic effect and is effective in the treatment of ARF (Nortman and Franklin, 1984). However, dopamine is not orally applicable, which is nescessary in a profylactic therapy for ARF or ATN. Gamma-glutamyl dopa (Gludopa) is a renal selective vasodilator prodrug (Minard et al., 1980; Jeffrey et al., 1987), but is not orally effective either. Epinine-4-O-phosphate is a prodrug with a renal selective vasodilatory action, and is orally applicable (Casagrande et al., 1988), but it has to be given in relatively high doses compared to dopamine. New renal selective vasodilators are needed and the prodrug approach seems to be the most profitable way to reach this goal.

ad (ii). Local treatment with immunosuppressive agents has more beneficial effects than systemic administration of the same compounds, as demonstrated by Ruers et al. (1986, 1987) and Gruber et al. (1988). In these experiments, a local infusion via an osmotic minipump was given in the suprarenal artery of rats. At equal dose and constant systemic plasma concentrations of prednisolon, the renal concentrations of prednisolon were twice as high following an intrarterial infusion compared to an intravenous infusion. In clinical practice, it would be much easier if the drug could be administered orally and had a kidney selective effect. A prodrug of an appropriate immunosuppressant seems to be a promising candidate for reducing the allograft rejection and thus improve the succes rate of renal transplantation. 
ad (iii). Focal and segmental glomerulosclerosis (FGS) can be a complication or the end-stage of several pathologic states of the kidney, such as primary nephrotic syndrome, glomerulonephritis, diabetes mellitus, a complication of kidney transplantation or a result of drug (mis)use (Brenner et al., 1982; Schnaper and Robson, 1988 and references cited therein; Diamond and Karnovsky, 1988; Leunissen et al. 1988; Weening et al., 1988). A number of factors is involved in the developrnent of FGS, such as proteinuria (Brenner et al., 1982), glomerular hypertension (Anderson et al., 1985; Meyer et al., 1987), hyperlipidemia (Appel et al., 1985), mesangial deposition of macromolecules (Grond et al., 1982,1985), glomerular hypertrophy (Yoshida et al., 1989), inflammation processes (Kreisberg et al., 1982) and intraglomerular activation of blood clotting factors (Adler, 1988).

Several of these processes can be affected pharmacologically. For instance, NSAID's could exert a beneficial action at two levels. They inhibit the prostaglandin synthesis in the kidney, which is involved in the regulation of the renal hemodynamics (Badr et al., 1989; Bullivant et al., 1989; Livio et al., 1989; Schlondorf et al., 1989); and they can reduce proteinuria (Golbetz et al., 1989).

Inhibition of the angiotensin-converting enzyme (ACE) causes a decrease of the systemic blood pressure, which slows down the development of FGS (Anderson $e t$ al., 1986, Meyer et al., 1986,1987), but also has an effect on the mesangial cells (Bulger and Hebert, 1988). Mesangial cells contract under the influence of angiotensin II. A locally acting ACE-inhibitor could discriminate between the effect of a decrease in systemic blood pressure and the effect of a decrease in intraglomerular pressure through local ACE-inhibition on the progress on FGS.

These two examples show that kidney-selective prodrugs may have a beneficial effect in the treatment of progressing FGS. If $\mathrm{N}$-acetyl-y-glutamyl prodrugs are used for kidney-selective delivery of the drugs, the conversion of the prodrug to the active drug takes place in the tubular cells and not in the glomeruli. This might impose limits on the selectivity of these prodrugs.

\subsection{REFERENCES}

Adler, S. Inhibition of rat glomerular visceral epithelial cell growth by heparin. Am. J. Physiol. 255: F781-F786, 1988.

Anders, M.W., Lash, L., De Kant, W., Elfarra, A.A, and Dohn, D.R., Biosynthesis and biotransformation of glutathione S-conjugates to toxic metabolites. CRC Critical Rev. Toxicol. 18: 311-341, 1988.

Anderson, S, Meyer, T.W., Rennke, H.G. and Brenner, B.M. Control of glomerular hypertension limits glomerular injury in rats with reduced renal mass. J. Clin. Invest. 76: 612-619, 1985.

Anderson, $S_{\text {, }}$ Rennke, H.G. and Brenner, B.M. Antihypertensive therapy must control glomerular lyppertension to limit glomerular injury. J. Hypertension 4 (suppl. 5): 242-244, 1986.

Appel, G.B., Blum, C.B., Chien, S., Kunis, C.L. and Appel, A.S. The hyperlipidemia of the nephrotic syndrome. Relation to plasma albumin concentration, oncotic pressure and viscosity. New Engl. 
J. Med, 312: 1544-1548, 1985.

Aoyagi, M., Agranoff, B.W., Washburn, L.C. and Smith, Q.R. Blood brain barrier transport of 1-aminocyclohexane carboxylicacid, a non-metabolizable aminoacid for in vivo studies of brain transport. J. Neurochem. 50: 1220-1225, 1988.

Audus, K.L. and Borchardt, R.T. Bovine brain microvessel endothelial cell monolayers as model system for the blood-brain barrier. In: Biological approaches to the controlled delivery of drugs (ed.: Juliano, R.L.). Ann. N. Y. Acad. Sci. 507: 9-18, 1987.

Badr, K.F, DeBoer, D.F., Takahashi, K., Harris, R.C., Fogo, A. and Jacobson, H.R. Gilomerular responses to platelet-activating factor in the rat: role of thromboxame A2. Am. J. Physiol. 256: F35-F43, 1989 .

Bekersky, I., Renal excretion. J. Clin. Pharmacol. 27: 447-449, 1987.

Bencini, A.F, Mol, W.E., Scaf, A.H., Kersten, U.W., Wolters, K.T, Agoston, S. and Meijer, D.K.F., Uptake and excretion of vercuronium bromide and pancuronium bromide in the isolated perfused rat liver. Anesthesiology 69:487-492, 1988.

Berndt, W.O. Organic base transport: a comparative study. Pharmacology 22* 251-262, 1981.

Bianchine, J.R. Drugs for Parkinson's disease. In: The pharmacological basis of therapeutics (eds.: Gilman, A.G., Goodman, L.S. and Gilman, C.). mcMillan, New York, 1980, pp. 475 487.

Bodor, N. and Brewster, M.E. Problems of delivery of drugs to the brain. Pharmacol. Therap. 19: $337-386,1983$.

Bodor, N., Shek, E. and Higuchi, T. Delivery of a quaternary pyridinium salt across the blood-brain barrier by its dihydropyridine derivative. Science 190: 155-156, 1975.

Bodor, N., Shek, E. and Higuchi, T. Improved delivery through biological membranes. 1. Synthesis and properties of $\mathrm{N}$-methyl-1,6-dihydropyridine-2-carbaldoxime, a prodrug of $\mathrm{N}$-methylpyridinium-2-carbaldoxime chloride. J. Med. Chem. 19: 102-107, 1976.

Boyer, J.L. New concepts of mechanisms of hepatocyte bile formation. Physiol. Res. 60: 303-326, 1980.

Brater, D.C. The pharmacological role of the kidney. Drugs 19:31-48, 1980.

Brenner, B.M., Meyer, T.W. and Hostetter, T.H. Dietary protein intake and the progressive nature of kidney disease. N. Engl. J. Med. 307: 652-659, 1982.

Brightman, M.W. Morphology of blood brain interfases. Exp. Eye Res. suppl. 1-25, 1977.

Brosnan, J.T. The role of the kidney in aminoacid metabolism and nutrition. Can.J. Physiol. Pharmcol. 65: $2355-2362,1987$.

Bulger, R.E. and Hebert, S.C. Structure-functional relationships in the kidney. In: Diseases of the kidney (eds.: R.W. Schrier and C.W. Gottschalk), 4th edition, Little-Brown, Boston, 1988, p. 13.

Bullivant, E.M.A., Wilcox, C.S. and Welch, W.J. Intrarenal vasoconstriction during hyperchloremia: rolle of thromboxane. Am. J. Physiol. 256: F152-F157, 1989.

Bundgaard, H. Falch, E., Larsen, C., Mosher, G.L. and Mikkelson, T.J. Pilocarpine esters as novel sequentially labille pilocarpine prodrugs for improved ocular delivery. Ju. Med. Chem. 28: 979-981, 1985.

Bundgaard, H., Falch, E., Larsen, C. and Mikkelson, T.J. Pilocarpine prodrugs. I. Synthesis, physiochemical properties and kinetics of lactonization of pillocarpic acid esters. J, Pharm. Sci. 75: $36-43,1986$.

Casagrande, $C_{\text {. }}$ Ghirardi, $\mathrm{P}$. and Marchetti, G. Ibopamine. New drugs anmual: Cardiovascular drugs (ed.: Scriabine, A.), vol. 3. Raven Press, New York, 1985, pp. 173-196.

Casagrande, $C_{n,}$ Merlo, L.x Santangelo, $F_{\text {. }}$, Doggi, F., Gerli, F., Pocchiari, Fo, Pataccini, R. and Semeraro, $\mathrm{C}$. SIM 2055, $\mathrm{N}$-methyl dopamine 4-O-phosphate, an orally active renal vasodilator. Communication presented at the Xth international symposium on medicinal chemistry, Budapest, Hungary, 15-19 aug. 1988.

Cefalu, W.T. and Pardridge, W.M. Restrictive transport of a lipid soluable peptide (cyclosporin) through the blood-brain barrier. J. Neurochem. 45: 1954-1956, 1985.

Chabrier, P.C., Roubert, P., and Braquet, P. Specific binding of atrial natriuretic factor in brain microvessels. Proc. Nat. Acad. Sici. USA 84: 2078-2081, 1987.

Commandeur, J.N.M., Brakenhoff, J.P.G., De Kanter, F.J.J. and Vermeulen, N.P.E. Nephrotoxicity of mercapturic acids of three structurally related 2,2 -diffuoroethylenes in the rat. Biochem. Pharmacol. 37: 4495-4504, 1988. 
Diamond, JR. and Karnovsky, M.J. Focal and segmental sclerosis: analogies to atherosclerositis. Kidney Int. 33: 917-924, 1988.

Di Virgilio, $\mathrm{F}_{\text {, Fasolato }} \mathrm{C}$. and Steinberg. T.H. Inhibitors of membrane transport system for organic anions block furd-2 excretion from PC12 and N2A cells. Biochem. J. 256: 959-963, 1988.

Floridi, A., Gambacurta, A., Bagnato, A., Bianchi, C., Paggi, M.G. Silvertsrini, B. and Caputo, A. Modulation of adriamycin uptake by lonidamine in Ehrlich ascites tumor cells. Exp. Mol. Pathol. 49: 421-431, 1988.

Frank, H.J.L. Partridge, W.M. Morris, W.L, Rosenfeld, R.G. and Choi, T.B. Binding and intermalization of insulin and insulin-like growth factors by isolated brain microvessels. Diabetes 35 : $65466151,1986$.

Ganapathy, V., Medicino, J. and Leibach, F.H. Evidence for a dipeptide transport system in renal brush border membranes from rabbit. Biochim. Biophys. Acta 642: 381-391, 1981.

Gerlach, J,H, Kartner, $\mathbb{N}_{\text {, }}$ Bell, D.R. and Ling, V. Multiple drug resistance. Cancer surveys 5: 25-46, 1986.

Gewirz, D.A. and Holt, $S$, A. Protein binding as a component of drug interaction in cellular pharmacokinetic studies. Biochem. Pharmacol. 34: 747-754, 1985.

Gewirz, D.A., Randolph, J.K. and Goldman, I.D. Potent bile salt and organic anion inhibition of methotrexate uptake and accumulation in the freshly isolated rat hepatocyte. Cancer Res. 40: $1852-1857,1980$.

Golbetz, H., Black, V., Shemesh, O. and Myers, B.C. Mechanism of the antiproteinuric effect of indomethacin in nephrotic humans. Am. J. Physiol. 256: F44-F51, 1989.

Goldman, I.D. The characteristics of the membrane transport of amethopterin and the naturally occurring folatets. Ann. New York Acad. Sci. 186: 400-422, 1971.

Gottesman, M. and Pastan, l. Resistance to multiple chemotherapeutic agents in human cancer cells. Trends Pharmacol. Sci. 9: 54-58, 1988.

Griffith, O.W., Bridges, R.J. and Meister, A. Transport of $\gamma$-glutamyl amino acids: role of glutathione and $\gamma$-glutamyl transpeptidase. Proc. Nat. Acad. Sci. USA 76: 63119-6322, 1979.

Grond, J., Schilthuis, M.S., Koudstaal, J. and Elema, J.D. Mesangial function and glomerular sclerosis in rats after unilateral nephrectomy. Kidney Int. 22: 338-343, 1982.

Grond, J., Koudstaal, J. and Elema, J.D. Mesangial function and glomerular sclerosis in rats with aminonucleoside nephrosis. Kidney Int. 27: 405-410, 1985.

Gruber, S.A., Cippole, R.J., Canafax, D.M., Erdmann, G.R., Burke, B.A., Rabatin, J.T., Hynes, P.E., Ritz, J.A., Gould, F.H., Ascher, N.L., Simmons, R.L. and Hrushesky, W.J.M., An implantable pump for intrarenal infusions of immunosuppressants in a canine autotransplant model. Pharmac. Res. 5: 781-785, 1988.

Guder, P.K. and Ross, B.D., Enzyme distribution along the nephron. Kidney Int. 26: 101-111, 1984.

Habberle, D.A. Characteristics of p-aminohippurate transport in the mammelian kidney. In: Renal transport of organic solutes (eds.: Greger, R., Lang, F $_{\text {. }}$ and Silbernagl, S.), Springer verlag, Brelin, 19981 , pp 189-209.

Hesse, G.W., Jacob, J.N. and Shashoua, V.E. Uptake in brain and neurophysiological activity of two lipid esters of $\gamma$-aminobutyric acid. Neuropharmacology 27: 637-640, 1988.

Huber, K.R., Rosenfeld, H. and Roberts, J. Uptake of glutamine antimetabolites 6-diazo-5-oxo-Lnorleucine (DON) and acivicin in sensitive and resistant tumor cell lines. Int. J, Cancer 41: 752-755, 1988.

Hutter, J.F. Piper, H.M. and Spieckermann, P.G. Mycoardial fatty acid oxidation: evidence for an albumin-receptor mediated membrane transfer of fatty acids. Basic Res. Cardiol. 79: 274-282, 1984.

Jeffrey, R.F., MacDonald, T.M. and Lee, M.R. A comparison of the renal actions of $\gamma$-L-glutanyl-Ldopa and $\gamma=\mathrm{L}$-glutamyl-L-tyrosine in normal man. Clin. Sci. 74: 37-40, 1988a.

Jeffrey, R.F., MacDonald, T.M., Marwick, K. and Lee, M.R. The effect of carbidiopa and indometacin on the renal response to $\gamma$-L-glutanyl-L-dopa in normal man. Br. J. Clin Pharmacol. 25; 195-201, $1988 \mathrm{~b}$.

Jeffrey, R.F., MacDonald, T.M., Brown, J., Rae, P.W.H. and Lee, M.R. The effect of lithium on the renal response to the dopamine prodrug gludopa in normal man. Br. J. Clin. Pharmacol. 25: 
$725-732,1988 \mathrm{c}$.

Kalaria, R.N., Gravina, S.A., Schmidley, J.W., Perry, G. and Harik, S.I. The glicose transparter of the human brain and blood brain barrier. Ann. Neurol. 24: 757-764, 1988.

Kates, R.E., Tozer, T.N. and Saby, D.N. Increased methotrexate toxicity due to soneurrent probenecid administration. Biochem. Pharmacol. 25: 1485-88, 1976.

Kates, R.E. and Tozer, T.N. Biliary secretion of methotrexate in rats and its inhibition by probenecid. J. Pharm. Sci. 65: 1348-1352, 1978.

Kramer, R.A., Fouteman, G., Greene, K.E. and Reed, D.J., Nephrotoxicity of S-(2-chloroethyl)glutathione in the Fischer rat: evidence for $\gamma$-glutamyltranspeptidase-independent uptake by the kidney. J. Pharmacol. Exp. Ther. 242; 741-748, 1987.

Kramer, W., Leipl, I, Petzoldt, E. and Gerbig, F. Characterization of the transport system for $\beta$-lactam antibiotics and dipeptides in rat renal brush border membrame vesicles by photoaffinity labeling. Biochim. Biophys. Acta 939: 167-172, 1988.

Kreisberg, J.I., Karnovsky, M.J. and Levine. L. Prostaglandin production by homogenous cultures of rat glomerular epithelial and mesangial cells. Kidney Int. 22: 355-359, 1982.

Lash, L.H. and Jones, D.P. Transport of glutathione by renal basal lateral membrane vesicles. Biochem. Biophys. Res. Comm. 112: 55-60, 1983.

LeHir, M. and Dubach, U.C. Sodium gradient energized concentrative transport of adenosine in renal brush border vesicles. Pflügers Arch. 401: 58-63, 1984.

LeHir, M. and Dubach, U.C. Uphill transport of pyrimidine nucleasides in renal brush border vesicles. Pflügers Arch. 404: 238-243, 1985.

Leunissen, KJ., Bosman, F.T, Kootstra, G., Van den Berg-Loonen, P.M. and Van Hooff, J.P. Focal glomerulosclerosis in neonatal kidney grafts. Nephron 51: 29-31, 1988.

Livio, M., Benigni, A., Zoja, C., Begnis, R., Morelli, C., Rossini, M., Garattini, S. and Remuzzi, G. Differential inhibition by aspirin of platelet thromboxane and renal prostaglandins in the rat. $J$. Pharmacol. Exp. Ther. 248: 334-341, 1989.

McCormic, J.I. and Johnstone, R.M. Simple and effective purification of a $\mathrm{Na}^{+}$-dependent anninoacid transport system from Ehrlich ascites cell plasma membrane. Proc. Nat. Acad. Sci. USA 85: 7877-7881, 1988.

Meijer, D.K.F., Blom, A., Weitering, J.G. and Hornsveld, R., Pharmacokinetics of the hepatic transport of organic anions: influence of extra- and intrahepatic binding on hepatic storage of dibromosulfophtalein and interactions with indocyanine green. J. Pharmacokin. Biopharm. 12: 43-65, 1984.

Meyer, T.W., Anderson, S., Rennke, H.G. and Brenner, B.M. Reversing glomerular hypertension stabilizes established glomerular injury in renal ablation. J. Hypertension 4 (suppl, 5): \$239-241, 1986.

Meyer, T.W, Anderson, S., Rennke, H.G. and Brenner, B.M. Reversing glomerular hypertension stabilizes established glomerular injury. Kidney Int. 31: 752-759, 1987.

Minard, F.N., Grant, D.S., Cain, J.C., Jones, P.H. and Kynch, J. Metabolism of $\gamma$-glutantyl dopamide and its carboxylic acid esters. Biochem. Pharmacol. 29:69.75, 1980.

Mol, W.E., Folkkema, G.N., Weert, B. and Meijer, D.K.F., Mechanisms for the hepatic uptake of organic cations. Studies with the muscle relaxant vecuronium in isolated rat hepatocytes. $J$. Pharmacol. Exp. Ther. 244." 268-275, 1988.

Möller, J.V, and Sheikh, M.I. Renal organic anion transport systems: pharmacological, physiological and biochemical aspects. Pharmacol. Rev. 34: 315-358, 1983.

Monks, T.J., Lau, S.S., Highet, R.J. and Gillette, J.R. Glutathione conjugates of 2-bromoliydroquinome are nephrotoxic. Drug Metab. Dispos. 13: 553-559, 1985.

Monks, T.J., Lau, S.S. Renal transport processes and glutathione conjugate mediated nephrotoxicity. Drug Metab. Dispos. 15: 437-441, 1987.

Murer, H. Renal transport of amino acids: membrane mechanism. Contrib. Nephrol. 33: 14-28, 1982.

Nakaya, N. and Tasaka, K. Histamine incorporation into murine myeloblasts and promyelocytes. Biochem. Pharmacol. 37: 4523-4530, 1988.

Nelson, J.A., Vidale, E. and Enigbokan, M. Renal transepithelial transport of nucleosides. Drug Metab. Dispos. 16: 789-792, 1988. 
Oldendorf, W.H., Crane, P.D., Brann, L.D., Gotschalk, E.A. and Diamond, J.M. pH dependence of histidine affinity for blood brain barrier carrier transport systems for newtral and cationic amino acids. J. Neurochem. 50: 857 861 , 1988.

Pardridge, W.M. Carrier mediated transport of thyroid hormones through the rat blood brain barrier: primary role of albumin bound hormone. Endocrinology 105: 605-612, 1979.

Pardridge, WM. Brain metabolism: a perspective from the blood-brain barrier. Physiol. Rev. 63: $1481-1535,1983$.

Pardiddge, W.M. Strategies for drug delivery through the blood brain barrier. In: Directed drug dellivery (edls: Borchard, R.T. Reptan, A.J, and Stella, V.J.). Humana, New Jersey, 1985, pp. 83-96.

Pardridge, W.M. Receptor mediated peptide transport through the blood brain barrier. Endocrinol. Rew. 7: 314.330, 1986 .

Pardridge, W.M. Recent advances in blood brain barrier transport. Ann. Rev. Pharmacol. Toxicol. 28: 25-39, 1988 .

Pardridge, W.M. Eisenberg, J. and Yang, J. Human blood brain barrier insulin receptor. J. Neurochem, 44: 1771-1778, 1985.

Park, C.H. Transcellular processing of proteins in renal tubular epithelium. Ann. New York. Acad. Sci. 507: 351-3.52, 1987.

Plageman, P.G.W., Wohlhueter, R.M. and Woffendin, C. Nucleoside and nucleobase transport in animal cells. Biochim, Biophys. Acta 947: 405-443, 1988.

Price, E.M., Ratnam, M., Rodeman, K.M. and Freisheim, J.H. Characterization of the methotrexate transport pathway in Murine $L 1210$ leukemia cells: involvement of a membrane receptor and a cytosolic protein. Biochemistry 27: 7853-7858, 1988.

Rankin, B.B. and Curthoys, N.P. Evidence for the renal paratubular transport of glutathione. FEBS Letters 147: 193-196, 1982.

Rennick, B.R. Renal tubule transport of organic cations. Am. J. Physiol. 240: F83-F89, 1981.

Röigaard-Petersen, H. Jacobsen, C. and Sheikh, M.I. Transport of L-proline by luminal membrane vesicles from pars secta of rabbit proximal tubule. Am. J. Physiol. 254: F628-F633, 1988.

Rose, R.C. Transport of ascorbic acid and other water soluble vitamins. Biochim. Biophys. Acta 947: $335-366,1988$.

Ruers, T.J.M., Buurman, W.A., Smits, J.F.M., Van der Linden, C.J., Van Dongen, J.J., Struyker Boudier, H.A.J., Kootstra, G. Local treatment of renal allographs, a promising way to reduce the dosage of immunosuppressive drugs. Transplantation 41: 156-159, 1986.

Ruers, T.J.M., Buurman, W.A., Van Boxtell, C.J., Van der Linden, C.J., Kootstra, G. Immunohistological observations in rat kidney allografts after local steroid administration. J. Exp. Med. 166: 1205-1210, 1987.

Russel, F.G.M. Renal clearance of anionic drugs.. Thesis. Nijmegen 1988, pp 15-43.

Russel, F.G.M., Wouterse, A.C. and Van Ginneken, C.A.M., Renal clearance of substituted hippurates in the dog. I. Benzoylglycine (hippurate) and methyl-substituted benzoylglycines. J. Pharmacol. Exp. Therap. 248: 428-435, 1989a.

Russel, F.G.M., Wouterse, A.C. and Van Ginneken, C.A.M., Renal clearance of substituted hippurates in the dog. It. 4-Amino-, hydroxy-and methoxy-substituted benzoylglycines. J. Pharmacol. Exp. Therap. 248: 435-446, 1989b.

Saier, M.H., Daniels, G.A., Boerner, P. and Lin, J. Neutral amino acid transport systems in animal cells: potential targets of oncogene action and regulators of celular growth. J. Membrane Biol. 104: $1-20,1988$.

Schaeffer, V.H. and Stevens, J.L. Mechanism of transport for toxic cysteine conjugates in rat kidney cortex membrane vesicles. Mol . Pharmacol. 32: 293-298, 1987.

Schalli, $\mathrm{C}_{\text {, }}$ Schild, L., Overney, J. and Roch-Ramel, F. Secretion of tetraethylammonium by proximal tubules of rabbit kidneys. Am. J. Physiol 245: F238-F246, 1983.

Schlondorff, D., Singhal, P., Hassid, A., Satriano, J.A. and DeCandido, S. Relationship of GTP-binding proteins, phospholipase $\mathrm{C}$ and $\mathrm{PGE}_{2}$ synthesis in rat glomerular mesangial cells. Am. J. Physiol. 256: F171-F178, 1989.

Schnaper, H.W. and Robson, A.M. Nephrotic syndrome: minimal change disease, focal glomerulosclerosis and related diseases. In: Diseases of the kidney (eds.: R.W. Schrier and C.W. Gottschalk), 
Little-Brown, Boston, 4 th ed. 1988, pp 1949-2004.

Schrader, W.P., Miczek, A.D, West, C.A. and Samsonof, W.A. Evidence for receptor mediated uptake of adenosine deaminase in rabbit kidney. J. Histochem. Cytochem. 36: 14811487, 1988.

Shashoua, V.E., Jacob, J.N., Ridge, R., Campbell, $A$ and Baldessorini, $\mathbb{R}$. ., $\gamma$-aminobutyric acid esters. I. Synthesis, brain uptake and pharmacological studies of aliphatic and steroid esters of $\gamma$-aminobutyric acid. J. Med. Chem. 27: 659-664, 1984.

Shimada, H., Moewes, B. and Burckhardt; G. Indirect compling to $\mathrm{Na}^{+}$of p-aminohippuric acid uptake into rat renal basolateral membrame vesicles. Am. J. Physiol. 253: F795-F801, 1987.

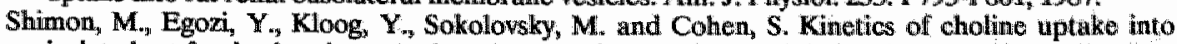
isolated rat forebrain microvessels: evidence of endocrine modullation. J. Neurochem. 50: 17191724,1988 .

Sirotnak, F.M. and Barrueco, J,R. Membrame transport and the antineoplastic action of nucleoside analogues. Cancer Metastasis Rev, 6: 459-480, 1987.

Sirotnak, F.M., Moccio, D.M., and Yong, C.W. Increased accumulation of methotrexate by nutine tumor cells in vitro in the presence of probenecid which is mediated by a preferential inlibition of efflux. Cancer Res. 41: 966-970, 1981.

Sirotnak, F.M., Otter, G.M., Piper, J.R. and DeGraw, J.I. Analogs of tehahydrofolate directed at folate-dependent purine biosynthetic enzymes. Characteristics of mediated entry and transport related resistance in L1210 cells for 5,10 dideazate-tetrahydrofolate and two 10-alkyl derivatives. Biochem. Pharmacol. 37: 4775-4777, 1988.

Skopicki, H.A., Fisher, K, Zikos, D., Flouret, G., Bolch, R., Kubillus; S. and Peterson, D.R. Carrier mediated transport of pyroglutamyl histidine in renal brush border membrane vesicles. Am. $J$. Physiol. 255: C822-C827, 1988.

Sokolof, L., Reivich, M., Kennedy, C., DesRosiers, M.H., Patlak, C.S., Pettigrew, K.P., Sakurada, O. and Shinohara, $\mathrm{M}$. The $\left.1^{14} \mathrm{C}\right]$ deoxyglucose method for the measurement of local cerebral glucose utilization: theory, procedure and normal values in the conscious and anesthetized albino rat. $J$. Neurochem. 28: 897-916, 1977.

Somogyi, A. New insights into the renal secretion of drugs. Trends Pharmacol. Sci. 8: 354-357, 1987.

Sorrentino, D., Licko, V., Weisiger, R.A., Alpini, G. and Berk, P.D. Phenobarbital specifically increases the hepatocellular uptake of sulfobromophtalein-glutathione. Biochem. Biophys. Res. Comm. 149: 921-926, 1987.

Spector, R. Hypoxanthine transport and metabolism in the central nervous system. I. Neurochem. 50: 969-978, 1988.

Speth, R.C. and Harik, S.I. Angiotensin II receptor binding sites in brain microvessels. Proc. Nat. Acad. Sci. USA 82: 6340-6343, 1985.

Stacey, N.H. Effects of chlorpromazine on taurocholate transport in isolated rat hepatocytes. Biochem. Pharmacol. 37: 4129-4134, 1988.

Stella, VJ. and Himmelstein, K.J. Site-specific drug delivery. J. Med. Chem. 23: 1275-1282, 1980.

Stella, V.J. and Himmelstein, K.J. Critique of prodrugs and site-specific drug delivery. In: Optimalization of drug delivery (eds.: Bundgaard, H., Hansen, A.B., Kofod H.). Munksgaard, Copenhagen, 1982 , pp. $134-153$.

Stella, V.J., Charman, W.N.A., Naringrekar, V.H. Prodrugs. Do they have advantages in clincial practice? Drugs 29: 455-473, 1985.

Tarloff, J.B. and Brand, P.H. Active tetraethylammonium uptake across the basolateral membrane of rabbit proximal tubule. Am. J. Physiol. 251: F141-F149, 1986.

Tazuma, S. Barnhart, R.I., Reeve, L.E. Tokumo, H. and Holzbach, R. T. Biliary secretion of organic anions in the dog. Association with defined lipid particles. Am. J. Physiol. 255: G745-G751, 1988.

Tejani-Butt, S.M., Hauptmann, M., DiMello, A., Frara, A., Marcoccia, J.M. and Brunswick, D.J. Evaluation of mono- and dibenzoyl esters of dopamine as potential prodrugs for dopamine in the central nervous system. Naunyn Schmiedeberg's Arch. Pharmacol. 338: 497-503, 1988.

Terasaki, $T_{\text {, }}$ Tamai, $\mathbf{I}_{\text {, }}$ Takanosu, $K_{\text {, }}$ Nakashima, E. and Tsuji, A. Kinetic evidence for a common transport route of benzylpenicillin and probenecid by freshly prepared hepatocytes in rats. Infuence of sodium ion, organic anions, amino acids and peptides on benzylpenicillin uptake. J. Pharmocobiodyn. 9: 18-28, 1986. 


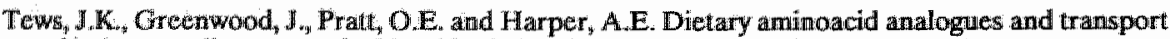
of lysine or waline actoss the blood brain barrier in rats. J. Nutrition $118: 756-763,1988$.

Towar, $A_{1}$, Tewt, I.K. Torres, $N$, and Harper, A. E. Some characteristics of theonime transport across the blowd brain barrier of the rat. J. Newrochem. 51 : 1285-1293, 1988.

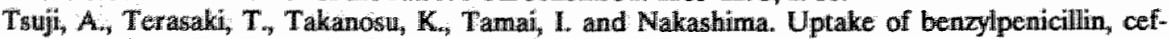
piramide and cefazolin by freshly prepared rat hepatocytes. Evidence for a carrier-mediated traneport system. Biochem. Pharmacol. 35: 151-158, 1986.

Tsuruo, T, and Lida, H. Effects of cytochallasins and colchicine on the accumulation of daunomycin and vineristine in drug resistant tumor cells. Biochem. Pharmacol. 35: 1087-1090, 1986.

Ulrich, $K$ J and Rumrich, G. Contraluminal transport systems in the proximal renal tubule inwolved in secretion of organic anions. Am. J. Physiol. 254: F453-F462, 1988.

Ulrich, K.J., Rumrich, $G_{\text {. }}$ and Klöss, S. Contraluminal para-aminohippurate (PAH) transport in the proximal tubule of the rat kidney. Pfligers Archi $413_{*}^{*} 134-146,1988$.

Van Berkel, TJ.C., Kruijt, J.K., Harkes, L, Nagelkerke, J.F., Spanjer, H. and Kempen, H-J.M. Receptor dependent targeting of native and modified lipoproteins to liver cells. In: Site-specific drug delivery (eds Tomilinson, $\mathrm{E}_{x, \mathrm{y}}$ Davis, S.S.) John Willey, Chichester, 1986, pp 49-68.

Van Bree, J.B.M.M, Audus, K.L. and Borchardt, R.T. Carrier-mediated transport of baclofen across monolayers of bovine brain endothelial cells in primary culture. Pharm. $\mathbb{R}$ es. $5 * 369-371,1988$.

Van Ginneken, C.A.M. and Russel, F,G.M., Saturable pharmacokinetics in the renal excretion of drugss. Clin. Pharmacokin. 16: 38-54, 1989.

Waldstein, B., Mechanism of action of omeprazole.Scand. J. Gastroenterol. 21 (suppl 118): 11-16, 1986.

Weening, J.J., Beukers, $\mathbb{H}_{\text {J.B. }}$, Grond, J. and Elema, J.D. Genetic factors in focal segmental glomerulosclerosis. Kidney Int. 29; 789-798, 1988 .

Widdas, W.F. Old and new concepts of the membrane transport for glucose in cells. Biochim. Biophys. Acta 947: 385-404, 1988

Wijns, W. Merlin, J.A., Leners, N. Ferrant, A., Keyeux, A., Rahier, J., Coyneau, M., Midel, C., Bol, A., Robert, A., Pouleur, $\mathbf{H}_{\text {., }}$ Charlier, A. and Beckers, C. Accumulation of polymorphonuclear leukocytes in reperfused ischemic canine myocardium: relation with tissue viability assessed by fluorin-18-2-deoxy-glucose uptake. J. Nucl. Med. 29: 1826-1832, 1988,

Wilk, S, Mizoguchi, H. and Orlowski, M. Gamma glumamyl dopa. A kidney-specific dopamine precursor. J. Pharmacol. Exp. Ther. 206: 227-232, 1978.

Yoshida, Y., Fogo, A, and Ichikawa, I. Glomerular hemodynamic chanes ws hypertrophy in experimental glomerullar sclerosis. Kidney Int. 35: 654-660, 1989.

Youdim, M.B.H., Kerem, D. and Duvdevani, Y. The glycine prodrug, milacemide increases the seizure threshold dwe to hyperbaric oxygen; prevention by 1-deprenyl. Eur. J. Pharmacol. 150 . $381-384,1988$ 


\section{SUMMARY}

The goal of drug targeting is to achieve high levels of drug in the target tissue and low levels in other tissues. In this way a maximal pharmacologic effect can be produced with a minimum of side effects, i.e. the therapeutic index is optimized. In the introduction (chapter 1), a survey is given of the different strategies used for drug targeting. The experimental section of this thesis focuses upon prodrugs as a drug delivery system to achieve a site-specific effect; in particular the mechanism of the renal selectivity of $\mathrm{N}$-acetyl-L-y-glutamyl prodrugs was investigated.

Part one of the experimental section describes studies into the renal selectivity of the vasodilator prodrug CGP 22979. It was shown (chapter 2) that upon prodrug administration the active drug (CGP 18137) accumulates in renal tissue compared to other tissues. The half-life of the active drug appeared to be very short, due to a chemical reaction with ketones or aldehydes that are present in the blood. Because of this short half-life, the active drug can only interact with the resistance vessels near the site where the active drug is liberated from the prodrug. This is an important factor in the renal selectivity of CGP 22979.

Studies on the possible involvement of active transport of the prodrug in the renal accumulation of the active drug and the possibility of intracellular conversion are described in chapter 3 . It was found that the enzyme $\gamma$-glutamyl transpeptidase is not involved in the renal accumulation of the active drug. Inhibitors of the transport of $\gamma$-glutamyl compounds and of other anions, on the other hand, sharply decreased renal active drug levels. Furthermore, it appeared that cytosolic systems are able to convert the prodrug, in contrast to microsomal systems.

In order to correlate the renal levels of active drug to the pharmacologic effects, the consequences of enzyme and transport inhibitors on the renal hemodynamic responses to CGP 22979 were investigated (chapter 4 ). The results of this study confirm the importance of active transport in the renal selectivity of the prodrug. Inhibition of $\gamma$-glutamyl transpeptidase, however, caused a significant decrease in effect, while no attenuation of the tissue levels of active drug was found. This shows that the levels of active drug do not always correlate well with the pharmacologic responses when the concentration measurement and the interaction of the active drug with its target are not at the same site. As conclusion of part 1, a model is proposed for the renal handling of the prodrug.

In part 2 (chapter 5-7), experiments are described which were carried out in order to validate and extend this model, especially with respect to the active transport of the prodrug and the nature of the intracellular conversion. For this purpose, a prodrug was chosen of which not only the active drug, but also the prodrug itself and the deacetylated prodrug could be analysed, namely $\mathrm{N}$-acetyl- $\gamma$-glutamyl sulfamethoxazole (chapter 5). In in vitro studies it was found that the prodrug is activated in two steps, the first one being deacetylation, followed by removal of the $\gamma$-glutamyl group. In vivo, it was found that the prodrug accumulated in the kidney, 
and that this accumulation was due to carrier-mediated transport, sensitive to buthionine sulfoximine and probenecid (see also chapter 7 ).

A disadvantage of the sulfa-prodrug is that no pharmacologic effect can be measured. Hence, a prodrug was wanted with an intracellular site of action (as opposed to CGP 22979 , which has an extracellular site of action). The $\mathrm{N}$-acetyl- $\gamma$ glutamyl prodrug of 4'-aminowarfarin was designed as a possible application of the prodrug approach to renal selective drug action. Unfortunately, this prodrug did not have a renal selective action. The cause hereof appeared to be a combination of a high plasma protein binding and a limited transport into the kidney (chapter 6). These findings are important for the design of new renal prodrugs. The structure-transport relationship of $\mathrm{N}$-acetyl- $\gamma$-glutamyl prodrugs will have to be investigated in order to be more able to predict the selectivity of these prodrugs.

In chapter 7 , the use of kidney slices as a method to assess the renal accumulation of the prodrugs is evaluated. These experiments provide additional proof of the existance of a carrier system for $\mathrm{N}$-acetyl- $\gamma$-glutamyl compounds. Incubations with kidney slices are also suited for the determination of intracellular conversion of the prodrug and of the ability of the slices to retain the active drug. Part 2 of this thesis is concluded by a discussion on the importance of some pharmacokinetic parameters on the renal selectivity by carrier-transported prodrugs. It is shown that it is very important to control the plasma concentration of the prodrug at a relatively low level, especially if the same carrier system is aiso present in non-target tissue.

The possibilities and limitations of the prodrug approach to site-specific drug delivery are discussed in chapter 8 . Emphasis is laid on the possibility to achieve site-specificity through carrier-mediated transport for (future) drugs with an intracellular site of action; several tissues are reviewed with respect to their transport capabilities. Finally, some possible applications for kidney-selective prodrugs are given. 
"Drug targeting" is het zodanig veranderen van een geneesmiddel dat het zo selectief mogelijk op het doelorgaan werkt. Hierdoor wordt een zo groot mogelijk farmacologisch effect met een minimum aan bijwerkingen bereikt, of, met andere woorden, de therapeutische index wordt geoptimaliseerd. In de introductie (hoofdstuk 1) wordt een overzicht gegeven van de verschillende benaderingswijzen tot drug targeting. Het experimentele gedeelte van dit proefschrift behandelt prodrugs als manier om een orgaan-specifieke werking te verkrijgen; met name is het mechanisme achter de nier-selectiviteit van $\mathrm{N}$-acetyl-L- $-\gamma$-glutamyl prodrugs onderzocht.

Deel 1 (hoofdstuk 2-4) beschrijft het onderzoek naar het mechanisme van de nierselectiviteit van CGP 22979, een prodrug van de vaatverwijder CGP 18137. Het werd aangetoond (hoofdstuk 2) dat wanneer CGP 22979 toegediend wordt aan ratten, CGP 18137 zich selectief in de nier ophoopt. De halfwaardetijd van CGP 18137 bleek zeer kort te zijn als gevolg van een chemische reactie in het bloed met ketonen of aldehydes, zoals bijwoorbeeld pyrodruivezuur. Door deze korte halfwaardetijd kan het actieve geneesmiddel alleen reageren met de weerstandsvaten in de buurt van de plaats waar de prodrug omgezet wordt naar de actieve verbinding. Dit is een belangrijke factor in de nierselectiviteit van CGP 22979.

Hoofdstuk 3 beschrijft het onderzoek naar de mogelijke betrokkenheid van actief transport en intracellulaire omzetting van de prodrug in de nieraccumulatie van CGP 18137. Het bleek dat het enzym $\gamma$-glutamyltranspeptidase niet betrokken was bij de nieraccumulatie van de actieve verbinding. Remmers van het transport van $\gamma$-glutamylverbindingen en van andere anionen daarentegen, veroorzaakten een scherpe daling van de concentratie CGP 18137 in de nier. Bovendien werd gevonden dat cytosolische systemen in staat zijn om de prodrug om te zeten, in tegenstelling tot microsomale systemen.

Om de gehaltes aan geneesmiddel in de nier te kunnen correleren met de grootte van het farmacologische effect, werden de gevolgen van enzym- en transportremming op het hemodynamische effect van CGP 22979 onderzocht (hoofdstuk 4). De resultaten van dit onderzoek bevestigen het belang van actief transport voor de nierselectiviteit van de prodrug. Echter, remming van het enzym $\gamma$-glutamyl transpeptidase veroorzaakte een significante daling van het effect van de prodrug, terwijl dit geen invloed had op de concentraties aan actieve verbinding in de nier (hoofdstuk 3). Dit laat zien dat de geneesmiddelconcentraties niet altijd goed correleren met de farmacologische effecten wanneer de plaats van concentratiemeting en de plaats van werking van het geneesmiddel niet dezelfde zijn. Aan het eind van deel 1 wordt een model voorgesteld voor de opname en omzetting van de prodrug in de nier.

In deel 2 (hoofdstuk 5-7) zijn de experimenten beschreven welke uitgevoerd zijn. om dit model te valideren en wit te breiden, met name wat betreft het actieve 
transport en de aard van de intracellulaire omzetting. Hiervoor werd een prodrug uitgekozen waarvan niet alleen de actieve verbinding, maar ook de prodrug en de desacetylprodrug gemeten kunnen worden, namelijk $\mathbf{N}$-acetyl-y-glutamyl sulfamethoxazol (hoofdstuk 5). In vitro onderzoek liet zien dat de prodrug in twee stappen geactiveerd wordt: eerst deacetylering; gevolgd door afsplitsing van de rolutamyl groep. In vivo werd gevonden dat de prodrug zelf ophoopt in de nier, en dat die ophoping een gevolg is van carrier-gemedieerd transport, welke gevoelig is voor buthionine sulfoximine en probenecid (zie ook hoofdstuk 7).

Een nadeel wan de sulfa-prodrug is dat er geen farmacologisch effect gemeten kon worden. Daarom is er gezocht naar een prodrug met een intracellulaire plaats van werking (in tegenstelling tot CGP 22979, welke een extracellulaire plaats van werking heeft). De $\mathrm{N}$-acetyl-y-glutamyl prodrug van 4'-aminowarfarine (een werbinding met een intracellulaire plaats van werking) werd ontworpen als een mogelijke toepassing van de prodrug benadering tot het verkrijgen van een nierselectief effect. Helaas bleek dat deze prodrug niet nierselectief is. De oorzaak hiervan bleek te liggen in een combinatie van een hoge plasma-eiwit binding en een beperkt transport de nier in (hoofdstuk 6). Deze bevindingen zijn belangrijk voor het ontwerpen van nieuwe renale prodrugs. De struktuur-transport relatie van $\mathrm{N}$-acetyl-L-y-glutamyl prodrugs moet onderzocht worden om beter in staat te zijn de selectiviteit van prodrugs te kunnen voorspellen.

In hoofstuk 7 wordt het gebruik van nier-slices voor het bepalen van de renale accumulatie van prodrugs geëvalueerd. Deze proeven geven extra bewijs voor het bestaan van een carrier systeem voor $\mathrm{N}$-acetyl-y-glutamyl verbindingen. Incubaties met nier-slices zijn ook geschikt voor het bepalen van de intracellulaire omzetting van de prodrug en het vermogen van de slices om de actieve verbinding vast te houden. Deel 2 van dit proefschrift wordt afgesloten met een discussie over het belang van enkele farmacokinetische parameters voor de nierselectiviteit van carrier-getransporteerde prodrugs. Hierin wordt aangetoond dat het belangrijk is om de plasma concentraties van de prodrug op een relatief laag niveau te houden, vooral als dezelfde carrier ook in andere weefsels dan het doelorgaan voorkomt.

De mogelijkheden en beperkingen van de prodrug-benadering voor het verkrijgen van een orgaanspecifieke afgifte van geneesmiddelen worden besproken in hoofdstuk 8. Hierbij wordt de nadruk gelegd op de mogelijkheid voor (toekomstige) geneesmiddelen met een intracellulaire plaats van werking om orgaan specificiteit te bereiken via carrier-gemedieerd transport. De transportmogelijkheden van verschillende weefsels worden besproken. Tenslotte worden enkele mogelijke toepassingen voor nier-selectieve prodrugs gegeven. 


\section{Curriculum vitae}

$10-10-1961$

1980

1980

1983

$1985-1986$

aug. 1986

dec. 1986

dec. 1989 geboren te Meppel

diploma gymnasium $\beta$ aan het Johan de Witt Gymnasium te Dordrecht

aanvang studie farmacie aan de R.U. Leiden

kandidaatsexamen farmacie

onderzoek naar het mechanisme van de toxiciteit van dulcine op de vakgroep toxicologie (dr. J.F. Nagelkerke en prof. dr. G.J. Mulder)

doktoraal diploma farmacie

verbonden als wetenschappelijk assistent aan de vakgroep farmakologie van de R.U. Limburg

aangesteld als post-doktorale medewerker aan de vakgroep farmakologie van de R.U. Limburg op een projekt van de Nierstichting Nederland (onderwerp: verdere ontwikkeling van nier-selectieve prodrugs).

De experimenten waarop dit proefschrift gebaseerd is zijn ook beschreven in de volgende publicaties:

Drieman, J.C., Vervoort-Peters, H.T.M. and Thijssen, H.H.W., Pharmacokinetic studies on the mechanism of the renal selectivity of the vasodilator produg CGP 22979. Int J. Pharmac. 46: 203-209, 1988.

Drieman, J.C., Thijssen, H.H.W., Zeegers, H.H.M., Smits, J.F.M and Struyker Boudier, H.A.J., Renal selective N-acetyl-y+glutanyl prodrugs. I. A study on the mechanism of activation of the renal vasodilator prodrug CGP 22979. Br. J. Pharmacol. in press, 1989.

Drieman, J.C., Thijssen, H.H.W. and Struyker Boudier, H.A.J., Renal selective N-acetyl- $\gamma$-glutamyl prodrugs. II. Carrier-mediated transport and intracelular conversion as determinants in the renal selectivity of $\mathrm{N}$-acetyl- $\gamma$-glutamyl sulfamethoxazole. Manuscript submitted for publication.

Drieman, J.C. and Thijssen, H.H.W, Limuts to the renal selectivity of N-acetyl-yglutamyl prodrugs: the fate of $N$-acetyl-L- $\gamma$-glutany -4 amino warfarin in the rat. Manuscript submitted for publication. 